\title{
Role of plasmonics in detection of deadliest viruses: a review
}

\author{
Foozieh Sohrabi $^{1}$, Sajede Saeidifard ${ }^{1}$, Masih Ghasemi ${ }^{1}$, Tannaz Asadishad ${ }^{1}$, \\ Seyedeh Mehri Hamidi ${ }^{1, a}$, Seyed Masoud Hosseini ${ }^{2}$ \\ ${ }^{1}$ Magneto-Plasmonic Lab, Laser and Plasma Research Institute, Shahid Beheshti University, \\ Daneshju Boulevard, 1983969411 Tehran, Iran \\ 2 Department of Microbiology and Microbial Biotechnology, Faculty of Life Sciences and Biotechnology, \\ Shahid Beheshti University, Evin, Tehran, Iran
}

Received: 1 April 2021 / Accepted: 8 June 2021

(C) The Author(s), under exclusive licence to Società Italiana di Fisica and Springer-Verlag GmbH Germany, part of Springer Nature 2021

\begin{abstract}
Viruses have threatened animal and human lives since a long time ago all over the world. Some of these tiny particles have caused disastrous pandemics that killed a large number of people with subsequent economic downturns. In addition, the quarantine situation itself encounters the challenges like the deficiency in the online educational system, psychiatric problems and poor international relations. Although viruses have a rather simple protein structure, they have structural heterogeneity with a high tendency to mutation that impedes their study. On top of the breadth of such worldwide worrying issues, there are profound scientific gaps, and several unanswered questions, like lack of vaccines or antivirals to combat these pathogens. Various detection techniques like the nucleic acid test, immunoassay, and microscopy have been developed; however, there is a tradeoff between their advantages and disadvantages like safety in sample collecting, invasiveness, sensitivity, response time, etc. One of the highly resolved techniques that can provide early-stage detection with fast experiment duration is plasmonics. This optical technique has the capability to detect viral proteins and genomes at the early stage via highly sensitive interaction between the biological target and the plasmonic chip. The efficiency of this technique could be proved using commercialized techniques like reverse transcription polymerase chain reaction (RT-PCR) and enzyme-linked immunosorbent assay (ELISA) techniques. In this study, we aim to review the role of plasmonic technique in the detection of 11 deadliest viruses besides 2 common genital viruses for the human being. This is a rapidly moving topic of research, and a review article that encompasses the current findings may be useful for guiding strategies to deal with the pandemics. By investigating the potential aspects of this technique, we hope that this study could open new avenues toward the application of point-of-care techniques for virus detection at early stage that may inhibit the progressively hygienic threats.
\end{abstract}

\footnotetext{
a e-mail: m_hamidi@sbu.ac.ir (corresponding author)
} 


\section{Introduction}

During the years, viruses have threatened human life globally. Some viral diseases have spread in regional borders; however, some are pandemic diseases pushing their adverse effect on the entire world [1]. As a recent example, COVID-19 has infected more than 150 million people worldwide until now, with more than 3,000,000 victims [2]. Not only many people have died due to viral pathogens, but also, the countries are going to suffer from subsequent economic downturns besides other challenges like a deficiency in the online educational system, psychiatric problems and poor international relations. In these pandemics, the number of cases is growing until the researchers can find reliable vaccines and medications [3]. Contrary to having a limited number of proteins, the viruses have structural heterogeneity with a high tendency to mutation besides multiple host/virus interactions, which cause their study difficult [3]. The heredity information is encoded in the genome. Therefore, the virus is called a DNA or a RNA virus. Molecules of DNA and RNA can be single or double stranded. They can also include multiple pieces of nucleic acid (i.e. segmented) or non-segmented [4]. Generally, laboratory techniques for viral infection detection include nucleic acid test (NAT), microscopy methods, host antibody detection, Hemagglutination Inhibition (HI) assay, etc. NATs include two main subgroups of polymerase chain reaction (PCR) and sequencing. NAT detects the particular nucleic acid sequence for identifying the species of organisms, like virus or bacteria, which are pathogens in body secretions such as blood, tissue, and urine [5-8]. Due to the tiny amount of target genetic materials, NATs require amplification procedure called nucleic acid amplification tests (NAATs). NAATs include PCR, reverse transcription-PCR (RT-PCR), quantitative PCR (qPCR), strand displacement assay (SDA), or transcription-mediated assay (TMA), and nucleic acid sequence-based amplification (NASBA). The sensitivity of this technique to identify the specific gene target is high; however, the performance is timeconsuming, and its kits are expensive and have a limited supplier. Although these techniques are rather proper for early detection, they are not sensitive enough to detect some kinds of viruses like Severe Acute Respiratory Syndrome Coronavirus (SARS-CoV) in body secretions or serums within three days after the onset of the initial symptoms. About half of the SARS patients cannot be diagnosed at the early stage using these techniques. Besides, the tests from the sputum swabs are reliable only after 14 days from infection. In addition, they are not capable of recognizing the cured disease. Another limitation is the temperature-dependency and complicacy of these devices that require expert operators in molecular genetic diagnostics. Therefore, NAT-based techniques are not suitable for large-scale screening for multiple samples. In Fig. 1, the standard detection techniques of viral diseases are categorized.

Other detection techniques can be microscopy method that has two subgroups of immunofluorescence (IF) or immunoperoxidase (IP) and transmission electron microscopy (TEM). Moreover, computed tomography (CT) is an X-ray imaging taken from different orientations which are processed by a computer to create cross-sectional images of internal organs, bones, soft tissue and blood vessels in a non-invasive manner [9]. For instance, CT can play a role in the detection of viral pathogenesis in the respiratory system by showing different opacity in the infectious lungs in comparison with healthy lungs [8]. However, this expensive technique suffers from low specificity and required technical expertise and equipment.

Immunoassay is a biochemical technique that detects the molecules in a solution via antigen and antibody bindings $[10,11]$. In this technique, labels are linked/conjugated to the target antibodies and antigens. Specific diagnostic labels are enzymes, radioactive isotopes, DNA reporters, fluorogenic reporters, electrochemiluminescent tags and label-free immunoassays. Well-known techniques of enzyme-linked immunosorbent assay (ELISA), chemilumines- 


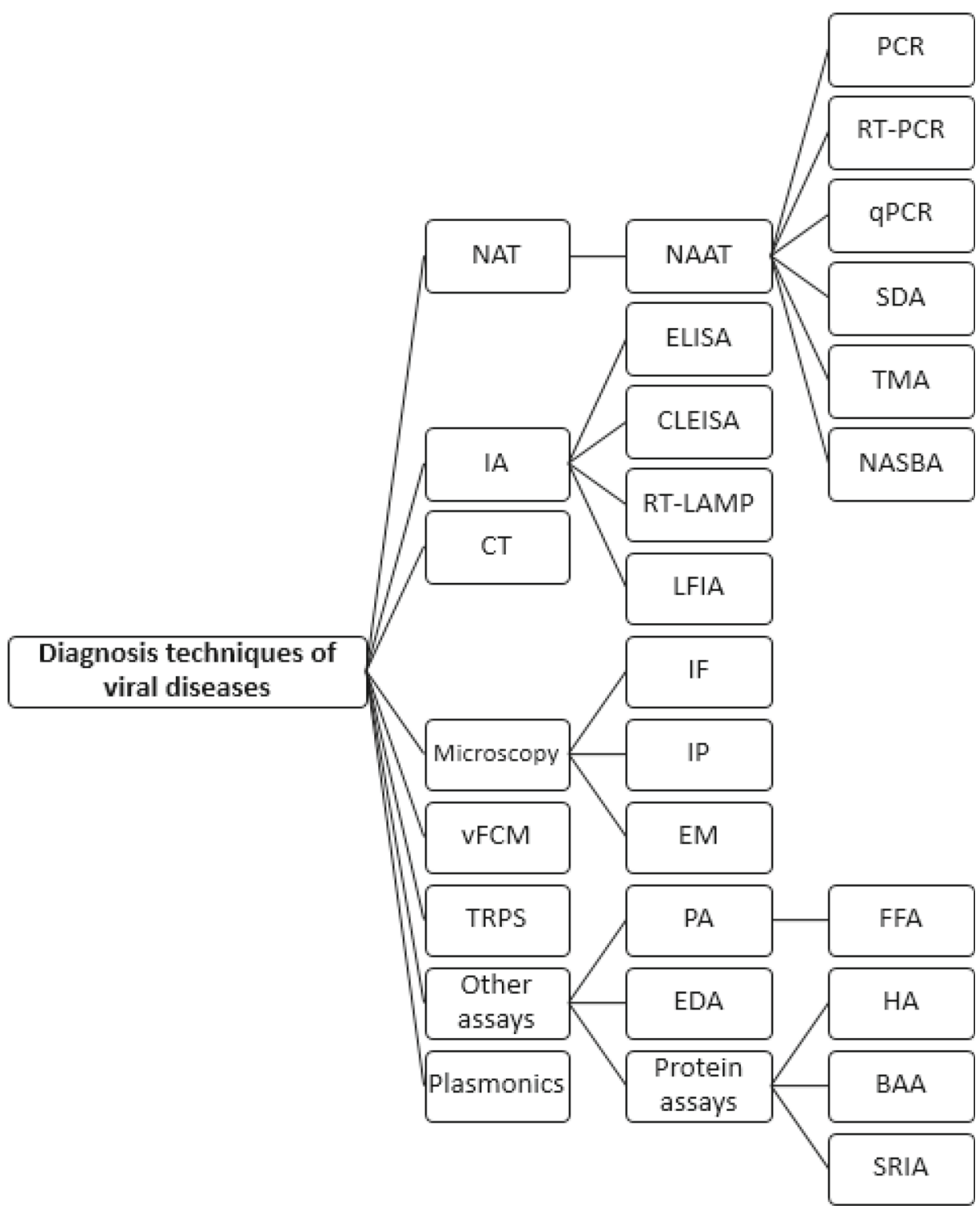

Fig. 1 Detection techniques for viral diseases. NAT Nucleic Acid Test, IA Immunoassay, CT Computed tomography, $v F C M$ viral Flow Cytometry, TRPS Tunable resistive pulse sensing, NAAT Nucleic Acid Amplification Test, ELISA enzyme-linked immunosorbent assay, CLEIA Chemiluminescence enzyme immunoassay, $R T$-LAMP reverse transcription loop-mediated isothermal amplification assay, LFIA lateral flow immunochromatographic assays, $I F$ Immunofluorescence, IP Immunoperoxidase, EM Electron Microscopy, $P A$ Plaque assay, EDA Endpoint Dilution Assay, PCR Polymerase Chain Reaction, $R T-P C R$ Reverse Transcription-PCR, qPCR quantitative PCR, SDA strand displacement assay, TMA Transcription-Mediated Assay, NASBA Nucleic acid sequence-based amplification (NASBA), FFA Focus forming assay (FFA), HA Hemagglutination Assay, $B A A$ Bicinchoninic Acid Assay, SRIA Single Radial Immunodiffusion Assay

cence enzyme immunoassay (CLEIA), reverse transcription loop mediated isothermal amplification assay (RT-LAMP), IF assay, serology test and lateral flow immunochromatographic assays (LFIA) are subgroups of this technique. In comparison with ELISA, IF assay is faster 
and can detect viruses as early as two days after the onset of symptoms [10]. CLEIA can push the limit of detection (LoD) to $1.56 \mathrm{pg} / \mathrm{mL}$. RT-LAMP is generally a gold film with enzymatic electrochemical genosensor and a rolling circle amplification PCR-based assay; however, it has low sensitivity [5]. Immunoassay techniques based on antibodies require much more time for giving the test results, so it is not suitable for early detection. Serology test is applicable 6-10 days after the appearance of the symptoms. In general, electrochemical immunosensors have high sensitivity, relatively low-cost that is user-friendly and miniature. Another user-friendly technique is LFIA that is also called lateral flow cell technique. In this test, a liquid sample goes along the surface of a pad according to the capillary force, and in its course, it reacts with reactive molecules that show visually positive and negative result. This technique is suitable for point-of-care diagnosis; however, it is poorly sensitive, and it is single-use.

There are also other assay techniques like protein microarray assay, viral plaque assay, Hemagglutination assay (HA) as well as other techniques like viral flow cytometry (vFCM) and isothermal rolling circle amplification (RCA) method [7].

As a significant feature, an early-stage detection technique that is user-friendly for the specialized and non-specialized medical team is critical, especially in pandemic situations that the isolation of infected people from healthy ones can prevent catastrophes. Another significant parameter is the response time of the detection techniques. Besides the diagnosis aspect, the analysis of the host/virus interactions plays a role in therapeutics [12].

In this review, we aim to find out the role of plasmonics in the virus detection, a technique that can detect virus genome as well as non-genome sections and human immune response in a short time. Plasmonics can detect various analytes with different molecular weights and binding affinities [3], and it can provide real-time information on the biomolecular interaction $[12,14]$. This technique is highly sensitive, label-free and non-invasive as well as being suitable for a small volume of sample or low concentration [12]. Another significant feature is its rapid response time and its high selectivity due to the inhibition of non-specific bindings $[6,12]$. In conventional SPR technique based on thin metallic (generally Au) film, a defined protein (i.e. ligand) is immobilized on the surface of the sensor chip, and its binding to the intended compounds is screened [12]. The binding of the compound/target protein modifies the refractive index at the interface that can be detected via the SPR response $[12,14]$. Increase in the SPR signal in response units (RU) shows the higher binding, and similarly, if the compound does not bind to the target protein, zero RU is given [14]. The corresponding affinity can be detected from the equilibrium binding level as a function of sample concentration as well as from the binding kinetics [15].

In section II of this Review, the principle of plasmonic biosensing is discussed. In subsequent sections, the role of plasmonics is specifically investigated in the most deadliest viruses including Coronaviridae Family, HIV, Influenza, Hepatitis, Zika, Rabies, Ebola, Norovirus and Dengue besides 2 common genital virus of HPV and HSV. We hope that this review could sum up the strong points of plasmonics in detection of viral diseases as a rapid, cost-effective and efficient technique as well as being helpful in vaccine study.

\section{Plasmonic biosensing}

Plasmonics focuses on the confinement and manipulation of the electromagnetic field of the incident light at the interface of a metal and a dielectric [16, 17]. Surface plasmons (SPs) are the coherent electron oscillations at metal and dielectric interface, which decay exponentially with the distance normal to the interface. SPs coupling with the incident light creates SPR, 

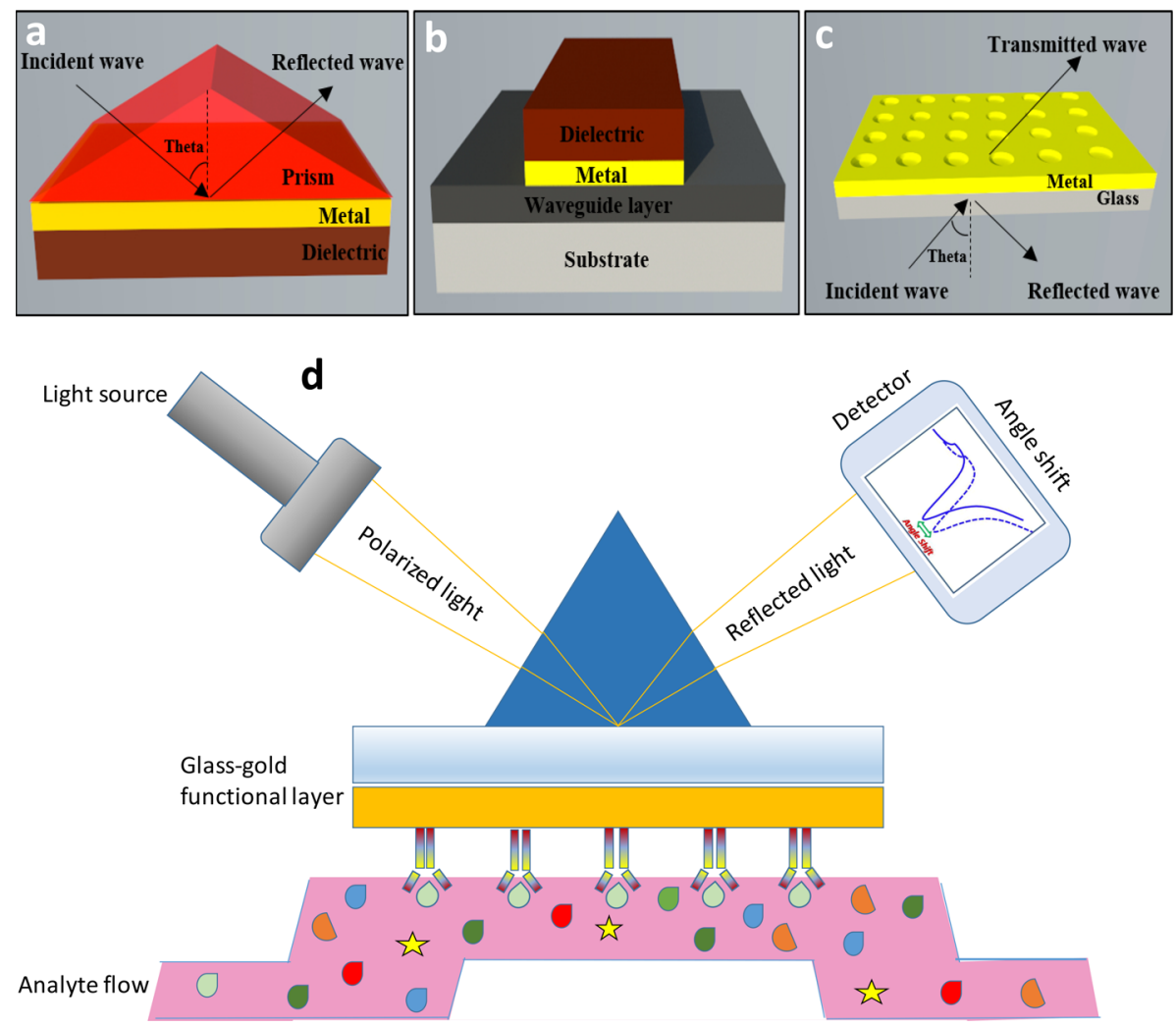

Fig. 2 Coupling methods of incident light to SPs a Kretschmann-Raether arrangement (prism coupling) b waveguide coupling $\mathbf{c}$ plasmonic crystal (grating coupling) [18]. d Schematic of the conventional plasmonic biosensor with immobilized antibodies on the gold surface. Binding of the antigens causes a difference in SPR signal [35]

emerging as a longitudinal electromagnetic wave. However, this coupling can occur under the phase-matching condition, called resonant condition. For meeting this criterion, the momentum of the incident light should match that of the plasmon. Generally, three configurations realize this condition: prism, waveguide and grating couplings [18] as observed in Fig. 2a-c. In these configurations, the presence of prism, waveguide and grating provides the matching condition. Most commercial SPR devices are working based on the first configuration. The operation regimes are angular, wavelength, intensity and phase modulations [19]. In the angular modulation, a monochromatic light is incident at the interface with various angles, and the angular spectrum of the reflected light is recorded. In this modulation, the resonance emerges for the angle in which a dip occurs in the spectrum [20]. In wavelength modulation, a polychromatic light is incident at the interface, and the narrowest reflection dip at a specific wavelength demonstrates the coupling [21]. In intensity modulation, a monochromatic light with a fixed angle is incident, and the intensity of the reflected light is recorded [22]. In phase modulation, a monochromatic light with a fixed angle is incident and the phase shift of the reflected light is recorded [23]. These properties make plasmonics a good candidate for various applications like sensing, optical communication, etc. [17]. 
Plasmonic sensing is based on the changes in the refractive index or layer thickness at the metal/dielectric interface [24-28]. Therefore, any variations at the adjacent dielectric change the resonance condition. This fact realized the potential of this technique in detecting the changes in cells [29-31], tissue [32,33] and in vivo [34]. Moreover, the SPR technique can provide a highly resolved, rapid platform for detecting the interactions at the interface of the plasmonic chip and the biological sample. Various functionalization protocols can be performed on the chip surfaces that make it proper for binding of the targeted substances, such as specific kind of virus [35]. Figure $2 d$ shows schematically the plasmonic sensing of biofluids based on ligand/target binding.

Apart from the conventional surface plasmon resonance (SPR), detection of virus can be performed using diverse plasmonic phenomena comprising localized SPR (LSPR), surface-enhanced Raman scattering (SERS), surface-enhanced fluorescence (SEF) and surface enhanced infrared absorption (SEIRA) spectroscopy [36]. In LSPR, the electromagnetic field is confined to noble metallic nanostructures either in periodic and non-periodic structures and the extinction spectrum has a peak at the resonance frequency. Any changes in the refractive index of the environment cause a shift in the LSPR peaks that is the fundamental of LSPR sensing [37]. Another feature of LSPR sensing is that it provides more sensing area (i.e. high aspect ratio) as well as not requiring bulky prism for satisfying phase-matching condition. In SEF technique, the local electric field of plasmonic structure augments the fluorescence of its adjacent fluorophore via dipole-dipole interaction [36]. Similarly in SERS and SEIRA techniques, the weak Raman signal and the infrared (IR) signal of the material are enhanced by adjoining plasmonic nanostructures, respectively. These combinatory techniques with plasmonics can increase the sensitivity of the integrated technique to refractive index change as well as other physical and chemical properties like conductivity and $\mathrm{pH}$ value. The readers are referred to [38] for more details on plasmonic effects on absorption, scattering and fluorescence.

In the next sections, the capabilities of the plasmonic technique (i.e. SPR, LSPR, SEF, SERS, SEIRA) on virus detection are discussed in detail.

\section{Coronaviruses}

There are over 20 known coronaviruses (CoVs) [39], seven of which are identified as human CoVs. These are 229E, OC43, NL63, HKU1, MERS-CoV, SARS-CoV and COVID-19, which mostly have serious respiratory tract infections [40]. In the 1960s, human coronaviruses were first discovered. 229E and OC43 cause diseases called common cold. The last five were discovered in 2004, 2005, 2012, 2003 and 2019. Among these, MERS-CoV, SARS-CoV and COVID-19 are investigated more due to their transmission to different regions of the world.

$\mathrm{CoVs}$ have a positive single-stranded RNA genome of approximately $30 \mathrm{~kb}$ that encodes structural proteins including the spike $(\mathrm{S})$, envelope $(\mathrm{E})$, membrane $(\mathrm{M})$, and nucleocapsid $(\mathrm{N})$ proteins [41]. In Fig. 3, the schematics of the viruses, their size, and structure as well as the location of the structural proteins can be found. As seen, SARS CoV and COVID19 have the size of around $120 \mathrm{~nm}$. S gene encodes the receptor-binding spike protein that plays a significant role in viral infection of the cell and membrane fusion. It also determines the host tropism and the capability of transmission. Other three structural proteins behave more conservatively besides playing a role in general $\mathrm{CoV}$ functions. In the next subsections, the plasmonic techniques used for detection of three main subgroups of CoV, i.e. SARS, MERS and COVID-19 are discussed. In Tables 1, 2, 3, 4, a summary on the virus model, size, structure, host, analyte, receptor as well as the type of plasmonic technique and the 


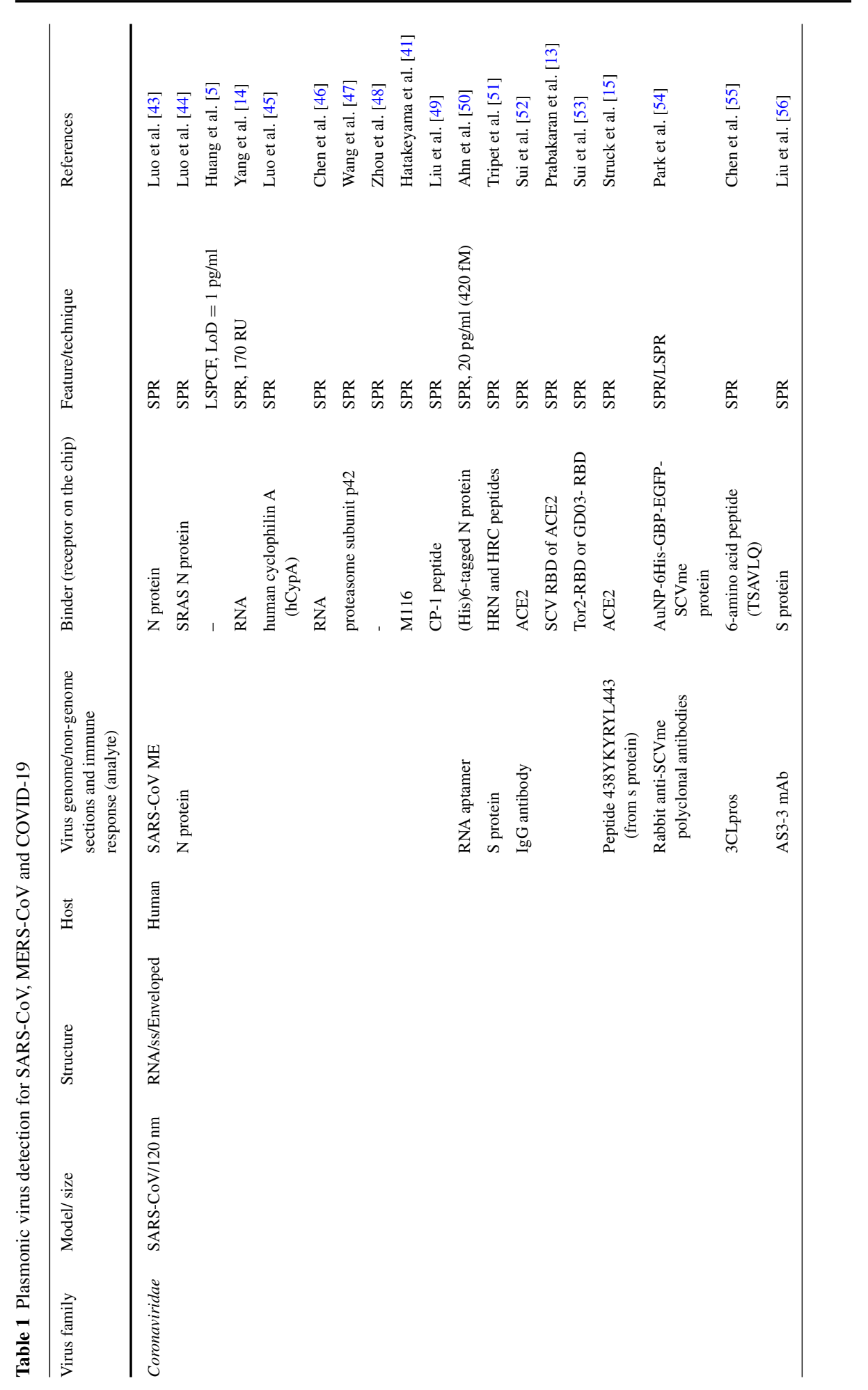




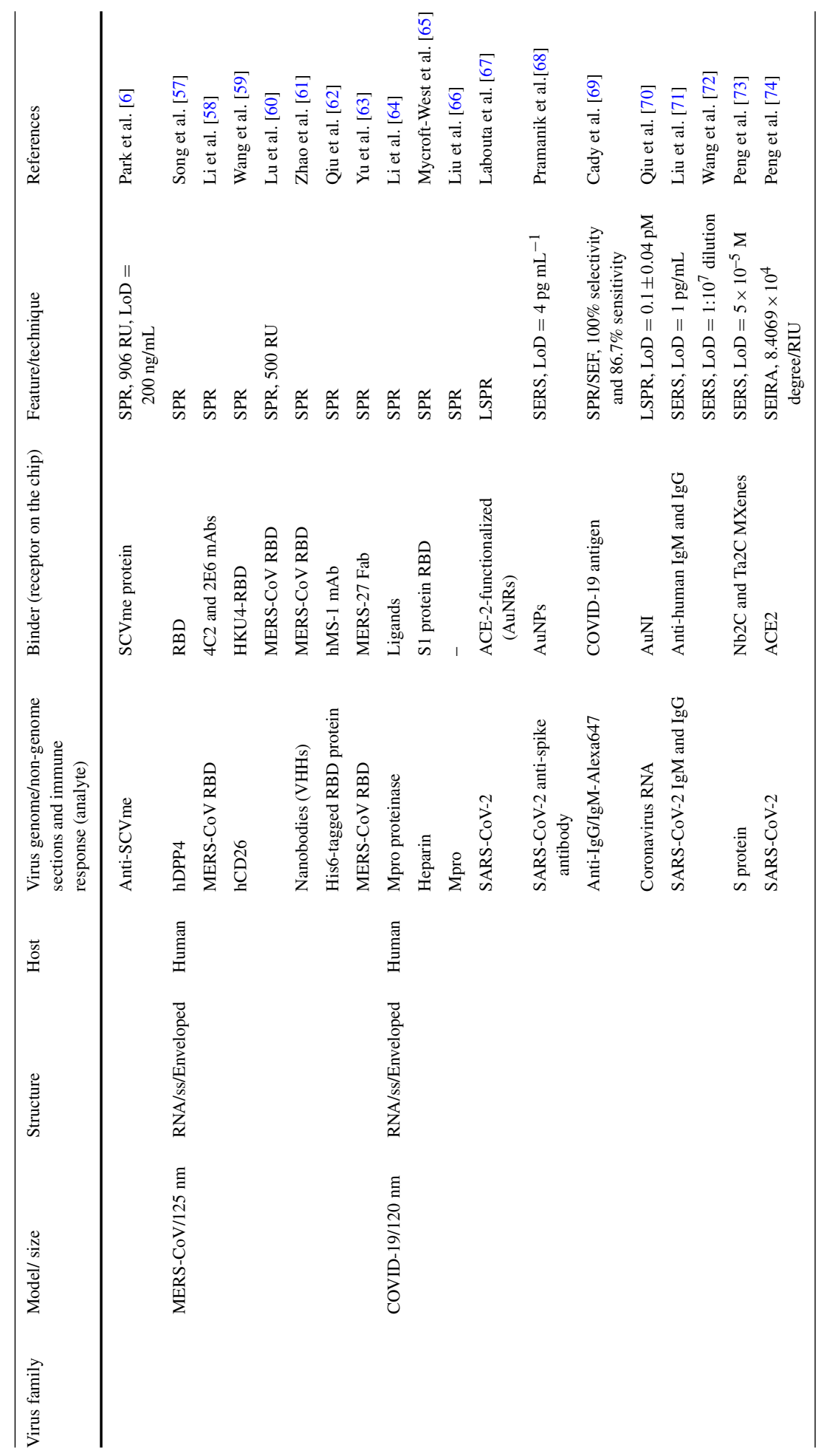




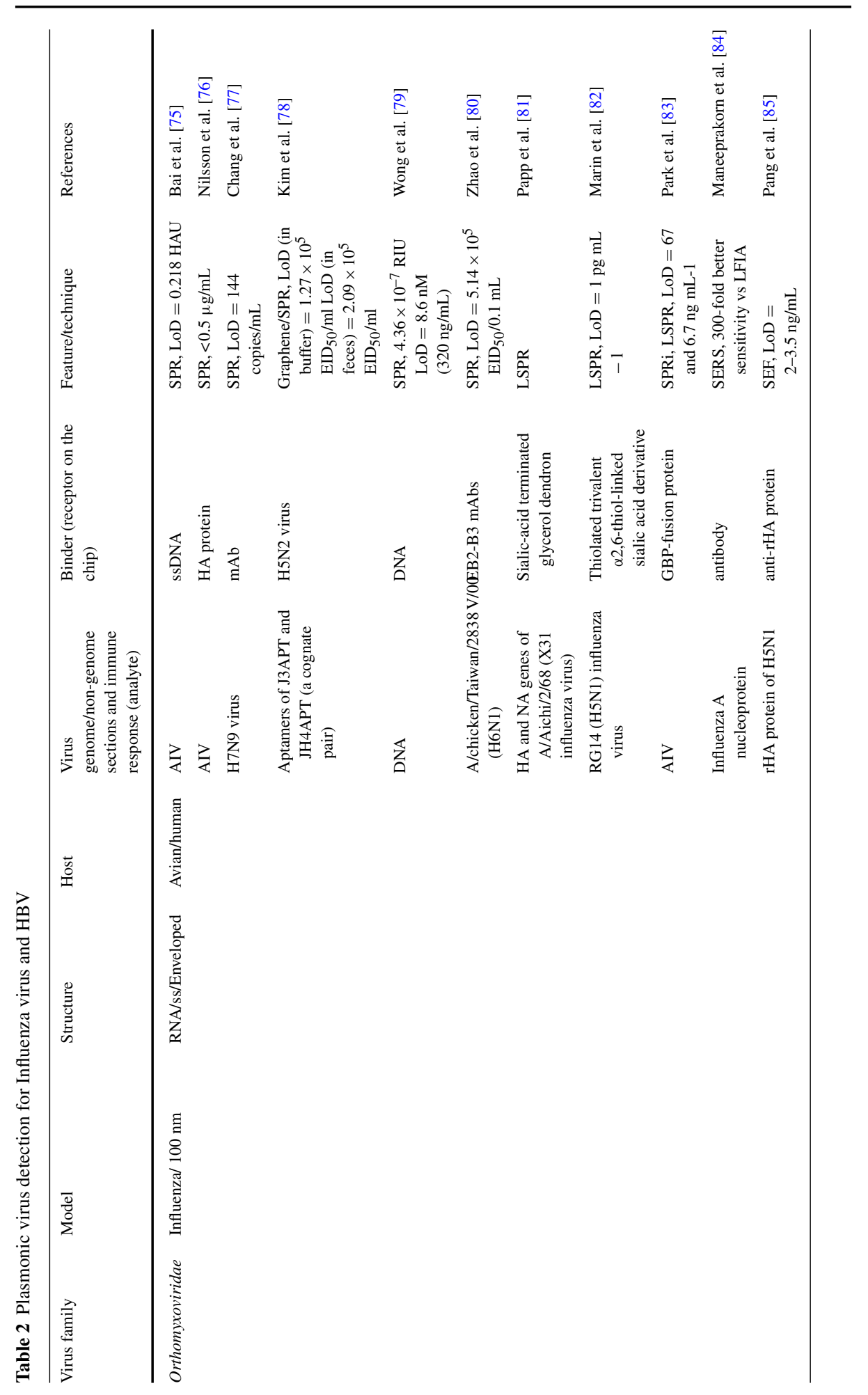




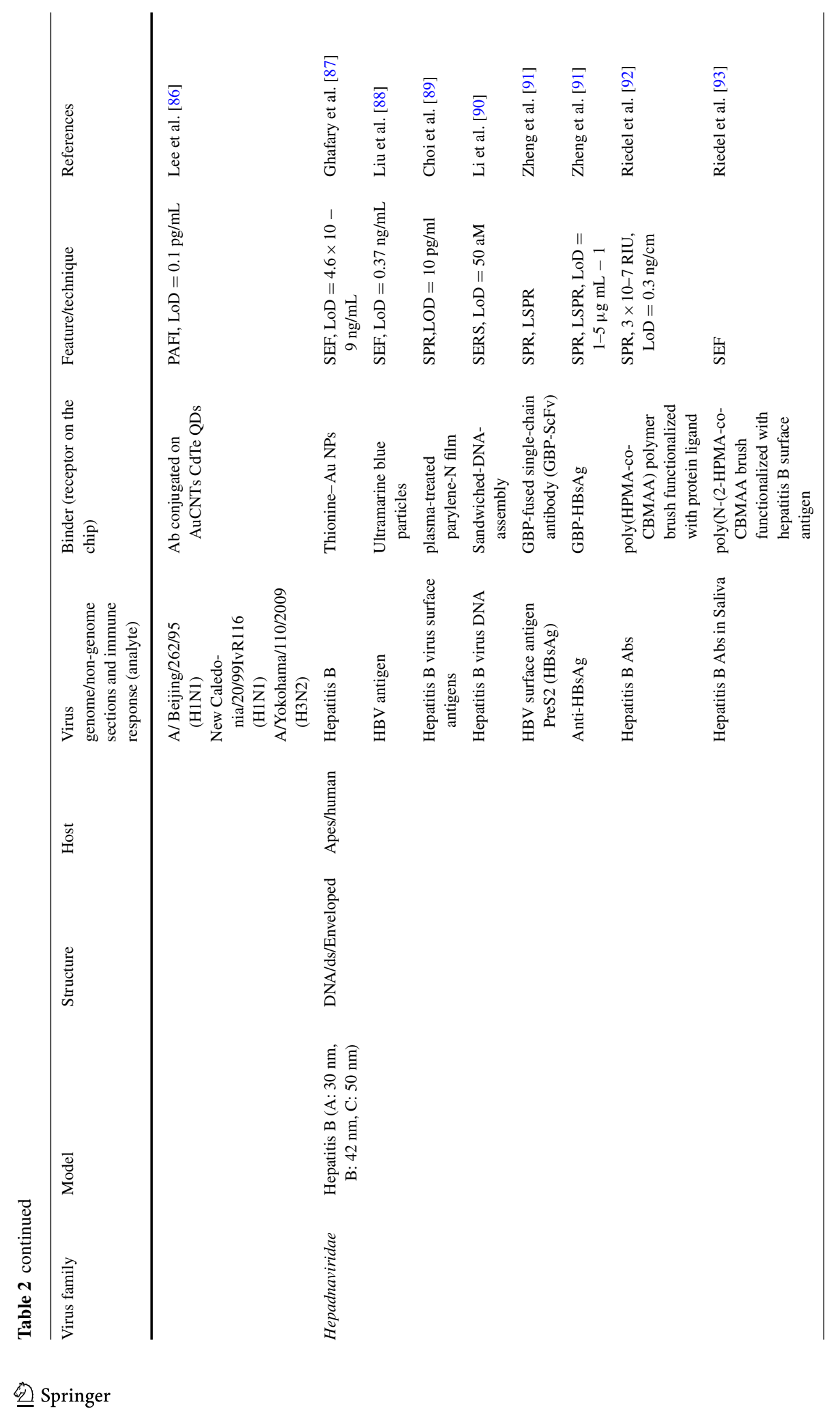




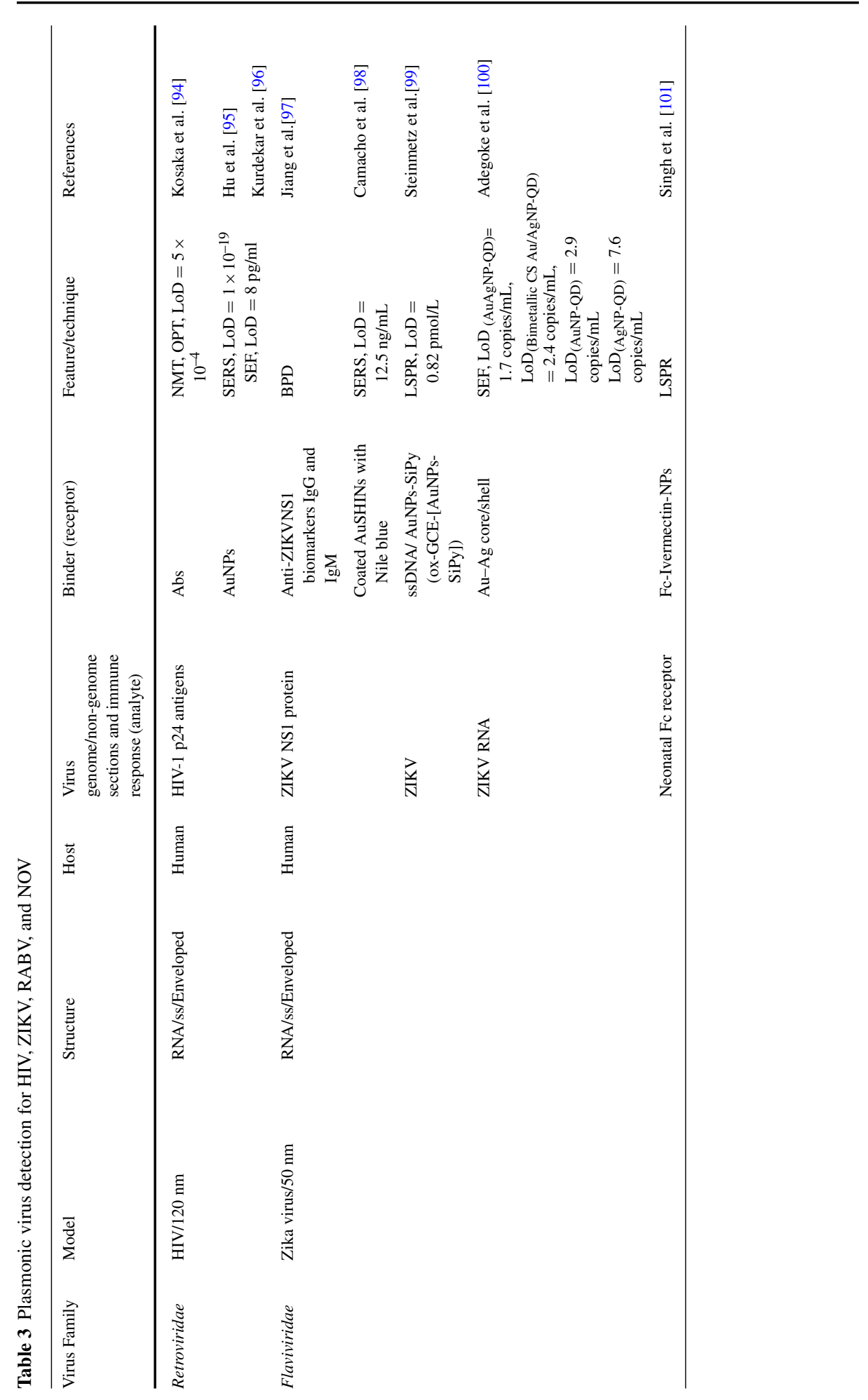




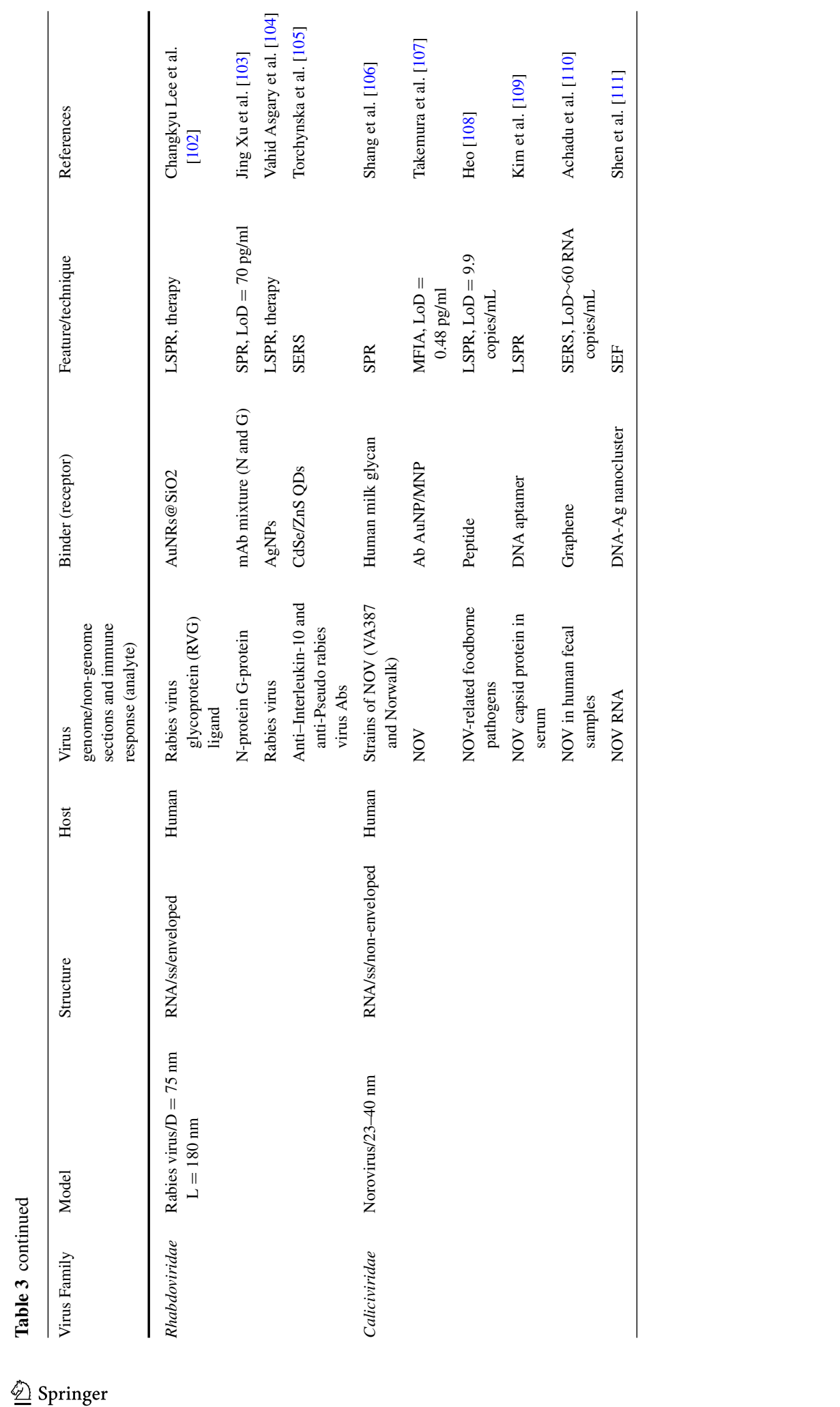




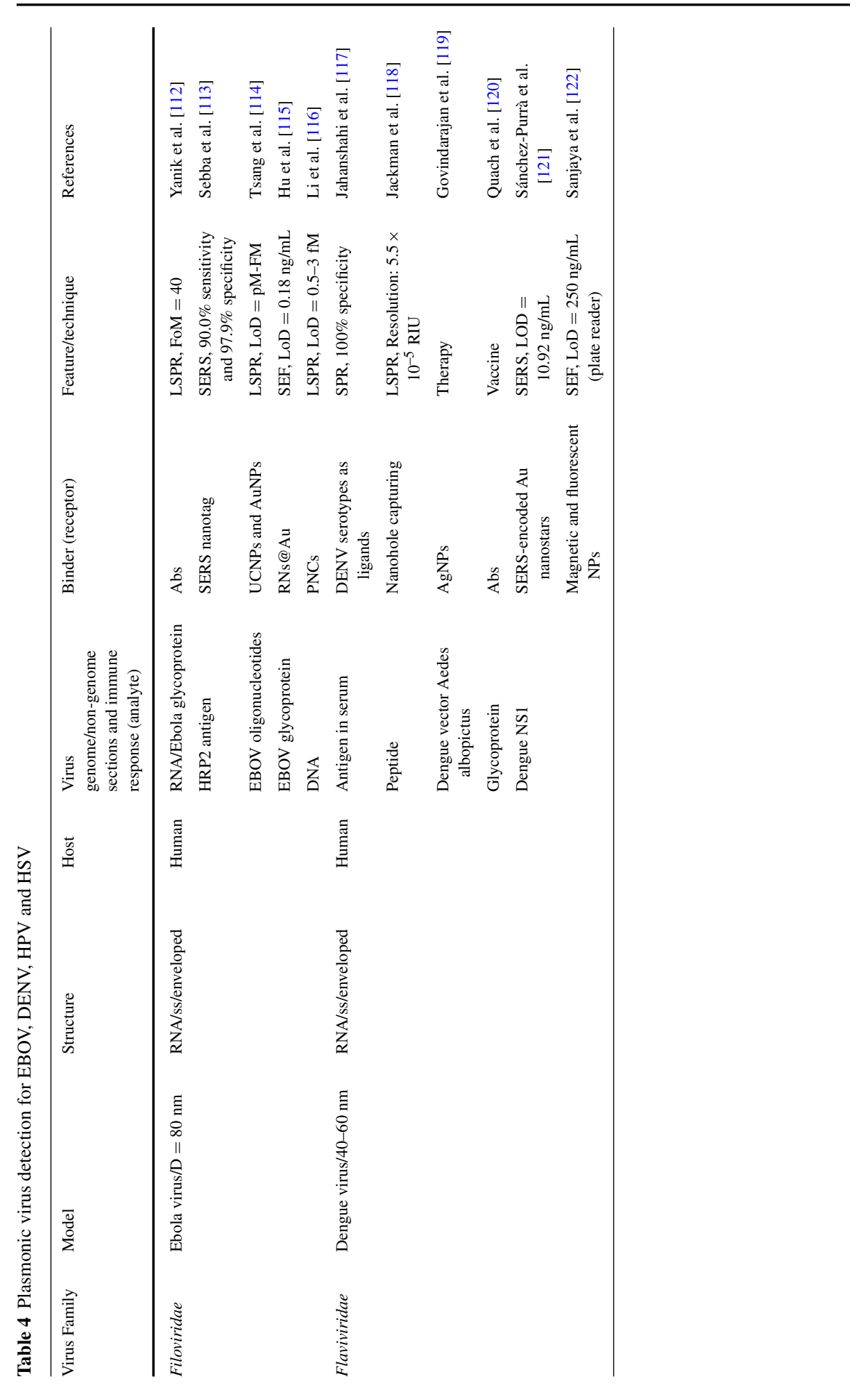




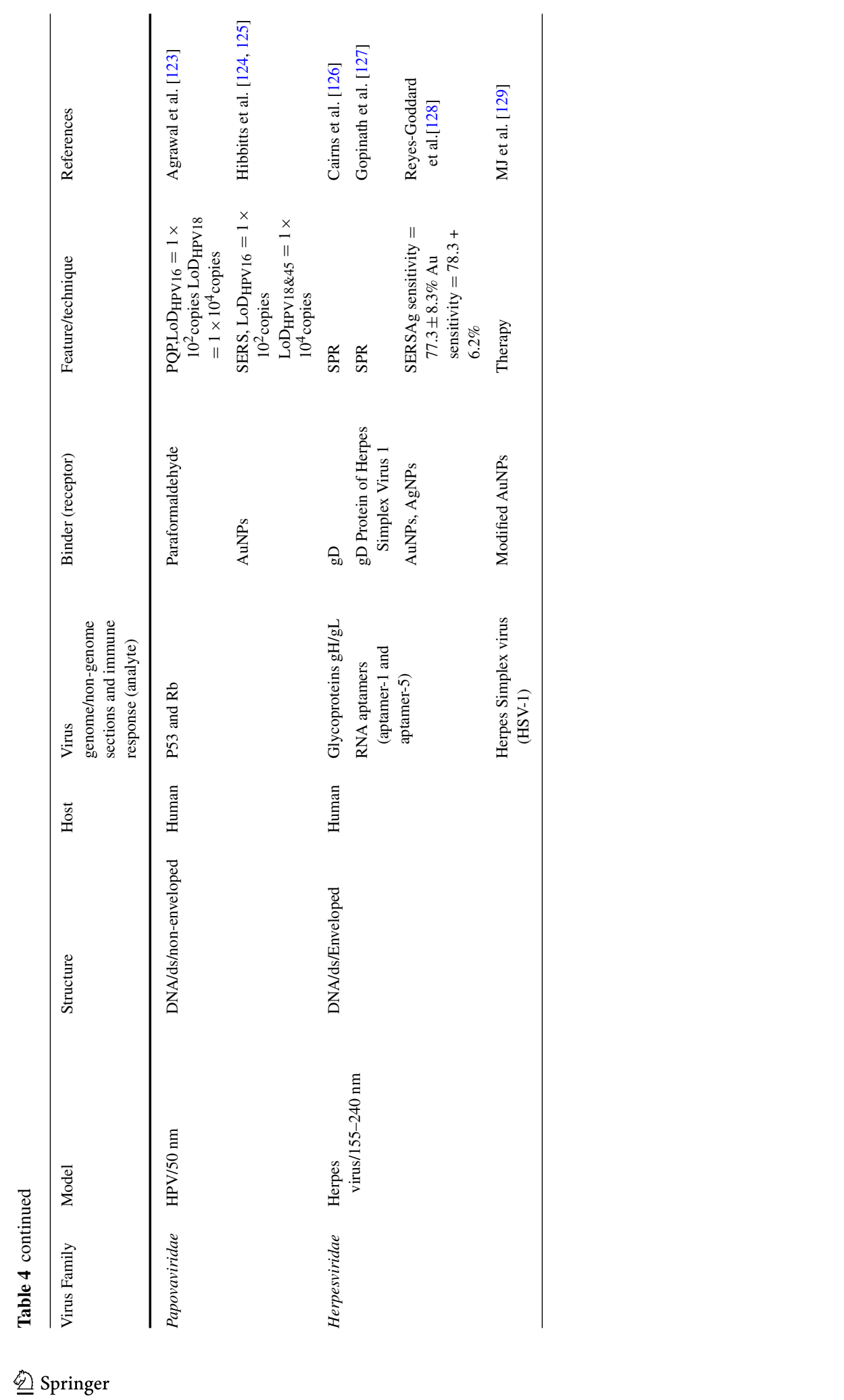



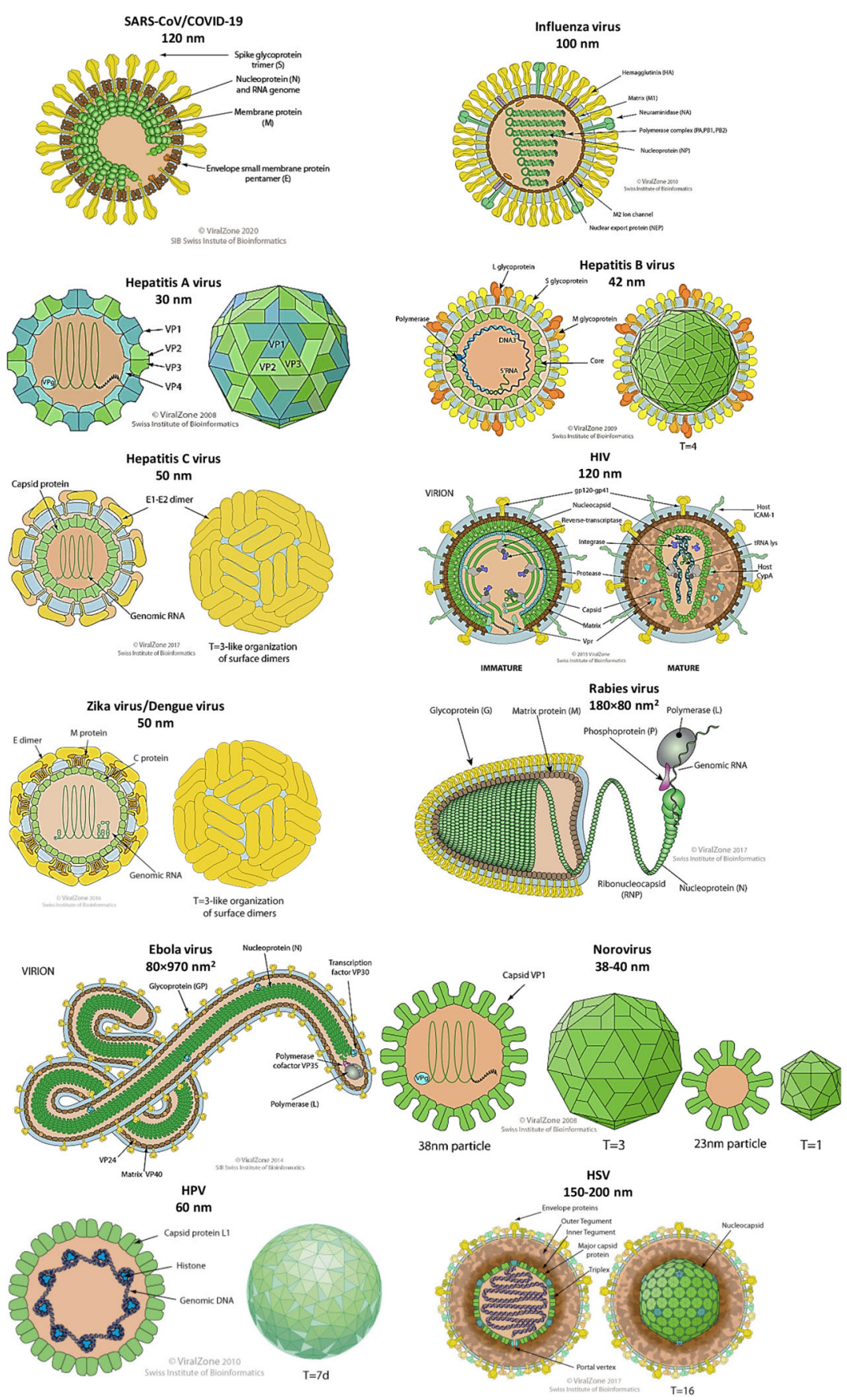

Fig. 3 The schematics of the viruses, their size, and structure that are studied in the current review. The virus schematics are extracted from the website of Swiss Institute of Bioinformatics [42]. These viruses are SARS-CoV/COVID-19, Influenza, Hepatitis A, Hepatitis B, Hepatitis C, HIV, Zika, Dengue, Rabies, Ebola, Norovirus, HPV and HSV with the diameters of $120 \mathrm{~nm}, 100 \mathrm{~nm}, 30 \mathrm{~nm}, 42 \mathrm{~nm}, 50 \mathrm{~nm}, 120 \mathrm{~nm}, 50 \mathrm{~nm}$, $50 \mathrm{~nm}, 180 \times 80 \mathrm{~nm}^{2}, 80 \times 970 \mathrm{~nm}^{2}, 38-40 \mathrm{~nm}, 60 \mathrm{~nm}$ and $150-200 \mathrm{~nm}$ 
sensitivity and LoD (if reported) are mentioned. Therefore, summarized information for selective Coronaviridae Family members including SARS-CoV, MERS-CoV and COVID19 can be found in Table 1.

\subsection{SARS coronavirus (SARS-CoV)}

The SARS coronavirus (SARS-CoV), as a member of the Coronaviridae Family, was first reported in 2003. Its outbreak began in the Guangdong Province of China and spread to more than 30 countries due to its high transmissibility [47]. According to the World Health Organization [130], the number of cases up to 4th July 2003 was 8439 with the fatality rate of $10 \%$. SARS-CoV was detected again in 2003/2004 by the independent transmission of this virus from palm civets to four individuals [131]. Mortality caused by SARS infection can be a consequence of two possibilities; first, the direct extensive lung damage and severe lymphopenia and second, the hyperactive antiviral immune response [47].

As seen in Fig. 3, SARS-CoV includes the spike (S) protein, the small envelope (E) protein, the membrane $(\mathrm{M})$ protein, and the nucleocapsid protein (N Protein). As mentioned above, $\mathrm{S}$ protein is a large type-I transmembrane glycoprotein, and it consists of two main domains of $\mathrm{N}$-terminal S1 and C-terminal S2. For the entrance of SARS-CoV, N-terminal S1 domain binds to the receptor called angiotensin-converting enzyme 2 (ACE2) in a receptorbinding domain (RBD) [15] and C-terminal S2 domain takes action in the membrane fusion of virus/cell [41]. By inhibiting the binding to ACE2, one can prevent SARS-CoV entrance to the host cell and neutralize the antibodies [13]. E protein is a type-II transmembrane glycoprotein, with the role of cation-selective ion channel, that is required for the formation of pseudoparticles in insect cells and has the smallest structural protein in SARS-CoV [41]. However, E protein is not essential for pseudoparticle formation in mammalian cells. Membrane (M) protein is a coiled $\alpha$-helical surface protein with four different regions, and it facilitates the viral assembly via its interaction with other $\mathrm{M}$ and $\mathrm{N}$ proteins [132]. Therefore, the replication of SARS-CoV can be managed by controlling the interaction between the $\mathrm{M}$ and $\mathrm{N}$ proteins [41]. In the following subsections, the role of plasmonics in detection of SARS-CoV via N-protein interaction, ACE2 receptor and antibodies, and 3-C-like protease (3CLpro) is investigated.

\subsubsection{SARS-CoV non-genome sections and immune response}

$\mathrm{N}$-protein In CoVs, the function of N protein is significant during the entry of the virus into the host cell, virus assembly and release [45]. This vital structural protein is abundant in infected cells. It binds on the viral RNA (vRNA), leading to the creation of helical nucleocapsid, the core complex structure of SARS-CoV virion [14, 45]. SARS-CoV N protein has intrinsic multimerization as well as being highly immunogenic and antigenic, so it plays an important role in of the host immune response and immunopathological damage [44, 47]. As previously mentioned, it plays complementary roles in replication, transcription and translation for CoVs [44]. It was previously proved that the antibodies against $\mathrm{N}$ protein lived longer and in greater abundance in comparison with other structural proteins, i.e. S, M and E proteins. It originates from this fact that in comparison, a high level of $\mathrm{N}$ protein exists after SARS-CoV infection so it can be detected in the serum after one day of infection. Hence, SARS-CoV N protein is a rapid and accurate candidate to detect the infection at an early stage. This protein is detectable in serums, so the infection risk in collecting the samples from nasopharyngeal aspirates is omitted. For this reason, researchers have investigated the role of $\mathrm{N}$ protein in the detection of SARS-CoV using SPR. 
- SPR

Using SPR analysis, Luo et al. [43] indicated that SARS-CoV ME interacts with N protein with a high affinity. They have immobilized SARS-CoV N protein on the surface of CM5 plasmonic chips with the RU of 2000, and purified SARS-CoV ME that was flowed over the $\mathrm{N}$ protein. For negative reference, the immobilization was performed using lysozyme (2200 RU). By studying the interaction between SARS-CoV ME and SARS-CoV N protein, they have found that the SARS-CoV ME could bind directly to SARS-CoV N protein. Considering the kinetic parameters of the association $\left(\mathrm{K}_{\mathrm{on}}\right)$ and dissociation $\left(\mathrm{K}_{\mathrm{off}}\right)$ rates for this interaction as $4.18 \pm 0.32 \times 10^{3} \mathrm{M}^{-1} \mathrm{~s}^{-1}$ and $2.23 \pm 0.19 \times 10^{-3} \mathrm{~s}^{-1}$ as well as $K_{\mathrm{D}}=k_{\text {off }} / k_{\text {on }}=$ $0.55 \pm 0.04 \mathrm{M}$, it was understood that this binding had high affinity. Luo et al. [44] have investigated the assembly features of SARS N protein using electrophoresis, chromatography and SPR. They have shown that in the absence of genomic nucleic acid, SARS N protein formed dimer at low concentrations but at higher concentrations, it tends to form trimer or polymer. Therefore, SARS N protein was helpful for protein oligomerization. SARS N protein/SRAS $\mathrm{N}$ protein interaction was analyzed using SPR. On the surface of CM5, SARS N protein was immobilized by amine coupling with RU level of 4000. To remove probable SRAS N protein oligomers, some injections of $\mathrm{NaOH}$ were performed. In another study, Luo et al. [133] have studied the interaction of SARS N/human hnRN protein A1 with the running and sample buffer of HEPES (containing $\mathrm{NaCl}$ ) at $25^{\circ} \mathrm{C}$. Zhou et al. [48] have investigated the binding kinetics of the $\mathrm{N}$ protein of SARS-CoV and 229ECoV to CM5 sensor chips. Hatakeyama et al. [41] have indicated a novel binding region for $\mathrm{N}$ and $\mathrm{M}$ proteins as well as confirming their interaction with mammalian cells. Moreover, they have found that the interaction of the $\mathrm{C}$-terminal portion of $\mathrm{N}$ with $\mathrm{M}$ could form pseudoparticles. The interaction between the peptides driven from N protein and M116 was studied using SPR analysis. By amine coupling, M116 was immobilized on CM5 at $5500 \mathrm{RU}$ with the running and sample buffer of HBS-EP. Tris- $\mathrm{HCl}$ was immobilized at the same level for a negative control test. Hatakeyama et al. [41] have mentioned that SPR could reveal that amino acids 351-422 of $\mathrm{N}$ interacted with amino acids $197-221$ of $\mathrm{M}$ and that the C-terminal region of $\mathrm{N}$ (amino acids 343-402) was necessary for its oligomerization. Tripet et al. [51] have immobilized the HRN and HRC peptides (which contained an N-terminal cysteine residue) using ligand thiol method at $25{ }^{\circ} \mathrm{C}$. They have shown that HRC1 and HRC2 peptides may represent potential candidates for use in a peptide vaccine against the SARS-CoV. Liu et al. [49] have benefited from SPR for studying the binding affinity and kinetics for SARS-CoV related peptides. They have found that $\mathrm{CP}-1$ peptide derived from the HR2 region could inhibit SARS-CoV infection in the micromolar range. This peptide could bind with high affinity to $\mathrm{N}$ protein-1 that was derived from the HR1 region.

$-\mathrm{SEF}$

Huang et al. [5] have worked on sandwich immunoassays based on LSP-coupled fluorescence (LSPCF) fiber-optic readout which enabled the analysis of recombinant SARS-CoV $\mathrm{N}$ protein in a buffer at concentrations as low as $0.1 \mathrm{pg} / \mathrm{ml}$.

The subsection can be summarized in this way that SARS-CoV ME interacts with $\mathrm{N}$ protein with a high affinity and SARS $\mathrm{N}$ protein is helpful for protein oligomerization. In addition, $\mathrm{HRC} 1$ and $\mathrm{HRC} 2$ peptides may present potential use in a peptide vaccine . 
ACE2 receptor and antibodies

- SPR

Neutralization of antibody to SARS-CoV is a common approach in SARS infection. Sui et al. [52] have investigated the binding kinetics and affinity of neutralizing antibodies (i.e. 80R scFv and 80R IgG1) and receptor ACE2 with different concentrations to the purified S1-Ig using SPR. S1-Ig was immobilized on CM5 chip using amine groups. The regeneration was performed using glycine- $\mathrm{HCl}$, and the buffer solution was selected to be HBS-EP.

Struck et al. [15] have monitored the peptide libraries using SPR to identify RBD binding epitopes. Their experimental results have shown that the peptide 438YKYRYL443, as a part of receptor-RBD of the spike protein of SARS-CoV, held the dominant binding epitope and bound to ACE2 with KD = $46 \mathrm{lM}$. Prabakaran et al. [13] have investigated the interaction between m396 and SCV RBD. Using carbodiimide coupling chemistry, RBD was immobilized onto the sensor, and various concentrations of Fab or IgG m396 were flew at $25^{\circ} \mathrm{C}$. Monoclonal antibodies (mAbs) with potent neutralizing activities are promising candidates for both prophylactic and therapeutic interventions against virus infections [58]. Hearty et al. [134] have discussed in their review about the affinity of each mAb for recombinant S318510 fragment (CR3014: $16.3 \mathrm{nM}$ and CR3022: $0.125 \mathrm{nM}$ ) and assess any allosteric effect by binding of both mAbs to the antigen. CR3014 was a semisynthetic human mAb and CR3022 was an antibody isolated a human convalescent patient. The combination of these two mAbs has demonstrated a synergistic neutralization effect. In their study, they have investigated the capability of SPR in SARS vaccine design. Sui et al. [53] have analyzed the binding of mAbs to various RBDs using the SPR technique at $25{ }^{\circ} \mathrm{C}$. On the plasmonic sensor chip, the antibody of anti-human IgG Fc was coated using the amine coupling. RBDs in HBS buffer had the flow rate of $30 \mathrm{ml} / \mathrm{min}$ with concentrations ranging from 0.15 to $100 \mathrm{nM}$ for Tor2-RBD or GD03- RBD. For D480A-RBD, the concentration was from 15.6 to $2000 \mathrm{nM}$. For negative control, the buffer injection was performed. The chip surface was regenerated with $3 \mathrm{M} \mathrm{MgCl} 2$ solution on each association and dissociation cycle.

Cui et al. [10] have detected the SARS-CoV antigens and monitored the reaction spots by proposing two designs. They have immobilized mAbs to SARS-CoV on the reaction spots with no immobilization on the reference spots using selective chemical modification. In the first design, the antibodies to SARS-CoV were directly immobilized after the activation of the chip. For deactivation and washing of the chip, ethanolamine and HBS buffers were used, respectively. After antibody immobilization, sterilized SARS-CoV was injected into the microfluidic system. In their second design, $0.5 \mathrm{mg} / \mathrm{ml}$ protein A solution was pumped in after the activation step. The solution of the mAbs to SARS-CoV was injected after the deactivation step to make binds with immobilized protein A. Then the chip was washed with PBS buffer. Similar to the first design, the same sterilized SARS CoV solution was pumped into the microfluidic device to react with the immobilized antibody. Protein A seems to be a useful agent for antibody immobilization by increasing the binding efficiencies between antigens and antibodies.

Park et al. [6] have developed an SPR biosensor for detection of SARS using a protein that was created by genetically fusing gold binding polypeptides (GBPs) to a SARS coronaviral surface antigen. The GBP-fusion proteins consist of two domains of the GBP fused to SARS-CoV membrane envelope (SCVme) protein. The fusion proteins can be directly selfassembled onto the SPR gold surfaces via the GBP portions without a complicated chemical modification of the gold surface, and the SCVme protein serves as a capture ligand for antiSCVme antibody. SPR analysis has shown that the fusion protein could be self-immobilized on the gold surface due to GBP without any need for surface chemical modification. This advantage made it a stable platform for anti-SCVme detection. AFM and plasmonic imaging 
a

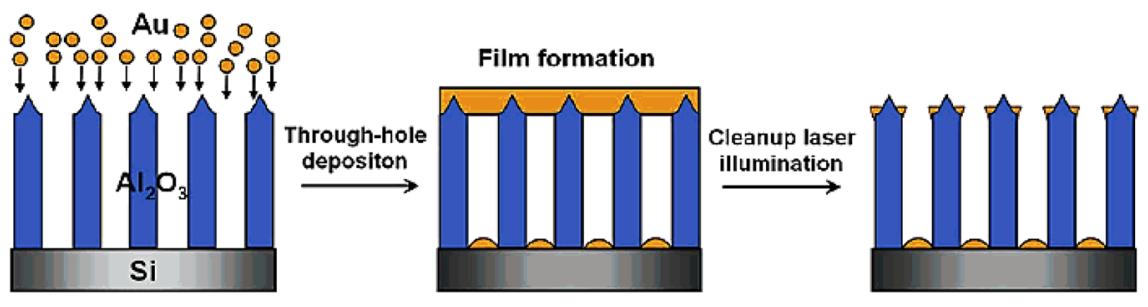

b
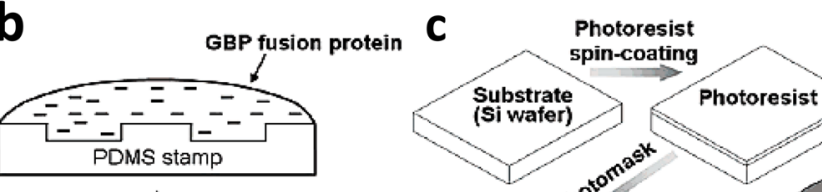

I Stamping
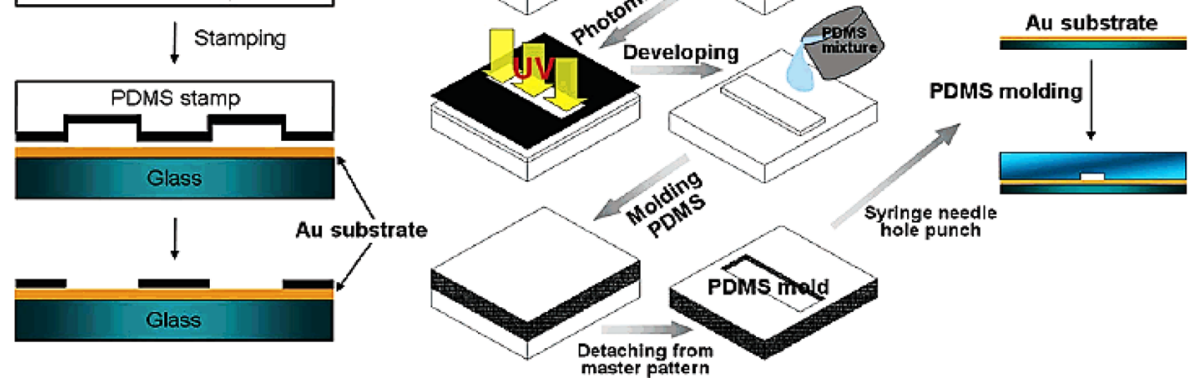

Fig. 4 a Laser-ablated deposition method used by Park et al. [54] for the generation of gold nanopatterns b microcontact printing procedure using the PDMS stamp, and $\mathbf{c}$ the fabrication process of the PDMS microfluidic device by photolithography. This chip was used as a sensing platform for SARS CoV

confirmed the specific binding of anti-SCVme to the fusion protein that was immobilized on the micropatterned plasmonic chip. The fabrication process flow for this chip was shown in Fig. 4 where laser-ablated deposition is used for creating gold nanopatterns. They have also demonstrated that the orientation of bound fusion protein by GBP was important for efficient binding of anti-SCVme antibody. 10 gmL-1 concentration of fusion protein provided the biggest detection response (906 RU) for anti-SCVme with the $\mathrm{LoD}$ of $200 \mathrm{ngmL}^{-1}$ anti-SCVme within $10 \mathrm{~min}$.

\section{- LSPR}

Park et al. [54] have reported a simple method for immobilizing the proteins on the plasmonic chip by a Gold-Binding Polypeptide (GBP)-fusion method. The GBP-fused SARS$\mathrm{CoV}$ me bound to gold nanoparticles (NPs) and interacted with the antibodies of the SAR$\mathrm{CoV}$. This interaction has led to the changes in the light absorption spectrum and provided a platform for SARS-CoV detection. For performing the measurement, an incoherent ppolarized, white light source was applied to SPR excitation. This collimated light was incident on as a prism/Au/thin-film/buffer flow cell assembly at a fixed angle. After passing a bandpass filter centered at $830 \mathrm{~nm}$, the reflected light was collected by a CCD camera. The plasmonic chip, consisting of gold nanodot arrays, was fabricated by laser-ablated deposition that modified the silicon substrate. 
Chen et al. [12] have reviewed the immobilization of SARS-CoV 3CLpro inhibitors on the plasmonic chip surface and screened the corresponding binding affinity and enzymatic inhibitory activity. Chen et al. [55] have investigated the binding affinities of the full-length and $\mathrm{N}$-terminal deleted SARS 3CLpros to the substrate peptide using SPR. They immobilized the full-length or N-terminal deleted proteinase on the surface of the plasmonic chip using HBS-EP buffer. The protein was coupled to carboxymethylated dextran of the sensing chip using amine coupling. The 6-amino acid peptide (TSAVLQ) for SARS 3CLpro was diluted in the running buffer and automatically injected in a series of increasing concentrations $(20-500 \mu \mathrm{M})$. Liu et al. [56] have immobilized the recombinant spike on the plasmonic chip, and the affinity of AS3-3, a human mAb Fab fragment, to this protein was investigated and measured (dissociation constant of AS3-3 $=1.98 \times 10^{-8} \mathrm{M}$ ). They have shown that AS3-3 reacted with SARS-CoV-infected cells. Chen et al. [135] have investigated the potent inhibitors of SARS-CoV 3CLpro using SPR. From 256 compounds, 52 have shown the binding to SARS-CoV 3CLpro.

\subsubsection{SARS-CoV genome}

\section{- SPR}

Ahn et al. [50] have investigated the binding affinity of different concentrations of RNA aptamer on immobilized (His)6-tagged N protein on the sensor surface. Yang et al. [14] have studied the molecular mechanism of RNA-protein interaction using SPR analysis. Their used sensor chip was coated with streptavidin-coated at $37{ }^{\circ} \mathrm{C}$ and $\mathrm{N}$ protein was injected on RNA hybridized sensor. Negative control was BSA protein and as expected the binding between BSA and RNA was not detected; however, the binding between N protein and RNA was 170 $\mathrm{RU}$, and its affinity was $\mathrm{Kd} 4.60 \pm 0.3 \mathrm{nM}$. Luo et al. [45] have found strong evidence that SARS N protein bound to human cyclophilin A (hCypA). Using SPR, they have shown that this binding has equilibrium dissociation constant ranging from 6 to $160 \mathrm{nM}$. Chen et al. [46] have examined the kinetics of RNA binding between non-phosphorylated and phosphorylated $\mathrm{CoV}$ infectious bronchitis virus $\mathrm{N}$ protein with nonviral and viral RNA. Previously, it was predicted that phosphorylation of $\mathrm{N}$ protein plays a role in RNA binding. Using plasmonics and streptavidin-coated chips, they have shown that non-phosphorylated $\mathrm{N}$ protein bound with the same affinity to viral RNA as phosphorylated N protein. Nevertheless, there was a higher affinity between the binding of phosphorylated $\mathrm{N}$ protein and viral RNA in comparison with non-viral RNA. It meant that the phosphorylation of $\mathrm{N}$ protein determined the recognition of virus RNA. During these experiments, they have used the running buffer and analyte diluting of HBS-EP (0.01 M HEPES, $0.15 \mathrm{M} \mathrm{NaCl}, 3 \mathrm{mM}$ EDTA, $0.005 \%$ surfactant P20 [pH 7.4]).

\subsection{MERS coronavirus (MERS-CoV)}

Middle East Respiratory Syndrome coronavirus (MERS-CoV), previously called human coronavirus-Erasmus Medical Center (HCoV-EMC), was first reported in Saudi Arabia in 2012 and spread to 20 different countries resulting in 853 infections with 301 deaths as of October 2, 2014 [39]. In South Korea, an outbreak of 180 confirmed MERS-CoV infected cases and 36 deaths were reported in May and June 2015 [7]. The fertility rate of MERS CoV is very high $(\sim 35 \%)$, and it exceeds the rate of SARS CoV; however, MERS-CoV remains somewhat limited in its transmissibility [58].

MERS-CoV and SARS-CoV have different receptors which are dipeptidyl peptidase 4 (DPP4 or CD26) and ACE2, respectively [39]. Both MERS-CoV and SARS-CoV have a 
severe respiratory infection, while MERS-CoV exhibits an additional unique symptom of renal failure [39]. Both MERS-CoV and SARS-CoV are single-stranded positive-sense RNA viruses with approximately $30 \mathrm{~kb}$ genome sizes. Each of their genes encodes two polyproteins called ppla and pplb that are processed by two proteases, a 3CLpro and a papain-like protease (PLpro). Many CoVs contain two PLpro enzymes (PLP1 and PLP2), but MERS$\mathrm{CoV}$ and SARS-CoV have only one PLpro enzyme. Both 3CLpro and PLpro are known to be essential for viral replication, making them attractive targets for antiviral drugs. Phylogenetic analysis has shown that MERS-CoV is genetically very similar to clade 2 cbeta $\mathrm{CoV}$ that appears in camels and insectivorous bats [57]. MERS-CoV can replicate itself in various cell lines extracted from human, non-human primate, porcine, and bat [57]. However, common laboratory animals like mice, hamsters, and ferrets resist MERS-CoV infection [57]. This short host list for MERS-CoV limits the animal models for pathogeneic studies [57].

\subsubsection{MERS-CoV non-genome sections and immune response}

- SPR

Lee et al. [39] have studied four known SARS-PLpro lead inhibitors against MERS-PLpro, and they found that none of the tested SARS PLpro lead inhibitors was effective against MERS-PLpro [39]. Song et al. [57] have identified several key residues in hDPP4 that were critical for RBD binding. These residues were K267 and R336 on binding patch 1, and L294, I295, R317 and Q344 on binding patch 2. Using amine coupling, RBD was immobilized on the sensing chip, and hDPP4 and its mutants were injected into the system with various concentrations. In Coronaviridae Family, antibodies frequently target the $\mathrm{S}$ protein that has $\mathrm{S} 1$ and S2 subunits where the first and second ones play a role in receptor recognition and membrane fusion, respectively [58]. Initially, the entry of MERS CoV occurs via S1 with the human receptor CD26 (hCD26, also known as dipeptidyl peptidase 4, DPP4) and then the membrane fusion takes place via S2 [58]. Li et al. [58] have stated that the disruption between MERS-RBD and hCD26 by mAbs could be an effective therapy for MERS-CoV infection. For their study, they have used two mouse-derived neutralizing mAbs (4C2 and 2E6) against MERS-CoV from mice immunized with MERS-RBD. The binding kinetics of these two mAbs to MERS-RBD were analyzed using SPR. The antibodies were immobilized on the surface of the plasmonic chip, and MERS-CoV RBD at gradient concentrations was injected on this surface. Wang et al. [59] have demonstrated that the RBD domain of BatCoV HKU4 (HKU4-RBD), but not the equivalent domain of Bat-CoV HKU5 (HKU5-RBD), could bind to hCD26. The binding affinity between HKU4-RBD and hCD26 was determined by SPR to be within the micromolar range. They have immobilized the RBD proteins on the chip surface under the flow of gradient concentrations of hCD26 or hACE2.

Zhao et al. [61] have determined the binding affinity of the two nanobodies for MERSCoV RBD using SPR. Nanobodies or camelid heavy-chain variable domains (VHHs) were one-domain antibodies in nanoscale that were extracted from heavy chain-only antibodies of camelid or shark. Nanobodies had four regions called framework regions (FRs) and three regions of complementarity determining regions (CDRs). FRs kept the structural integrity of nanobodies and CDRs bound to the antigen epitopes. Lu et al. [60] have demonstrated the potent interaction between MERS-CoV RBD and CD26 using SPR at room temperature. The MERS-CoV RBD and SARS-CoV RBD proteins were immobilized on the chip at about 500 RUs under the flow of human CD26 or human ACE2. Qiu et al. [62] have suggested that hMS-1 might be an effective immunotherapeutic agent for MERS-CoV patients, specially in 
new cases. hMS-1 is a humanized mAb that targeted the MERS-CoV RBD with high affinity. hMS-1 significantly blocked MERS-CoV RBD binding to hDPP4 receptor and neutralized the infection. For this study, they have immobilized hMS-1 on the surface of the plasmonic chip via amine coupling and His6-tagged RBD protein with various concentrations was flowed over the chip surface.

Yu et al. [63] have investigated the molecular basis of MERS-27 neutralization that could be helpful in the optimization of MERS-27 as a tool to fight against MERS-CoV infection. They have examined the effects of these RBD mutations on the binding of MERS-27 Fab using SPR at room temperature. The MERS-27 Fab was immobilized on the plasmonic chip via amine-coupling. For the collection of data, MERS-CoV RBD and its mutants were injected in a buffer at various concentrations.

\subsection{COVID-19}

Coronavirus disease 2019 (COVID-19) was discovered in the Hubei Province of China in December 2019. A cluster of patients was admitted with fever, cough, fatigue, shortness of breath, and other symptoms [8]. The symptoms expressed by COVID-19 patients are nonspecific and cannot be used for an accurate detection due to its first symptoms similar to common cold or influenza.

It was discovered that this new viral pathogen had about $80 \%, 50 \%$, and $96 \%$ homology to the genome of the SARS-CoV, MERS-CoV, and bat CoV RaTG13, respectively. Due to these similarities, its pathogen is also called SARS-CoV-2. This virus has high transmission rate from human to human via direct contact through droplet spread. As of May 2, 2021, the disease has spread to at least 220 countries and territories, infected more than 150 million people, and has resulted in at least 3 million deaths globally in the period from 22 January 2020 to 2 May 2021. COVID-19 can be transmitted from human to human. It has been recently found that cured individuals had the possibility to be re-infected. Recently, the artificial networks help to model COVID-19 spreading via human-human interaction [136]. Moreover, the mathematical analysis could show the temporal evolution and transmission dynamics of COVID-19 in selected geographical regions [137-142]. Some studies investigate the herd immunity against COVID-19 using the mathematical analysis like multifractal formalism [143].

Rapid diagnosis can play an essential role in the containment of COVID-19 and control its spread by applying effective isolation and contact tracking. Viral diagnosis is a rapidly moving topic of research, and a review article that encompasses the current findings may be useful for guiding strategies to deal with this pandemic [8].

It was observed that the virus has a diameter ranging from 60 to $140 \mathrm{~nm}$ using TEM (Fig. 3). Genetically, COVID-19 has a single-stranded positive-sense RNA genome that is around 30,000 nucleotides in length. The genome encodes 27 proteins including an RNAdependent RNA polymerase $(R d R P)$ and four structural proteins including the spike surface glycoprotein $(\mathrm{S})$, a small E protein, matrix protein $(\mathrm{M})$, and nucleocapsid protein $(\mathrm{N})$. The receptor of this virus is the ACE2. Understanding the biological properties of COVID-19 can enable researchers to find efficient detection approaches. 


\subsubsection{COVID-19 non-genome sections and immune response}

- SPR

Li et al. [64] have investigated the affinity between the ligands and Mpro proteinase as the key enzyme in proteolytic processing of viral replication of COVID-19. Mycroft-West et al. [65] have used SPR to measure the interaction between the COVID-19 Spike S1 protein $\mathrm{RBD}$ and heparin. The data demonstrated an interaction between the recombinant surface RBD and the polysaccharide that could be effective in the rapid development of a first-line therapeutic by repurposing heparin and tailor-made, GAG-based antivirals. Liu et al. [66] have virtually screened an FDA-approved drug database using the $\mathrm{HCoV}-19$ protease Mpro as a target and validated the binding affinity by the SPR assay so DIP could be identified as a lead drug.

- SEIRA

Labouta et al. [67] have suggested a localized plasmonic photothermal platform by which they have eliminated virus load from respiratory system and kept the hospitalized patients from the mortal impacts of the CoV. For this purpose, they relied on photothermal effects of the ACE-2-functionalized gold nanorods (AuNRs) by irradiating NIR. Peng et al. [74] have used tellurene and carboxyl-functionalized $\mathrm{MoS}_{2}$ layers and ACE2 receptor for detection of COVID-19 using near-infrared plasmonic sensing (i.e. SEIRA). The reported sensitivity is $8.4069 \times 10^{4}$ degree/RIU.

\section{- SERS}

Pramanik et al. [68] have employed antibody attached AuNPs for the naked eye detection of COVID-19 viral antigen or of pseudo SARS-CoV-2 using a very fast and simple colorimetric change. Based on 4-aminothiophenol and anti-spike antibody attached gold nanoparticle SERS, the antigen of COVID-19 or virus can be detected at very low concentrations within $5 \mathrm{~min}$. Liu et al. [71] have proposed SERS-LFIA for the detection of anti-SARS-COV2 IgM/IgG. Their SERS tags are SiO2@Ag core-shells with the receptor of Anti-human IgM and $\mathrm{IgG}$ and S-protein analyte. The reported the LoD of $1 \mathrm{pg} / \mathrm{mL}$. Peng et al. [73] have used $\mathrm{Nb} 2 \mathrm{C}$ and Ta2C MXenes as plasmonic SERS substrates for detection of SARS-CoV-2 S protein with reported LoD of $5 \times 10^{-5} \mathrm{M}$.

\section{- SEF}

Cady et al. [69] have developed a biosensor platform based on grating-coupled fluorescent plasmonics for the simultaneous measurement of antibody levels for several antigens in a single sample. The results have had compatibility with enzyme linked immunosorbent assay (ELISA) and a Luminex-based microsphere immunoassay. Based on SEF technique, Wang et al. [72] have detected the COVID-19 specific IgM and IgG using S1 protein-conjugated $\mathrm{SiO} 2 @$ dual QD core-shell structures that can bind to the receptors of goat anti-human IgM and $\mathrm{IgG}$. Their reported $\mathrm{LoD}$ is $1: 10^{7}$ dilution in serum.

\subsubsection{COVID-19 genome}

\section{- LSPR}




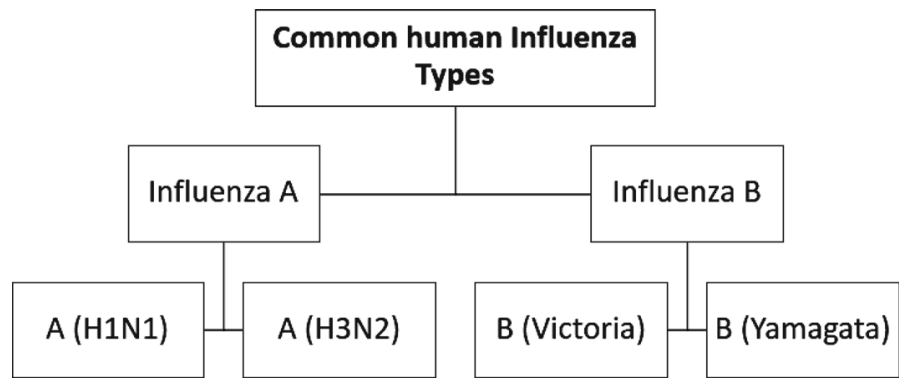

Fig. 5 Influenza A and B are most common influenza types for human. Influenza A is divided into two main subgroups of A (H1N1) and A (H3N2) and influenza B has two lineages of B (Victoria) and B (Yamagata) [146]

Qiu et al. [70] have reported the application of a nanoplatform including AuNI plasmonic chip for the quantitative measurement of SARS-CoV-2 within 30 min. They have suggested a novel concept based on the amplification-free-based direct viral RNA detection and an amplification-based cyclic fluorescence probe cleavage (CFPC) enabling the tests of clinical COVID-19 patient samples.

\section{Influenza virus}

Influenza is a zoonotic disease that occurs in animals as well as humans and it is caused by three main serotypes of Influenza virus A, Influenza virus B, and Influenza virus C. Influenza leads to respiratory infections like bronchitis, acute otitis media, pneumonia, and sinusitis and causes invasive infections like meningitis, septic arthritis, and cellulite [144]. Ecologic studies have brought this hypothesis that all mammalian influenza are originated from the avian influenza reservoir [145]. As seen in Fig. 5, influenza A has two main subtypes of $\mathrm{A}(\mathrm{H} 1 \mathrm{~N} 1)$ and $\mathrm{A}(\mathrm{H} 3 \mathrm{~N} 2)$, and influenza $\mathrm{B}$ has two lineages of $\mathrm{B} /$ Yamagata and $\mathrm{B} /$ Victoria. The pandemic of very virulent (vv) influenza H1N1 in 1918, with genes of swine origin, is the worst pandemic of the world with more than 500 million infected individuals and at least 50 million deaths. Another H1N1 pandemic occurred in 2009 called 2009-H1N1, which has continued to circulate seasonally, sometimes with small genetic changes. Influenza A (H3N2) is one of the frequent subtypes of influenza in human which tends to more rapid changes. However, influenza B has a low tendency to genetic changes in comparison with influenza A.

Some of the commercially available molecular genetics diagnostic kits for influenza virus are Directigen, ZStatFlu (ZymeTx, Inc.), FLU OIA A/B (Biostar Inc.), the 3 M Rapid Detection Flu A + B test (3MA + B), Binax NOW Flu A and Flu B, direct IF [147]. General detection techniques for influenza are NAT using RT-PCR, antigen test using immunofluorescence [148] or colloidal gold assay, latex particle agglutination (LAT), virus isolation via cell culturing, and serologic analysis [149]. However, the majority of these methods suffer from the tradeoff between response time and sensitivity [150]. Besides, the virus cannot be detected after the first days of infection in some of these techniques [151]. Recently, optical methods like highly sensitive paper-based lateral-flow assay (LFA) detection technique, waveguide sensing and Mach-Zehnder [152] interferometer have attracted attention. The colorimetric LFA sensor has shown a considerable sensitivity detection of AFB1 with an LoD of $0.3 \mathrm{ng} / \mathrm{mL}$. In comparison with the conventional ELISA technique, SERS-based LFA shows 
30 times higher sensitivity. SERS-based LFA could detect influenza virus using a core-shell $\mathrm{Au}$ and Ag NPs [153]. Similarly, evanescent-field-coupled waveguide-mode sensor [154], bioimprinting hydrogels [155] and electrochemical/piezoelectric biosensors [35, 156, 157] can be helpful in diagnosis.

Plasmonics have attracted attention as a label-free optical method. Therefore, summarized information for Orthomyxoviridae Family (influenza model) can be found in Table 2.

\subsection{Influenza virus non-genome sections and immune response}

\section{- SPR}

Nilsson et al. [76] have used SPR in their study for vaccine production by antibody inhibition assay using HA proteins immobilized on the sensor surface. Chang et al. [77] have detected H7N9 virus via intensity-modulated SPR (IM-SPR) biosensor integrated with a new generated $\mathrm{mAb}$ (Fig. 6a). As seen in Fig. 6a, the plasmonic chip surface was functionalized for selective binding of H7N9 and not for other influenza viruses and reflection was recorded in prism-coupling configuration. The LoD of their proposed technique was 144 copies $/ \mathrm{mL}$, that was 20-fold more sensitive than homemade target-captured ELISA with the same antibody. Their assay test took about $10 \mathrm{~min}$. Kim et al. [78] have reported a selection of a cognate pair of aptamers for whole avian influenza virus particles of H5N2 using graphene-oxide-based systemic evolution of ligands by exponential enrichment (GO-SELEX). Using persuasive techniques like SPR they have found that the aptamers of J3APT and JH4APT played the role of a cognate pair which bound to the virus at different locations simultaneously. In Fig. 6b, the development of dual aptamer using SPR assay and its application on lateral flow strip assay (LFSA) is shown. They have found that the LoD was $1.27 \times 10^{5} \mathrm{EID} 50 / \mathrm{ml}$ in the buffer and $2.09 \times 10^{5}$ EID50/ml in the duck's feces, respectively.

Zhao et al. [80] have developed a compact optical fiber sensor for the detection of influenza avian influenza virus (AIV)-H6 virus in poultry. As the process is shown in Fig. 6c, the gold surface of the SPR optical fiber sensor was used for chemical binding of a self-assembled monolayer of isopropanol. Then, the activation of $\mathrm{N}-(3-$ dimethylaminopropyl)-N ethylcarbodiimide/N-hydroxysuccinimide enabled EB2-B3 mAbs to capture A/chicken/Taiwan/2838 V/00 (H6N1) through a flow injection system. The LoD was $5.14 \times 10^{5} \mathrm{EID}_{50} / 0.1 \mathrm{~mL}$ for $\mathrm{A} /$ chicken/Taiwan/2838 V/00 with the average response time of $10 \mathrm{~min}$. Besides, gold NPs play a role in therapeutic and detection of influenza virus.

\section{- LSPR}

Papp et al. [81] have functionalized 14-nm gold NPs with a sialic-acid terminated glycerol dendron for the detection and inhibition of X31 influenza virus that was a reassortant H3N2 influenza virus carrying the HA and NA genes of A/Aichi/2/68. Marin et al. [82] have developed a plasmonic bioassay based on gold NPs for human influenza virus detection. As schematically shown in Fig. 6d, they have functionalized gold NP with thiolated trivalent $\alpha 2,6$-thiol-linked sialic acid derivative. At the presence of the influenza virus, the solution of the glyconanoparticles aggregated that caused a color change within $30 \mathrm{~min}$. A significant feature of this technique was that these particles were capable of distinguishing between human ( $\alpha 2,6$ binding) and avian ( $\alpha 2,3$ binding) RG14 (H5N1) influenza virus. Park et al. [83] have developed a plasmonic biosensor based on a multi-spot gold-capped NP array for detecting the AIV. As seen in Fig. 6e, the gold binding polypeptide (GBP)-fusion protein was immobilized on the gold surface that could interact with AIa and its anti-AI antibody. 
a

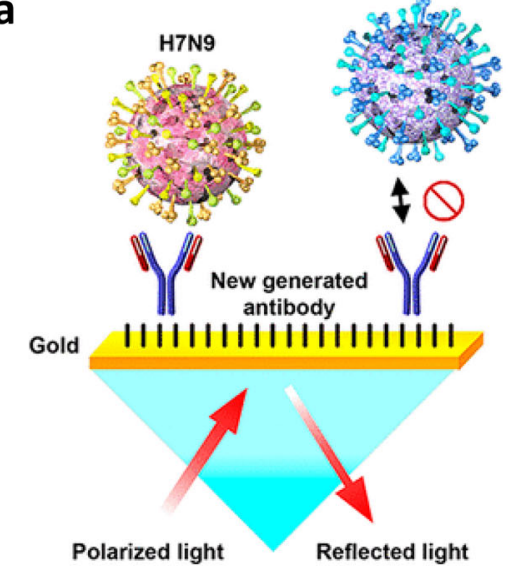

b
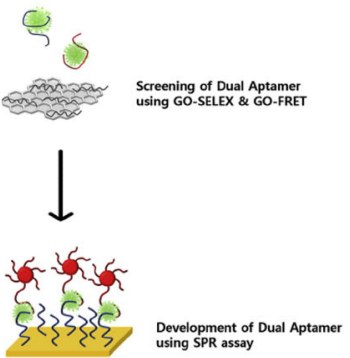

Development of Dual
using SPR assay

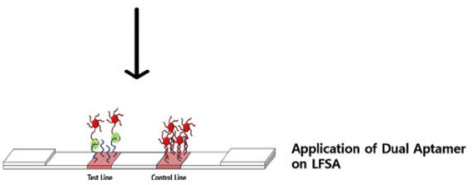

C
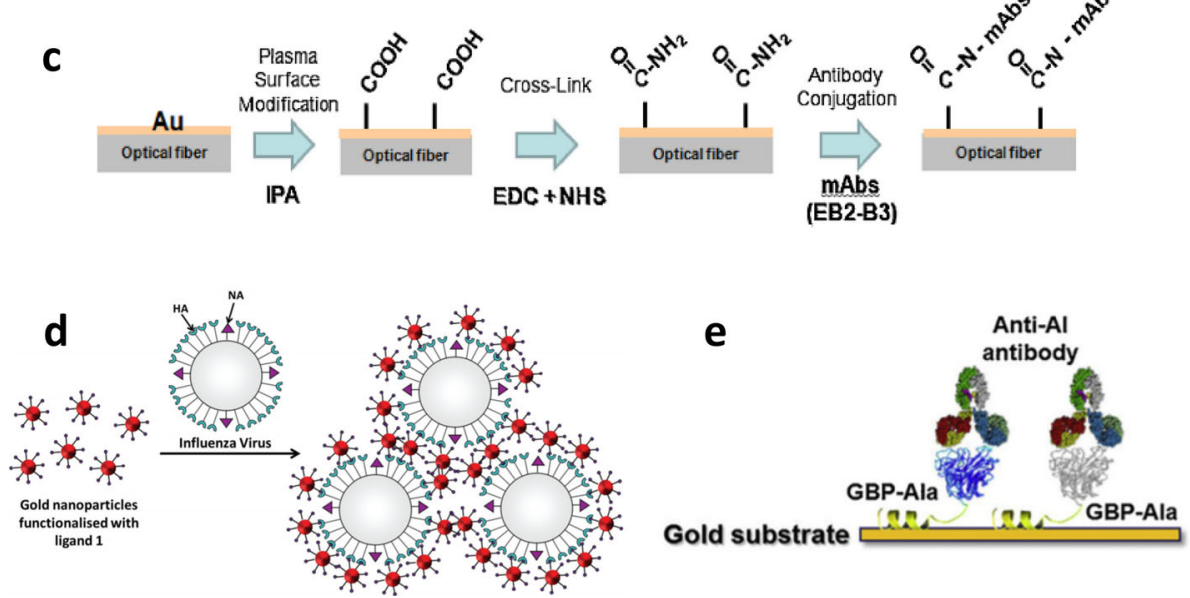

Fig. 6 a Schematic of the plasmonic chip used for the detection of H7N9 virus. The functionalized chip surface provided the selective binding for H7N9 by Chang et al. [77]. b The selection and application of a cognate pair of aptamers for H5N2 avian influenza. Kim et al. [78] have applied graphene-oxide-based systemic evolution of ligands by exponential enrichment (GO-SELEX). They have found that the aptamers of J3APT and JH4APT played the role of a cognate pair which bound to the virus at different locations simultaneously [78]. c The SPR optical fiber sensor surface was modified with the carboxyl group SAM layer and then activated by EDC/NHS. Zhao et al. [80] have proposed this optical fiber sensor for the detection of influenza H6 virus. d The aggregation of the glyconanoparticles in the presence of the influenza virus. At the presence of the influenza virus, the solution of the glyconanoparticles aggregated that caused a color change within 30 min [82]. e The gold binding polypeptide (GBP)-fusion protein was immobilized on the gold surface that could provide interaction with AIa and its anti-AI antibody [83]

\section{- SEF}

Lee et al. [86] have developed a plasmon-assisted fluoro-immunoassay (PAFI) to detect the influenza virus using gold NPs decorated with carbon nanotubes (AuCNTs) as the processes (i.e. sonication, stirring, shaking and binding) are shown in Fig. 7. PAFI utilized the phenomenon of plasmonic resonance energy transfer (PRET) that produces photoluminescence enhancement due to the interaction between the plasmonic structure and the semiconductor NPs. Antibodies for this virus were conjugated on the surface of AuCNTs cadmium telluride 


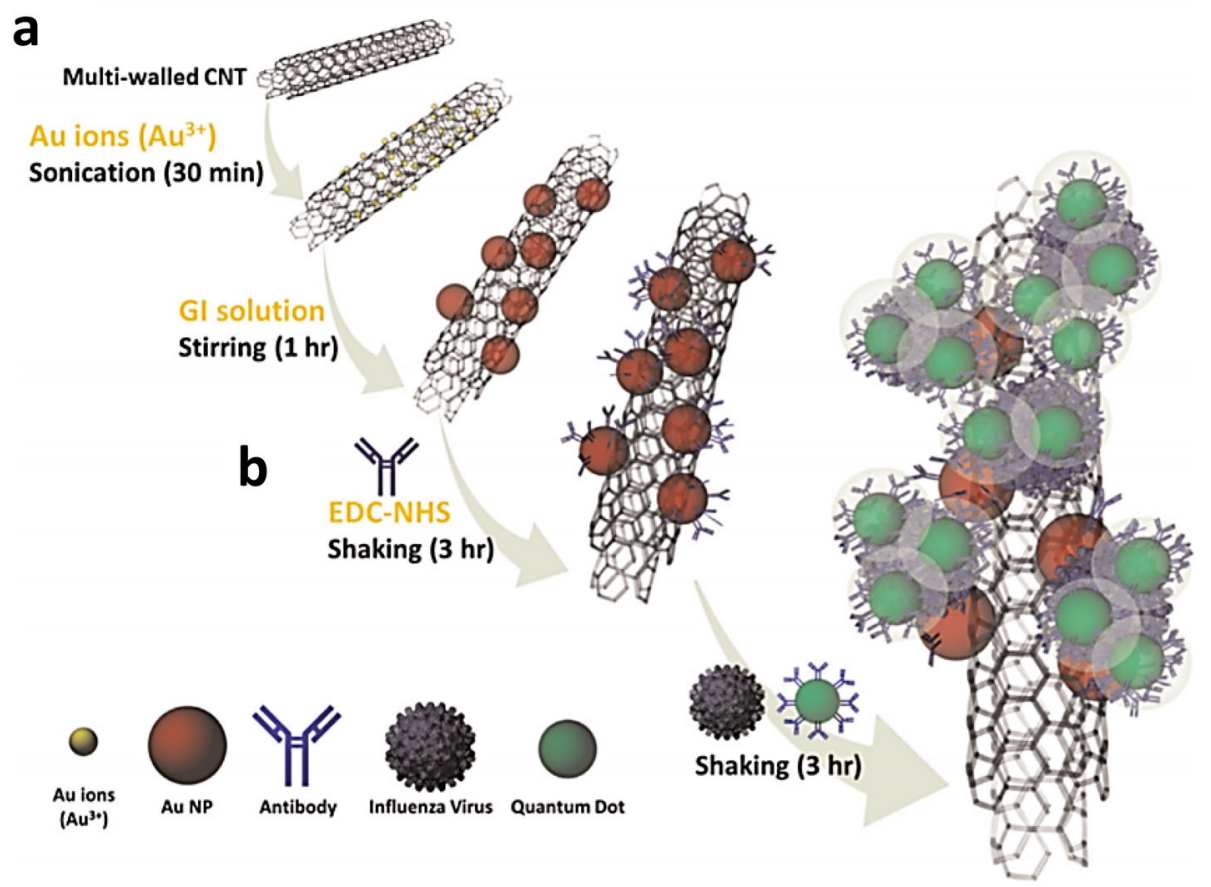

Fig. 7 A plasmon-assisted fluoro-immunoassay (PAFI) for detection of influenza virus using gold NPs decorated with carbon nanotubes (AuCNTs) a Preparation of AuNP-decorated CNT nanostructures (AuCNTs) b the process of influenza virus detection by using PAFI, non-scalable [86]

(CdTe) quantum dots (QDs). The photoluminescence intensity changed with the virus concentration. This detection technique had the $\mathrm{LoD}$ of $0.1 \mathrm{pg} / \mathrm{mL}$ for all three types of influenza viruses examined (i.e. A/ Beijing/262/95 (H1N1), New Caledonia/20/99IvR116 (H1N1), and A/Yokohama/110/2009 (H3N2).). Pang et al. [85] have detected the rHA protein of H5N1 influenza virus using a fluorescent sensor where the anti-rHA protein was immobilized. They reported the LoD of $2-3.5 \mathrm{ng} / \mathrm{mL}$.

\section{- SERS}

Using SERS and gold nanoparticles, Lim et al. [158] have shown that influenza viruses have surface proteins/lipids that produce typical Raman signals. Maneeprakorn et al. [84] have immobilized the antibodies targeted for influenza A nucleoprotein on the chip surface and they used tagged gold nanoparticles with ATP molecules as reporter. The sensitivity of the integrated SERS-LFIA technique was reported to be 300 -fold better in comparison with LFIA technique.

\subsection{Influenza virus genome}

- SPR

Bai et al. [75] have immobilized first streptavidin on the plasmonic chip and then immobilized biotinylated ssDNA. The analyte or AIVs were bound on this surface whose LoD is 0.218 HAU for AIV H5N1 in poultry swab. Wong et al. [79] have reported a plasmonic 
contrast imaging biosensor for influenza $(\mathrm{H} 3 \mathrm{~N} 2)$ virus protein-antibody and DNA-DNA biomolecular binding detections. Their sensor measured the intensity difference between the pand s-polarized light at plasmonic excitation. The p-polarized light excited the plasmonic resonance while s-polarized was not affected. For omitting the noise and improving the intensity, intensities of both images were subtracted. The sensor resolution was $4.36 \times 10^{-7}$ RIU.

$-\mathrm{SEF}$

Jeong et al. [159] have used graphene oxide in a fluorometric system to detect hemagglutinin gene of influenza virus. Using this technique, they could detect $3.8 \mathrm{pg}$ of influenza RNA.

\section{Hepatitis B virus (HBV)}

Hepatitis is an inflammatory disease of liver, and it dated back to the dinosaur era based on DNA fossils in bird genomes. Viral Hepatitis are mainly caused by five viruses of A, B, $\mathrm{C}, \mathrm{D}$ and $\mathrm{E}$. It has various origins like digestion of contaminated water/food, contact with infected blood and most importantly viral pathogens. Hepatitis A is a short-term disease while Hepatitis B, C and D are more chronic and Hepatitis $\mathrm{E}$ is more dangerous in pregnant women [160]. The Hepatitis A virus sheds in the faeces of infected persons and annually, there are 1.4 million cases worldwide reported for Hepatitis A. For hepatitis B, 240 million people have been infected by now, and 786,000 have died from this disease. Hepatitis B is the main cause of liver cirrhosis in the world. By 2020, it was estimated that 71 million people were infected with hepatitis $\mathrm{C}$ globally. Many people with Hepatitis C infection suffer from cirrhosis or liver cancer, and subsequently, 399,000 deaths occur each year. Considering Hepatitis D, it has infected about 15 million people worldwide, as the last recorded pandemic in 1987 originated from Spain [161].

There are various electrical, chemical and optical detection techniques for liver disorders. Hassanpour et al. [162] have reviewed the detection techniques of Hepatitis based on electrochemical, optical or piezoelectrical biosensors benefiting from nanomaterials. The liver infection causes some metabolic changes such as phenylalanine, tryptophan, L-proline, histidine, ethanol, tyrosine, fumaric acid and lactic acid [162]. The most common detection techniques for Hepatitis are blood testing consisting of recombinant immunoblot assay, PCR, biomarker assay, enzyme immunoassay and hepatitis RNA quantification in the serum. Laboratory diagnostic names of these techniques are RIA (radio-immunoassay), EIA (enzyme immunoassay), immuno-chemiluminescence and ICA (immuno-chromatographic assay) [162]. Zhou et al. [163] have used a plasma microRNA panel for detection of HBV. Sebastiani et al. [164] have employed non-invasive markers and biopsy for studying the liver fibrosis in chronic hepatitis B. Chou et al. [165] have worked on the review that showed many blood tests are moderately useful for identifying clinically significant fibrosis or cirrhosis in HCV-infected patients. Chevaliez has made a review on detection techniques of hepatitis C [166]. Stibbe et al. [167] have mentioned that FibroTest, Fib-4, and TE were the most accurate tests and their integration with non-invasive tests will increase the accuracy. Bissonnette et al. [168] have made a comprehensive study on the plasma biomarkers for the detection of alcoholic Hepatitis. Liu et al. [88] have employed immunochromatographic assay (ICA) based on labels of ultramarine blue particles, with a blue visible signal. Their technique was used to detect $\mathrm{HBV}$ antigen with the $\mathrm{LoD}$ of $0.37 \mathrm{ng} \mathrm{mL}^{-1}$. Moreover, there are various optical methods reported for this virus detection. Lu et al. [169] have detected HBV using Raman spectroscopy integrated with a multiscale convolutional neural network. 
Khan et al. [170] have detected HBV using Raman spectroscopy under the spectral range $400-1700 \mathrm{~cm}^{-1}$ that was improved by neural network classifier. This detection was based on the Raman shift, which gave molecular information of the target sample. The peak locations and their corresponding intensity of the Raman spectra gave information on the composition and concentration of the specific molecule. Wang et al. [171] have used photoacoustic viscoelasticity (PAVE) imaging for supplementary detection of hepatitis virus due to the hepatocyte enlargement and intracellular fluid increment. Cha et al. [172] have reported a silica NP-enhanced dynamic micro-cantilever biosensor for HBV DNA detection. The capture probe was on the surface of the micro-cantilever, and the detection probe was conjugated with silica NPs for the targeted DNA. HBV DNA of 243-mer could be detected at the picomolar level without NP and up to femtomolar at the presence of NP amplification. The graphical summary of the recent studies on HBV detection using plasmonics is brought in Fig. 8, 9,10.

\subsection{HBV non-genome sections and immune response}

Shevstov et al. [173] have made a comprehensive review on the metal NPs like gold and iron oxide particles applicable in the detection of HBV with higher efficiency. Yin et al. [174] have investigated the stability of hepatitis E vaccines for which they have used ELISA and SPR to assess the antigenicity of vaccines. Choi et al. [89] have used a plasma-treated parylene-N film for plasmonic sensing of HBV surface antigens. They have estimated that this type of immobilization could improve the sensitivity up to 1000-fold.SEF.

Ghafary et al. [87] have proposed a magnetoimmunoassay based on Thionine-Gold NPs as a fluorescence label for detection of HBV with the LoD of $4.6 \times 10^{-9} \mathrm{ng} / \mathrm{mL}$. The plasmonic effect of gold NPs amplified the fluorescence intensity. Figure 8a shows the preparation steps and SEF/protease-based sandwich-type immunoassay for HBV detection.

In another study, Riedel et al. [93] have developed a plasmonic biosensor for analysis of hepatitis B in Saliva. In comparison with the blood samples, saliva samples could be collected non-invasively. However, it faced two main challenges: low analytic concentration and increased surface fouling. For this reason, this team has amplified fluorescence sandwich immunoassay using plasmonics. For selective adsorption, they have utilized the brushes of poly[(N-(2-hydroxypropyl) methacrylamide)-co-(carboxybetaine methacrylamide)] on the gold surface and modified with hepatitis B surface antigen. Their optical setup integrated the angular interrogation of SPR with the plasmon-enhanced fluorescence detection technique [175]. P-polarized monochromatic beam with the wavelength of $633 \mathrm{~nm}$ was used for SPs excitation with the incident angle of $60^{\circ}$. The fluorophore Alexa Fluor 647 and related filters were used for the excitation wavelength of $633 \mathrm{~nm}$ and the emission wavelength of $670 \mathrm{~nm}$ at $25^{\circ} \mathrm{C}$. The fluorescence beam was focused at the input of a photomultiplier. The schematic of their optical setup with poly(HPMA-co-CBMAA) brush functioning as a binding matrix is shown in Fig. 10. As stated in their previous study, they have validated their results using the ELISA technique.

\section{- SPR}

Zheng et al. [91] have developed a biosensor for HBV detection using GBP fusion proteins, and they have benefitted from optical analytical methods like SPR or LSPR. They have detected both HBV surface antigen PreS2 (HBsAg) with GBP-fused single-chain antibody (GBP-ScFv) and anti-HBsAg with GBP-HBsAg as shown schematically in Fig. 8c. There was a high affinity between the GBP and the gold surface, which ensured the stability of the sensing platform. Riedel et al. [92] have developed a plasmonic sensor for analysis of HBV in serum samples. They have designed an efficient anti-fouling biointerface comprising of 
poly[( $N$-(2-hydroxypropyl) methacrylamide)-co-(carboxybetaine methacrylamide)] brushes that was functionalized with bioreceptors. Schematics of the gold surface with the tethered brush that is post-modified with protein ligand is shown in Fig. 9a.

Their plasmonic structure provided the facility for the direct detection of antibodies against hepatitis B surface antigen (anti-HBs) in serum samples. Besides, their structure could discriminate between anti-HBs positive and negative clinical samples within $10 \mathrm{~min}$. They have also verified their results using ELISA and regeneration of their chips could be carried out using simple treatment with glycine buffer. Their SPR setup was based on wavelength interrogation [176], and the incident angle of the polychromatic beam was set to adjust the SPR wavelength near to $750 \mathrm{~nm}$. As shown in Fig. 9b, the sensor chip was functionalized with poly(HPMA-co-CBMAA) brush as a binding matrix for direct detection of the anti-HBs target analyte. The setup functioned at the temperature of $25^{\circ} \mathrm{C}$ and had the resolution of $3 \times 10^{-7}$ RIU with LoD of $0.3 \mathrm{ng} \mathrm{cm}^{-2}$. In Table 2, the summary of the recent studies on plasmonic virus detection for $\mathrm{HBV}$ can be found.

\subsection{HBV genome}

\section{- SERS}

Li et al. [90] have introduced plasmonic nanorice antenna on triangle nanoarray for SERS detection of HBV DNA. Figure 8b shows the sandwich structure of Ag nanorice@Raman label@SiO2 used as the SERS sensor. They have reported the LoD of $50 \mathrm{aM}$ for this virus besides discriminating a single-base mutant of DNA.

\section{Human immunodeficiency virus (HIV)}

\subsection{Overview on HIV impression, mechanism, and cell morphology:}

Two types of well-known Human Immunodeficiency Virus (HIV), type I (HIV-1) and II (HIV-2) discovered by Barré-Sinoussi and Gallo in 1983 [177] and Clavel in 1986 [178], respectively, have been classified as the primary reason of getting a serious infection called Acquired Immunodeficiency Syndrome (AIDS). Analyses using epidemiologic and phylogenetic methods suggest that HIV was introduced into the human population around 1920 to 1940 . HIV-1 seems to be initiated from non-human primate immunodeficiency viruses from Central African chimpanzees (SIVcpz) and HIV-2 seems to be originated from West African sooty mangabeys (SIVsm) (i.e. an old world monkey found in forests from Senegal) [179-181]. According to United Nations Programme on HIV/AIDS (UNAIDS) HIV-1 is the primary cause of AIDS in the world, and approximately 37.9 million people across the world with different range of ages was identified until 2018. Among these infectious people, around 770,000 lost their lives in the same year from the illness caused by these two-virus [182]. HIVs as lentiviruses belong to Retroviridae Family, and similar to other viruses of this family keeps its genome information as RNA rather than as DNA. Infections caused by lentiviruses lead to a prolonged course of the disease, persistent viral reproduction and association of the central nervous system. Several distinguished lentiviruses are known in animals. Visna in sheep, simian immunodeficiency virus (SIV) in monkeys, or feline immunodeficiency virus (FIV) in cats count for lentivirus infections. However, HIV is capable of carrying genetic information, but for creation of a new cell of its type needs a host cell which is not a retrovirus type. When HIV succeeds to enter a human cell, it injects its RNA content and releases an 


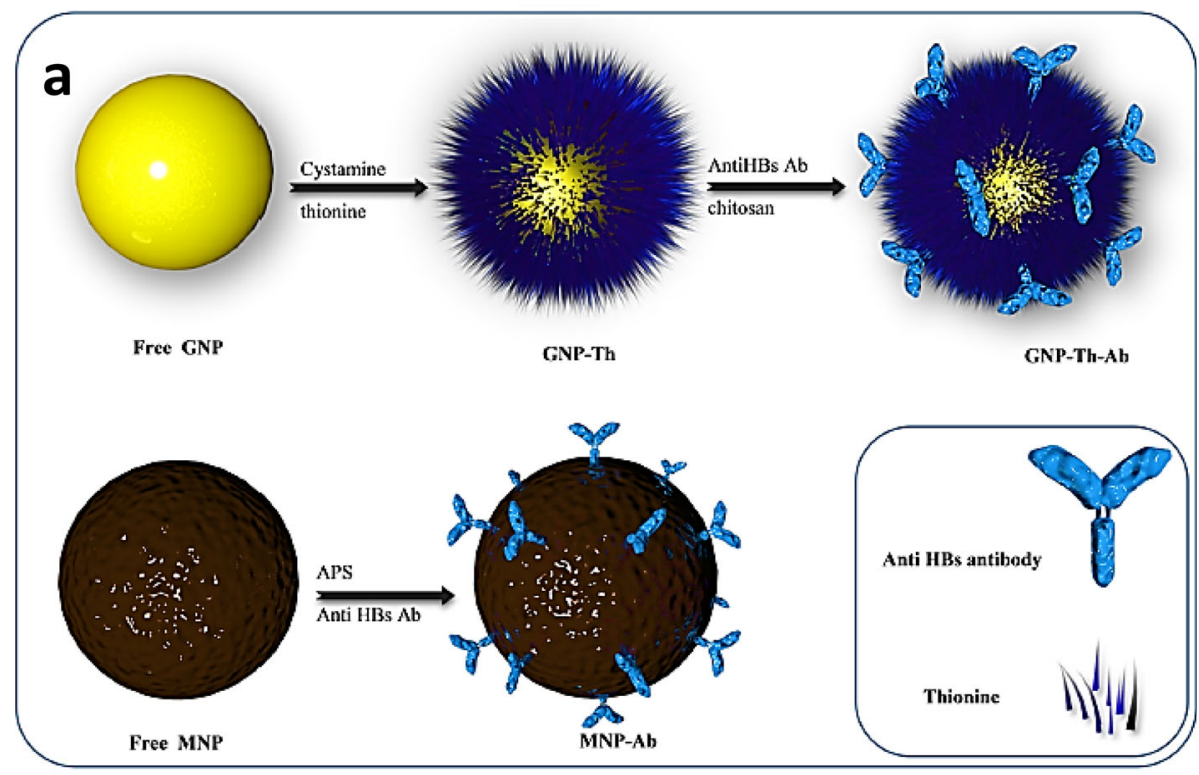

b
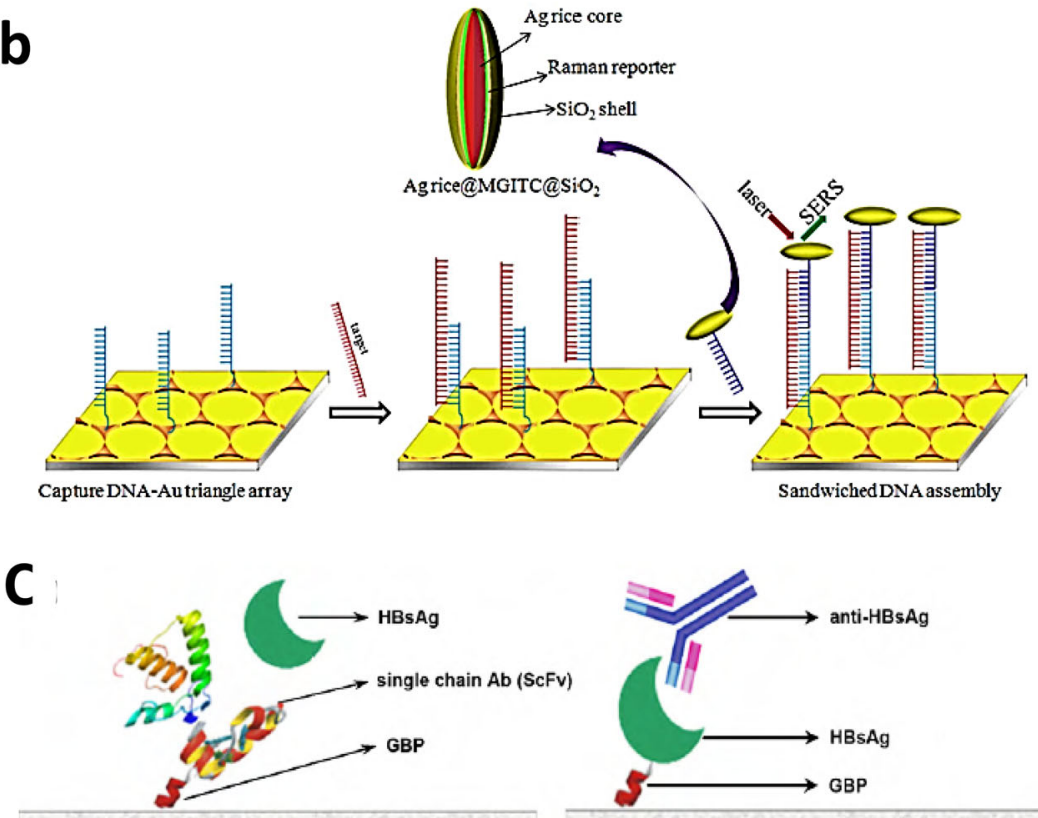

\section{Gold surface}

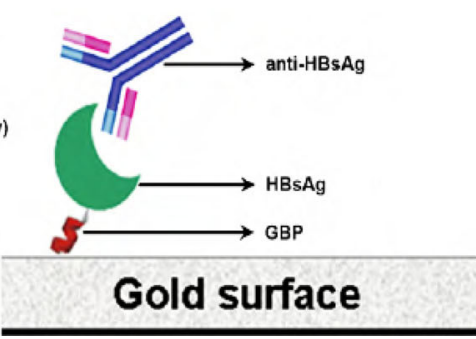

Fig. 8 a Preparation Steps and SEF/Protease-Based Sandwich-Type Immunoassay for Hepatitis B Detection. Ghafary et al. [87] have used these NPs as a fluorescence label where the plasmonic phenomenon amplified the fluorescence intensity. b The sandwich structure of Ag nanorice@Raman label@SiO2 and the operating principle of the SERS sensor for HBV DNA detection. Li et al. [90] have introduced plasmonic nanorice antenna on triangle nanoarray for surface-enhanced Raman scattering detection of hepatitis B virus DNA. c A biosensor for hepatitis B virus detection using GBP fusion proteins proposed by Zheng et al. [91] 
a

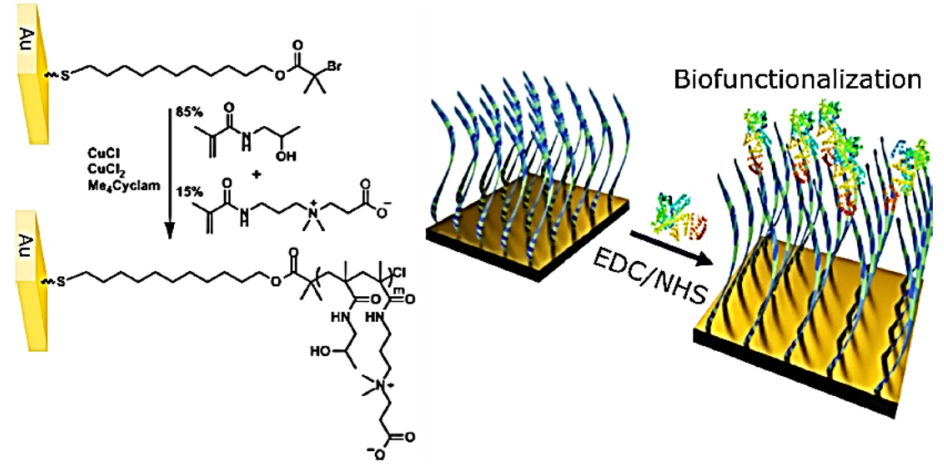

b

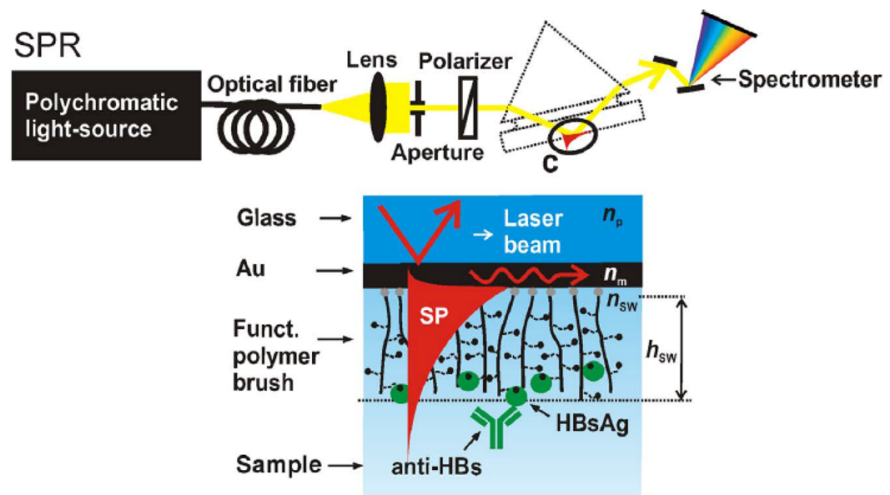

Fig. 9 a Synthesis and chemical structure of the poly(HPMA-co-CBMAA) polymer brush (left) and schematics of the gold surface with the tethered brush that is post-modified with protein ligand (right). b Riedel et al. [92] have proposed the SPR setup and sensor chip with poly(HPMA-co-CBMAA) brush functioning as a binding matrix for direct detection of the anti-HBs target analyte

enzyme called reverse transcriptase to construct a fully featured double-stranded molecule of DNA copy from HIV RNA [183]. The complete HIV DNA then firmly attached to the infected cell's DNA. Noteworthy fact on the process of DNA generation of the HIV is the reversed mechanism used by human cells, which is the production of an RNA copy of DNA.

Other diseases such as polio, influenza, or measles caused by non-retroviruses do not contribute in generating DNA copies after attacking the human cell. They make RNA copies of their original RNA instead of their DNA. Cell division of infected cells expands the number of a new copy of the integrated HIV DNA as well as its genes [184]. Major components on cell division of HIV are being influenced by three genes namely known as gag (groupantigen), pol (polymerase) and env (envelope), accordingly in the genome frame [185]. The sequence in the frame classically presented as 5'LTR-gag-pol-env-LTR 3'. The LTR (long terminal repeat) regions in Fig. 11 denote the two connection ports of the frame that are only connected to the cellular DNA of the host cell after integration and do not associate for any further intercellular interaction. The genetic code mapping for the nucleocapsid and the glycoproteins of the viral membrane organized by gag and env genes, whereas the reverse 


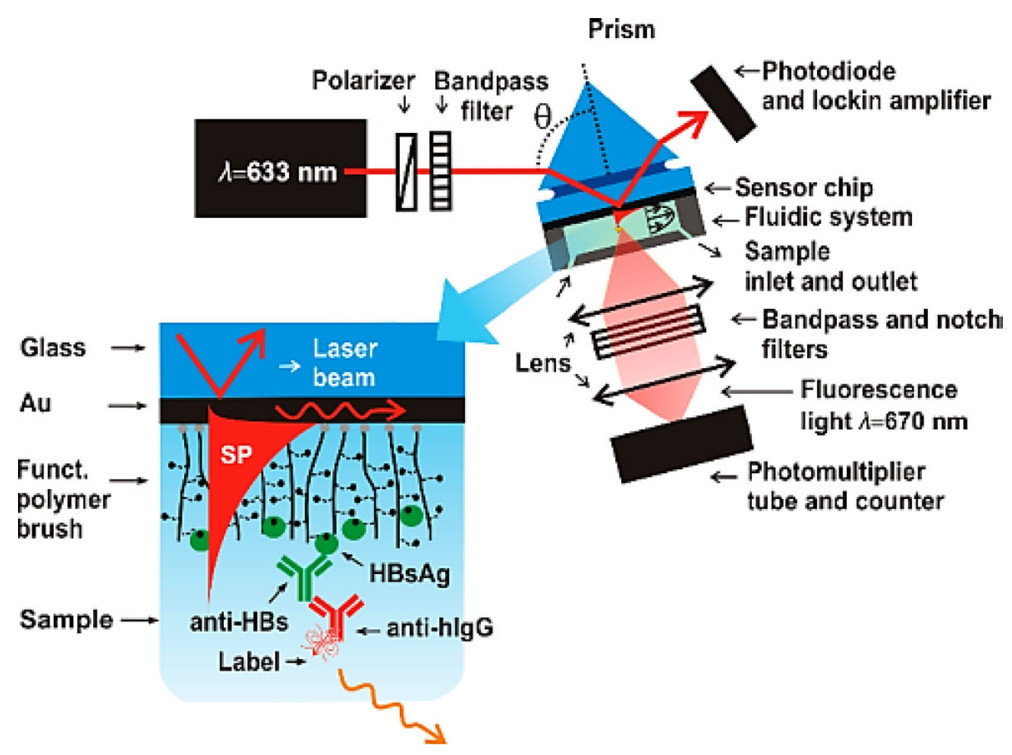

Fluorescence light $\lambda=670 \mathrm{~nm}$

Fig. 10 Plasmon-enhanced fluorescence spectroscopy biosensor with detail of sensor chip with poly(HPMAco-CBMAA) brush functioning as a binding matrix [93]

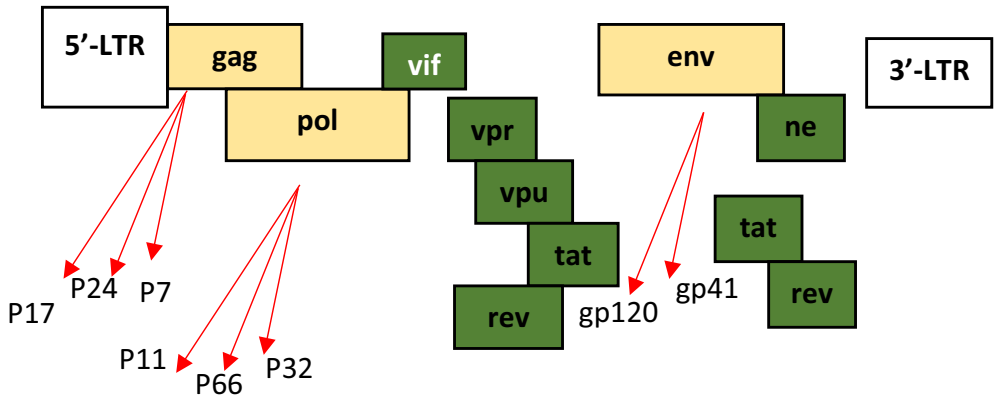

Fig. 11 Schematic of HIV genome structure [186]

transcriptase process (generation of complementary DNA from an RNA) and other required enzymes mainly made by the pol gene. Further information on proteins structures of HIV1, including six additional genes: vif, vpu, vpr, tat, rev and nefand, and their functions are explained in details in Table 5.

HIV structure demonstrated in Fig. 12, has a diameter of $100 \mathrm{~nm}$, and a lipoprotein membrane surrounds it like many other viruses [187-190]. Each envelop particle contains 72 complex knobs in conjunction with outer lipid membrane and each one made by trimers of an external glycoprotein gp120 surface protein (SU) and a transmembrane spanning protein gp41 (TM) [191]. Neutralizing antigenic identified on GP 120, which is the essential protein for attachment to specific cell surface receptors and only partially expressed on the unfolded denatured protein [192]. Gp120 can be found in the serum, plasma and even in the lymphatic tissue of HIV-infected patients [193]. Matrix protein (MA, p17) membrane binding requires 
the anchoring in the membrane lipid bilayer for covering and protecting inner capsid protein p24 (CA) (MA, p17) [194, 195]. The capsid protein (CA, p24) core carries two copies of HIV-1 RNA and following by anti-HIV antibodies (products of p24) count for the primary viral markers exploited to detect HIV infection and to monitor disease progression [196, 197].

In the situation of infection to HIV, the presence of p24 antigen is discoverable for the first two weeks owing to the initial eruption of viral replication that is connected with high levels of viremia during which the individual is highly infectious [198]. Nef envelope performed several vital functions in the genome structure of the viral. The mechanism of escape or hide from CD4 T cells (protein from GP family) or evade an attack brought about by cytotoxic CD8 $\mathrm{T}$ cells (transmembrane GP protein) is feasible by prompting downregulation (degeneration of cell components) of HIV-1 infected cells [199]. Nef may influence T cell (lymphocytes) regular activity by involving in the binding process to different proteins having fundamentals roles in intracellular signal transduction pathways [200]. The weakness point exactly drives from the moment when the infection mechanism starts by attaching HIV viral to helper T cells, and this group is responsible for managing other cells in the immune system. CD 4 as the receptor on the surface of these cells turn into CD $4+$ after establishing the connection with HIV [201].

The life cycle of HIV in the body starts by the designation of CD4 as CD4 + , and as it has shown in Fig. 13, the first stage is called attachment and penetration of immature HIV viral to the body of CD. After completion of this task, the second stage involves RNA and genetic code injection as well as RNA conversion initiated reverse transcriptase enzyme extracted from HIV. The critical point in this stage is a smooth mutation of HIV during the conversion of the viral RNA to DNA as the result of possible error throughout the activation of transcriptase enzyme and clonal expansion.

The third stage begins by evading CD $4+$ nucleus and entering accomplished HIV viral DNA, which formed in the previous stage. The next stage is also called DNA integration, and integrase enzyme, another production of HIV helps in the integration process of the target cell and HIV. The outcome of this DNA mutation at stage 5 is viral RNA and new proteins required for the creation of new HIV. The nucleus of the infected cell pushes the viral RNA out into the interior space of the CD4 + membrane (stage 6). The final step to release the viral RNA out of the cell membrane is called budding and throughout this process a fragment of the cell wrapped around itself and bubble up from a part of the cell membrane, and finally discarded to the outside (stage 7). The production of the budding process is called mature HIV (stage 8) and capable of infecting other cells, massive infection spreading and weakening the body's immune system [202]. In Table 3, the details of plasmonic virus detection for this virus can be found.

\subsection{HIV antigen p24}

HIV distribution in the human body would reach to the stage called Acute Human immunodeficiency virus Infection (AHI) from HIV acquisition until the time of appearance of detectable antibodies to HIV in the blood [196, 203]. This stage would take about four weeks, and its footprint appears in blood either by NAATs for the viral RNA measurement (first solution) or applying fourth-generation immunoassays for the HIV capsid antigen p24 (second solution). The NAATs method has the limitation of 20-35 RNA copies/mL (i.e. 10-18 virions/ $\mathrm{mL}$, the concentration amount can produce about two weeks after HIV acquisition) in detection. At the same time, the second approach turns out only at fourth-generation immunoassays that 
Table 5 Short brief on viral proteins functionalized in HIV-1 [186]

\begin{tabular}{|c|c|c|c|}
\hline Gene & Size* & Protein & Function \\
\hline \multirow[t]{5}{*}{ gag } & & Pr55Gag & Precursor of the inner structural proteins \\
\hline & p24 & Capsid protein (CA) & Formation of conical capsid \\
\hline & p17 & Matrix protein (MA) & $\begin{array}{l}\text { Myristoylated protein, forming the inner } \\
\text { membrane layer }\end{array}$ \\
\hline & $\mathrm{p} 7$ & Nucleoprotein (NC) & $\begin{array}{l}\text { Formation of the nucleoprotein/RNA } \\
\text { complex }\end{array}$ \\
\hline & p6 & & Involved in virus particle release \\
\hline \multirow[t]{5}{*}{ pol } & & Pr160GagPol & Precursor of the viral enzymes \\
\hline & $\mathrm{p} 10$ & Protease (PR) & $\begin{array}{l}\text { Proteolytic cleavage of Gag (Pr55) and } \\
\text { Gag-Pol (Pr160GagPol) precursor } \\
\text { protein; release of structural proteins } \\
\text { and viral enzymes }\end{array}$ \\
\hline & $\mathrm{p} 51$ & Reverse transcriptase (RT) & $\begin{array}{l}\text { Transcription of HIV RNA in proviral } \\
\text { DNA }\end{array}$ \\
\hline & p15 (66) & RNase $\mathrm{H}$ & $\begin{array}{l}\text { Degradation of viral RNA in the viral } \\
\text { RNA/DNA replication complex }\end{array}$ \\
\hline & $\mathrm{p} 32$ & Integrase (IN) & $\begin{array}{l}\text { Integration of proviral DNA into the host } \\
\text { genome }\end{array}$ \\
\hline \multirow[t]{3}{*}{ env } & & PrGp160 & $\begin{array}{l}\text { Precursor of the E proteins SU and TM, } \\
\text { cleavage by cellular protease }\end{array}$ \\
\hline & gp120 & Surface glycoprotein (SU) & Attachment of virus to the target cell \\
\hline & gp41 & Transmembrane protein $(\mathrm{TM})$ & $\begin{array}{l}\text { Anchorage of gp } 120 \text {, fusion of viral and } \\
\text { cell membrane }\end{array}$ \\
\hline tat & p14 & Trans activator protein & Activator of transcription of viral genes \\
\hline rev & p19 & RNA splicing regulator & $\begin{array}{l}\text { Regulates the export of non-spliced and } \\
\text { partially spliced viral mRNA }\end{array}$ \\
\hline nef & $\mathrm{p} 27$ & Negative regulating factor & $\begin{array}{l}\text { Myristoylated protein, influence on HIV } \\
\text { replication, enhancement of infectivity } \\
\text { of viral particles, downregulation of } \\
\text { CD4 on target cells and HLA cells on } \\
\text { target }\end{array}$ \\
\hline vif & p23 & Viral infectivity protein & $\begin{array}{l}\text { Critical for infectious virus production } \\
\text { in vivo }\end{array}$ \\
\hline vpr & $\mathrm{p} 15$ & Virus protein $r$ & $\begin{array}{l}\text { Component of virus particles, interaction } \\
\text { with p6, facilitates virus infectivity, } \\
\text { effect on the cell cycle }\end{array}$ \\
\hline vpu & p16 & Virus protein unique & $\begin{array}{l}\text { Efficient virus particle release, control of } \\
\text { CD4 degradation, modulates } \\
\text { intracellular trafficking }\end{array}$ \\
\hline vpx & p15 & Virus protein $x$ & $\begin{array}{l}\text { Interaction with p6 in virus particles, } \\
\text { involved in early steps of virus } \\
\text { replication of HIV-2, component of } \\
\text { virus particles }\end{array}$ \\
\hline tev & p26 & Tat/rev protein & $\begin{array}{l}\text { Tat-Env-Rev fusion protein, regulates the } \\
\text { activity of Tat and Rev in nucleus }\end{array}$ \\
\hline
\end{tabular}

\footnotetext{
*Numbers correspond to the size of the proteins (p) or glycoproteins (gp) in 1,000 Da
} 


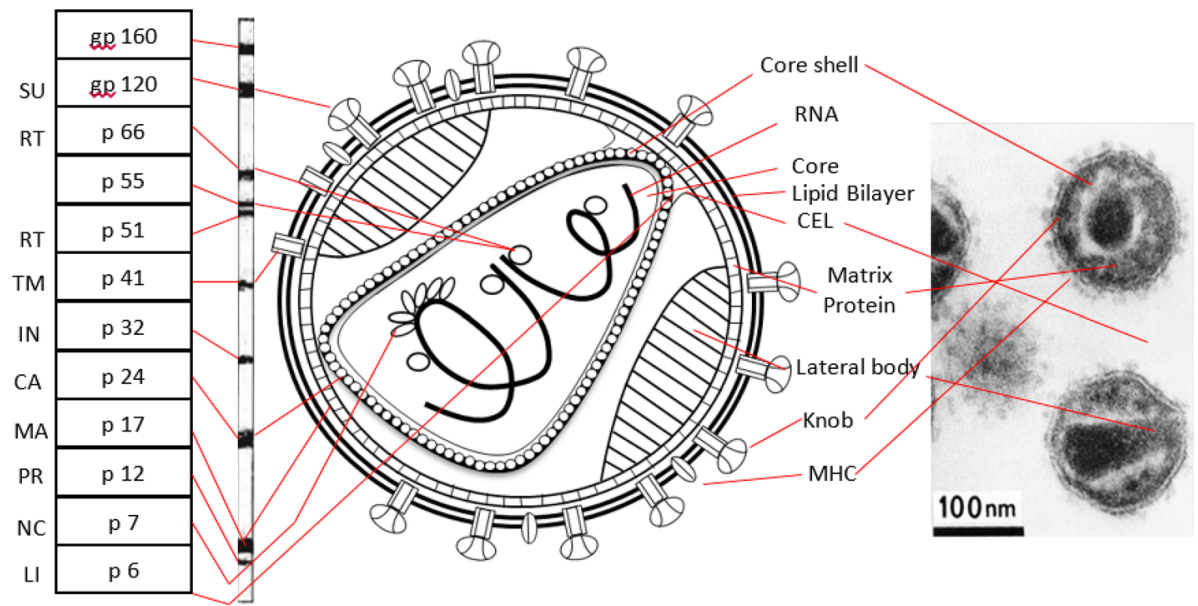

Fig. 12 Structure of an HIV virion particle on left image a and, electron microscope (issued by CDC Public Health Image Library) on right image b. Immunoblot bands on the left side of image b are showing $G p$ Glycoprotein, $p$ protein, $S U$ surface protein, $T M$ transmembrane protein, gp120 (precursor of SU and TM), $R T$ reverse transcriptase, $I N$ integrase, $C A$ capsid protein, $M A$ matrix protein, $P R$ protease, $N C$ nucleic acid binding protein, $L I$ link protein. MHCs (major histocompatibility complexes) are HLA antigens. Table 1 explicitly discusses the function of the different proteins [186]. (Graphic Hans Gelderblom, Robert Koch Institute, Berlin)

the concentration of p24 is measurable at LOD of $\sim 10 \mathrm{pg} / \mathrm{mL}$ only three or four weeks after infection [204].

\subsubsection{HIV genome/non-genome detection using SERS and SEF}

In the study made by Hu et al. (2010), two Raman labelled DNA sequences were developed on SERS active AuNPs and were utilized as the detection probes for HIV-1 through generelated DNA. Normally, Ag and Au NPs with high SERS activity are used as labels and substrates [205-209]. The Raman labels needs to be close enough to the NPs surface, thus the strong signal can be received [210-213]. In the performed experiment, the $\mathrm{P}_{0}$-modified Au electrode was initially incubated in HIV-1 DNA solution of certain concentration for $1 \mathrm{~h}$ at $55^{\circ} \mathrm{C}$, and then washed with buffer $(\mathrm{pH}=7.4,20 \mathrm{mM}$ phosphate, $0.75 \mathrm{M} \mathrm{NaCl})$. The hybridization process was moved on with further heating at $95^{\circ} \mathrm{C}$ for $5 \mathrm{~min}$ and cooled with ice water before entering to next phase of labelling. Target solutions namely known as P1 (complement of one-half (5' part) of the target strand HIV-1) and P2 (complement of P1) in which both contains 5' Rox (X-rhodamine) with absorption peak at $585 \mathrm{~nm}$ and $601 \mathrm{~nm}$ were prepared for the P0. The second and third phases of electrode labelling completed by incubating P0 in P1 and then P2-modified Au NPs solution for 30 min at $55^{\circ} \mathrm{C}$ after being washed in the buffer. The obtained electrode was dried in air for Raman measurement in ambient condition. The results of Raman spectra after using Raman instrument with the $632.8 \mathrm{~nm}$ excitation line and laser power of $1.2 \mathrm{~mW}$ implied on a detection limitation at $1 \times$ $10^{-19} \mathrm{M}$, which is comparable to the obtained value by PCR [95, 214].

Report prepared by Kurdekar et al. [96] introduced SEF technique in conjunction with conventional europium nanoparticle sandwich immunoassay (ENIA) to gain the sensitivity of less than $1 \mathrm{pg} \mathrm{mL}^{-1}$ in the detection of HIV-1 p24. The key point of the experiment was mechanism of surface functionalization using $150 \mathrm{~nm}$ gold NPs. The Sigma-Aldrich gold NPs 


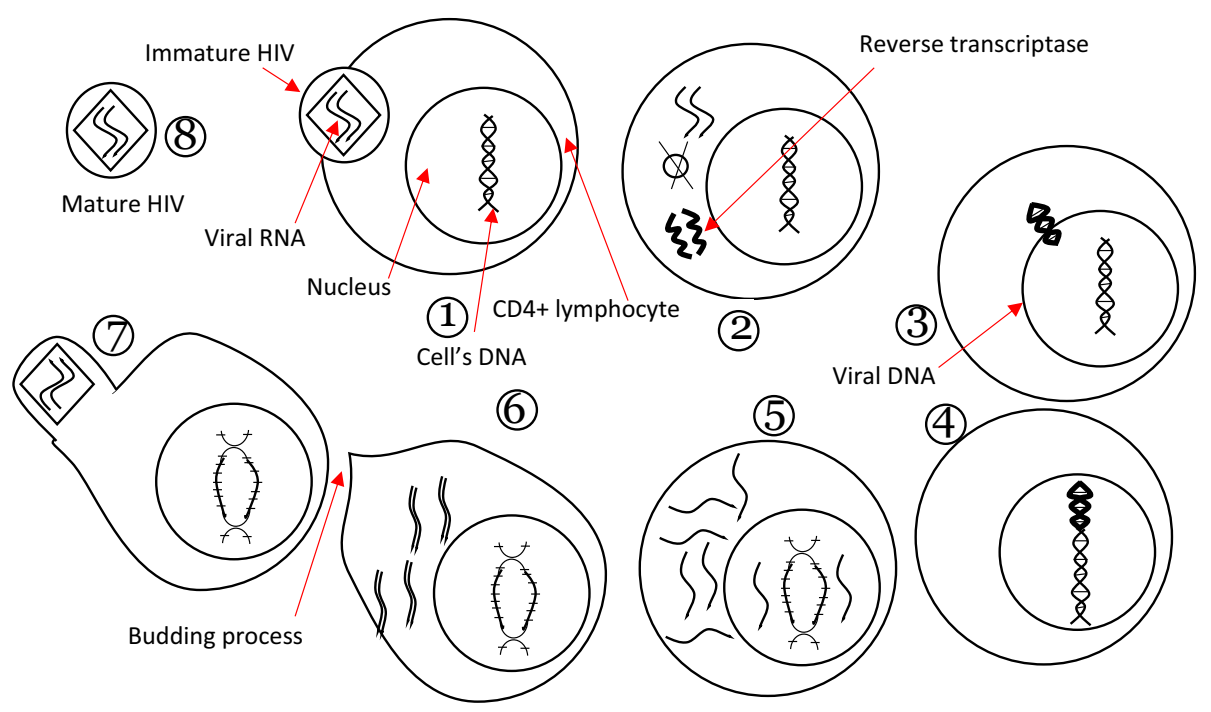

Fig. 13 Cyclic conversion of immature HIV to mature HIV

was citrate ligand and act as the capping agents, which prevent the agglomeration of the NPs. In addition, NPs prevented non-specific absorption between gold NPs and EuNPs [215]. The Perkin-Elmer commercially antibody coated kit which used to check the sensitivity through ENIA reported the sensitivity of $8 \mathrm{pg} \mathrm{mL}-1$ (not enough for HIV positive), whereas the enhancement through MEF increased the ratio to 1.8 which is an enough amount for verifying HIV positive.

\subsubsection{HIV cantilever sensor}

Captured antibodies which are usable for detection, initially bio-functionalized (Fig. 14a) over micro-structured cantilevers array (Fig. 14b), they incubated in $1 \mathrm{~mL}$ of the human serum sample for one hour at $37^{\circ} \mathrm{C}$ [94, 216]. This process forms a certain binding between the HIV-1 p24 antigens and immobilized captured antibodies over the surface of the cantilever.

Then, the unwanted adsorption was removed by the stringent rising of the micro-cantilever array (middle schematic of Fig. 14a). The gold NPs as the stimulator plasmonic agents interact with HIV-1 p24 antigens after immersing the cantilever in $1 \mathrm{~mL}$ solution containing $10 \mu \mathrm{g}$ gold NPs. The treated bio-functionalized micro-cantilever array by gold NPs again incubated at $37{ }^{\circ} \mathrm{C}$ for $15 \mathrm{~min}$ to compose a firm labeling of the captured p24 proteins on the cantilever (bottom schematic of Fig. 14a). Final step before optical measurement is subjected to one more time stringent rinsing to remove the NPs nonspecifically bound. The functionalized micro-cantilever in columnar array demonstrated in Fig. 14c has different concentration of p24 in human serum and ranging from 0 to $0.1 \mathrm{pg} / \mathrm{mL}$ carried to microliter plate for experimental measurement. Each test is repeated 3-5 times by the raw array of micro-cantilevers to investigate the accuracy and comparison of the measurement result. Two critical roles of gold NPs in the structure of the proposed sensor are producing signatures for the physical property known as particle mass and an optical feature called plasmonics. Meanwhile, silicon cantilever works as a mechanical resonator for quantifying the signature mass and optical cavity to boost the plasmonic signature of gold NPs. 
a

\section{Functionalized Cantilever}

Capture antibody

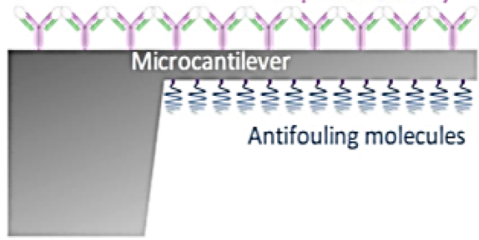

p24 Capture
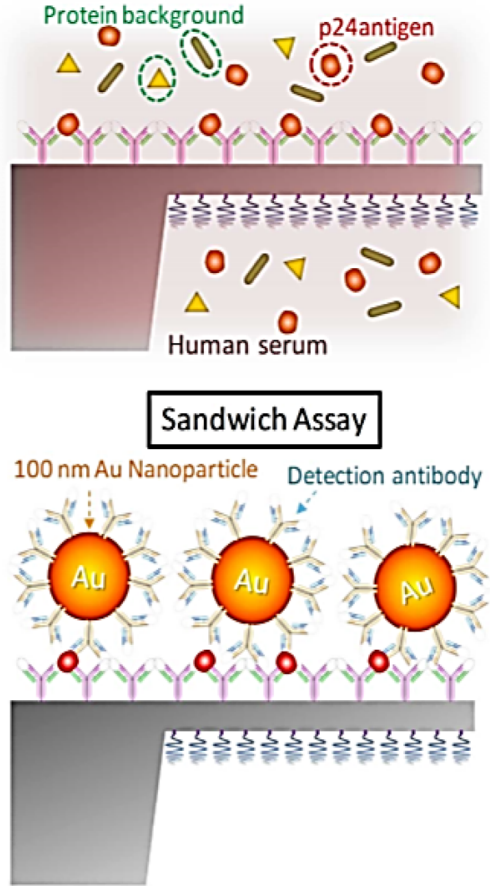

b

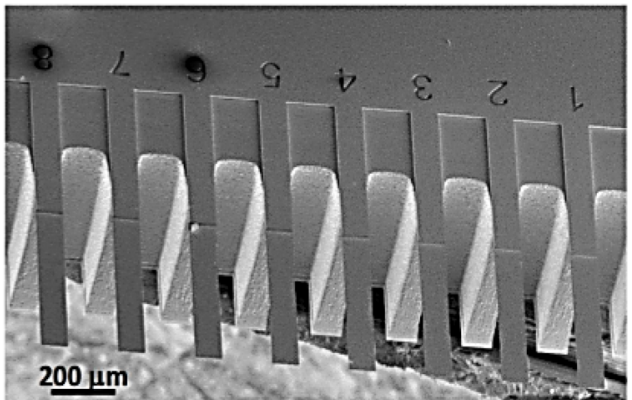

C

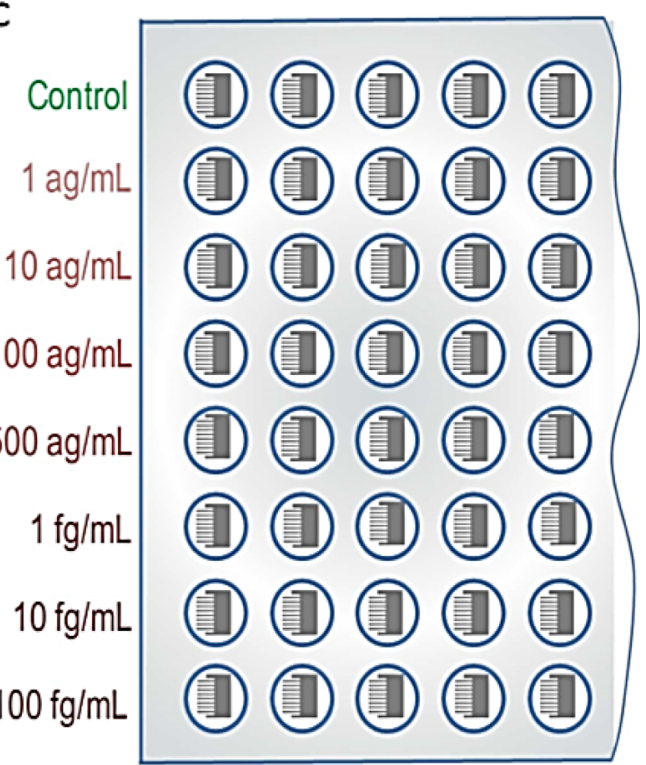

Fig. 14 Schematic of stepping bio-functioning process of the sandwich assay. a Top schematic, the functionalized top surface of cantilever treated by captured antibodies used against HIV-1 p24 antigen. Middle schematic, immersing the cantilever in the human serum sample provides the condition of binding to p24 to the cantilever surface. Bottom schematic, trapping 100-nm-dimeter gold NPs by the p24 antigen. b Scanning electron microscopy (SEM) image of the silicon micro-cantilever arrays c. 96-well microtiter plate schematic used for immunoassays experiment [94]

\subsection{Nanomechanical transduction method}

The laser beam deflection was measured continuously to determine the micro-cantilever vibration at nano-mechanical transduction method [217, 218]. The piezoelectric actuator as the source of vibration resides beneath the functionalized micro-cantilever chip base (Fig. 14a). The first three flexural vibration modes applied to the micro-cantilevers and mechanical resonance frequencies measured before (only air at the top surface) and after functionalization of the micro-cantilevers top surface. The essential use of several vibration modes was the minimization of the effect of adsorbed contaminants that revealed non-uniform spatial distribution over the micro-cantilever surface, and the main reason for uncorrelated 
frequency shifts contrasted with uniform adsorption. The measurement results of resonance frequency curves (Fig. 14b) for first three vibration modes with respect to the absence of p24 in human serum show the downward change of trend to $-0.3 \%$, whereas the situation after the presence of p24 (for $5 \times 10^{-4} \mathrm{pg} / \mathrm{mL}$ in human serum) emphasizes on an upward trend to $-0.8 \%$.

\subsection{Optoplasmonic transduction method}

Optical transduction is a visual technique which allows the detection of gold NPs becomes feasible through the plasmonic phenomenon [219]. The micro-cantilever with several reeds extended into the air found as a promising structure for enhancing the LSP formed around the gold NPs via coupling modes of air channel cavity between two air channels. These hybrid plasmonic super-modes enhance the scattering from gold NPs through backward scattering, multi-path scattering, multiple internal reflections and several background reflection with neighboring gold particles (Fig. 15a). The dark filed images taken for two micro-cantilevers previously analyzed by the nanomechanical transduction method (Fig. 15b, c) explaining that the trapped gold NPs play the deterministic role to spot the $\mathrm{p} 24$. The amount of received scattering intensity from micro-cantilever exposed to human serum with $5 \times 10^{-4} \mathrm{pg} / \mathrm{mL}$ of p24 is much higher than in the control experiment (human serum without p24). The effect caused by gold NPs is more visible explicitly in preclamping region shown in Fig. 15D before and after top surface functionalizing of micro-cantilever. Scatter coupling even at this region and formation of dipolar plasmon resonance of gold NPs existing at a farther distance is still enough to distinguish p24 in human serum.

\section{Zika virus (ZIKV)}

Zika virus (ZIKV) is an infectious disease associated with human congenital disabilities and a member of the Family Flaviviridae and mosquito-borne flavivirus genus. Their symptoms are mild, including fever, rash, conjunctivitis, muscle and joint pain, malaise or headache. However, its severe effect on pregnant women and the fetus is high and can lead to microcephaly and other congenital malformations in the born infants. After the first ZIKV infection for humans in 1953, much effort has been made to identify the reservoir of this virus [220-222]. Despite these investigations, ZIKV remained undetected due to its silent transmission cycle without monitoring any significant severe disease until its remarkable outbreak in 2007 [223-225].

The emerged current epidemic ZIKV strains in many parts of the world and its devastating effect on fetal development require the rapid emergence of various types of technical methods aiding in the cognition and point-of-care treatment of this virus. Accordingly, for better recognition of origins, mechanism of prevalence, and its detection, understanding several aspects of its pathogenicity seems necessary [226-229]. This enveloped and spherical virus is an RNA one (non-segmented positive-sense RNA genome) with approximately $50 \mathrm{~nm}$ diameter and an icosahedral-like configuration of surface proteins [230]. The open reading frame (ORF) of this illness encodes a polyprotein structure containing capsid (C), premembrane/membrane (PrM), envelope (E) and seven nonstructural proteins (NS), NS1, NS2A, NS2B, NS3, NS4A, NS4B, and NS5 [231, 232]. After relatively rudimentary recognition, the emergence of diverse methods for the accurate study of ZIKV in laboratories is essential. However, most types of virus diagnostic techniques are roughly expensive and not amenable 


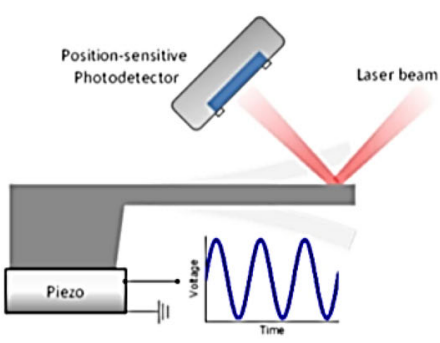

C

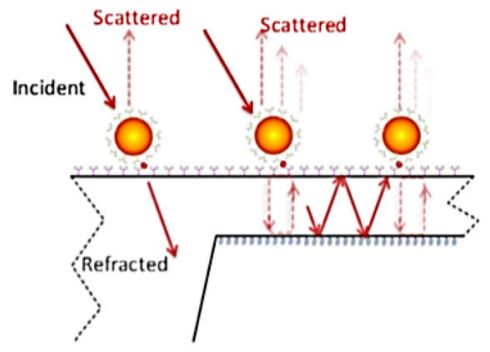

b
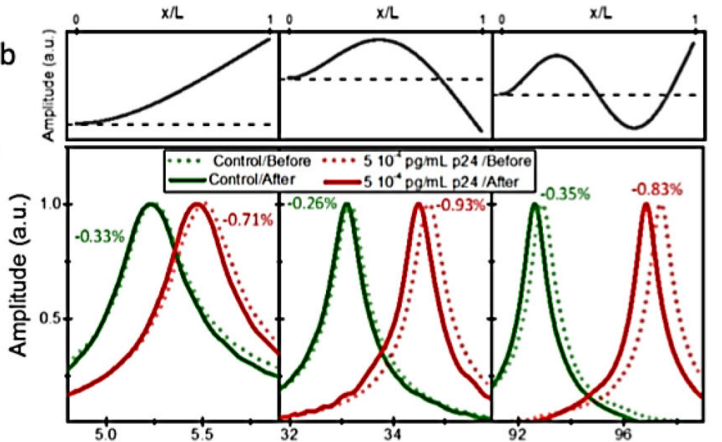

Frequency $(\mathrm{kHz})$

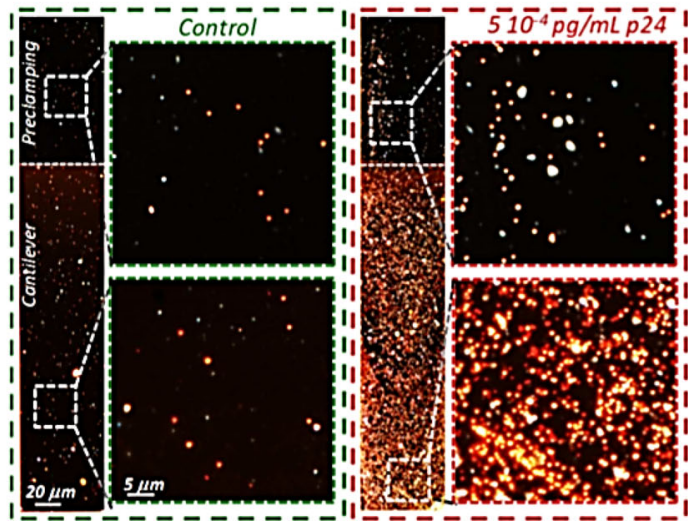

Fig. 15 Immunoreaction response to nanomechanical and optoplasmonic transduction mechanisms. a Schematic to the demonstration of simultaneous optical beam deflection and microcantilever vibration. A laser beam is focused onto the cantilever's reed, and at the same time, the deflection of the reflected beam during vibration by a piezoelectric actuator beneath the micro-cantilever array chip measured using a sensitive photodetector positioned on the top surface of micro-cantilever. b Resonance frequency peaks (bottom graphs) of the first three vibration modes (top panels) of a silicon cantilever before (dotted lines) and after (solid lines) the immunoreaction assay for a blank human serum sample (control) and $5 \times 10-4 \mathrm{pg} / \mathrm{mL}$ of p24 in human serum. The relative variations of the resonance frequencies are shown beside the resonance frequency peaks. c Schematics of the multiple pathways for light scattering by the gold NPs bound to the micro-cantilever. d Darkfield optical images of the microcantilevers analyzed in $\mathbf{b}$ after the immunoassays. The images show the microcantilever and chip preclamping regions. At the right, zoomed images of regions at the preclamping and the microcantilever are also shown [94]

to remote control facilities in laboratories [233-238]. Among these techniques, plasmonics biosensors are highly promising for cost-effective and sensitive biodiagnostics [29, 32].

\subsection{ZIKV non-genome sections and immune response}

\section{- SPR}

In 2017, Jiang et al.[97] have proposed a bioplasmonic paper-based device (BPD) according to interactions between ZIKV and its anti-ZIKVNS1 IgG and IgM (Fig. 16). C-terminal fragment of ZIKV nonstructural protein 1(NS1) is an essential element as a host-interaction molecule in viral replication and immune evasion. Figure 16A represents the fundamental of this BPD biosensor where NS1 served as an antigenic marker for ZIKV infections identifiable for 1-2 weeks [239]. Besides, the following host IgM/IgG responses to ZIKV-NS1 act as 
a tool for ZIKV biodiagnostics and allow the detection after numerous months. ZIKV-NS1 could have been utilized for the differentiation of ZIKV and other Flavivirus infections. By investigation of synthesized AuNRs functionalized with ZIKV-NS1, they have qualified the $\mathrm{IgG}, \operatorname{IgM}$ and IgA if present, linked to immune response. Currently, researchers have applied plasmonic NPs as a drug delivery system [101]. They have proposed an oral NP-based drug delivery platform in which ivermectin-loaded polymeric NPs could circulate in the blood system for a long period, target the nonstructural one protein of ZIKV, and finally deliver the ivermectin (IVM) drug to the site of interest, at a maintained rate. In this work, the neonatal Fc receptor (FcRn) bound to Fc-Ivermectin-NPs, and core-shell structure of NP provided a capsulated system to carry the drug. Figure 16c shows the representation of the drug delivery system in a mice body. For additional information on the definition, classification, and taxonomy of arbovirus, plasmonic prevention and control strategies, the review can be found in Refs [223, 240-244]. In Table 3, the recent studies on plasmonic virus detection for ZIKV can be found.

- SERS

Camacho et al. [98] have reported the detection of ZIKV without cross-reactivity with DENV NS1 antigens by SERS nanoprobes. They utilized synthesized gold shell-isolated NPs (i.e. Au NPs and silica shell coated with Nile Blue) to probe concentrations of ZIKV NS1 down to $10 \mathrm{ng} / \mathrm{mL}$.

\subsection{ZIKV genome}

\section{- LSPR}

For improving the plasmonic nanomaterial and synergic impact, silsesquioxanefunctionalized gold NPs (AuNPs-SiPy) were utilized to detect ZIKV in real human serum samples [178]. In this case, ZIKV ssDNA probe were immobilized on an oxidized glassy carbon electrode (ox-GCE) modified with AuNPs-SiPy (ox-GCE-[AuNPs-SiPy]) (Fig. 16b) [99]. To recognize the ZIKV target, they have recorded the variation of the charge transfer resistance of the redox marker used and the roughness of the electrode surface. They have achieved a considerable LoD of $0.82 \mathrm{pmol} \mathrm{L}^{-1}$ with a linear range of $1.0 \times 10^{-12}-1.0 \times$ $10^{-6} \mathrm{~mol} \mathrm{~L}^{-1}$ as well as stable and comparatively satisfactory sensitivity.

\section{- SEF}

In another study, LSPR-mediated fluorescence signal was compared between biometallic plasmonic NP QDs and single metallic plasmonic NP-Qdots for ZIKV RNA detection [100]. For this purpose, an $\mathrm{Au}-\mathrm{Ag}$ core/shell (CS) was presented for controlling the plasmonic properties. In this case, using the plasmonic characteristics of $\mathrm{Au}-\mathrm{Ag}$ plasmonic nanomaterials, they have introduced an optical sensing platform with potential selectivity for point-of-care aims.

\section{Rabies virus (RABV)}

Rabies virus (RABV) is a life-threatening disease that occurs when RNA virus-afflicted domestic/wild animals (rabid animals) transmit this virus to all warm-blooded animals through bites or scratches [245, 246].

Human Rabies virus is a member of the Family Rhabdoviridae and genus Lyssavirus comprising 7 genotypes [247]. The genotypes apting human inflation are types 1, 3-7, and 
a
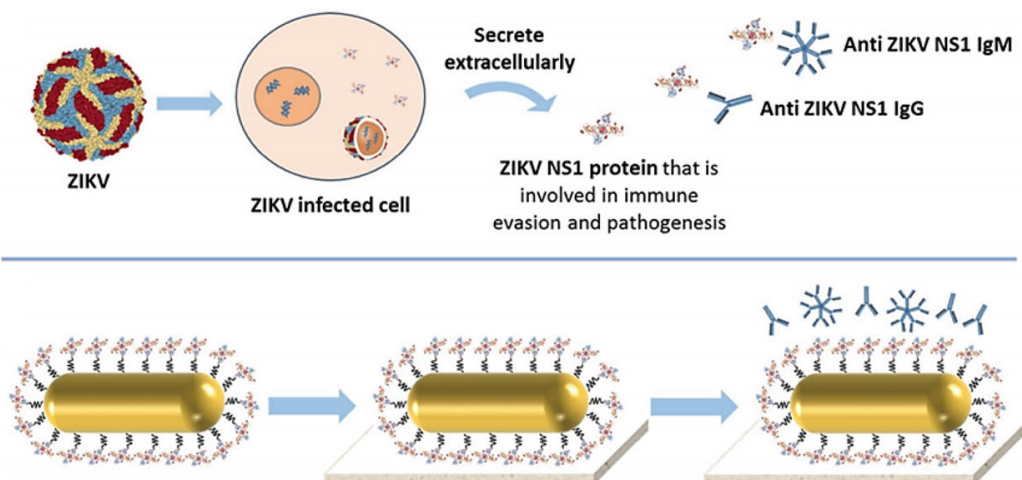

AuNRs conjugated with SH-PEG-ZIKV NS1
卜淡人添人

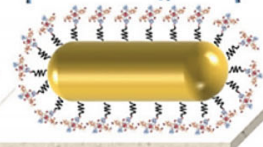

AuNRs-ZIKV NS1 paper

Detection of ZIKV NS1 antibody $\lg \mathrm{G}$ and $\operatorname{lgM}$

b
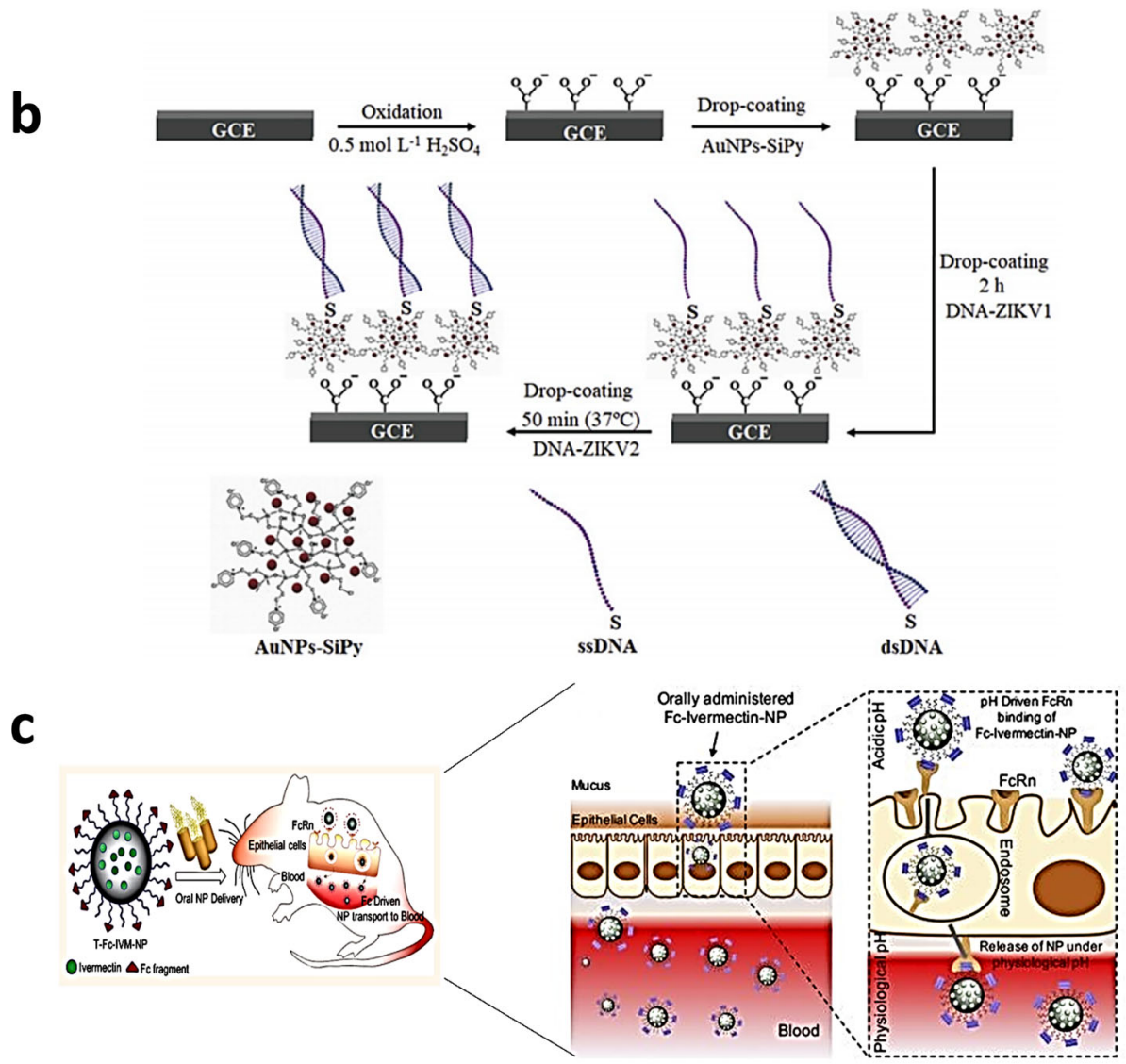

Fig. 16 a Overall description of BPD biosensor. $\mathbf{a}$ and $\mathbf{b}$ The process for elicitation of immune response by functionalization of AuNRs with ZIKV-NS1 protein [97]. b Consequences of assemblage of ox-GCE-[AuNPsSiPy]/ZIKV1 biosensor and DNA hybridization for ZIKV detection [99]. c Schematic representation of the stages of biosensor construction and drug delivery [101] 
rarely genotype 3 [248]. These non-segmented viruses are the bullet-shaped structures of approximately $75 \mathrm{~nm}$ by $200 \mathrm{~nm}$ [249]. Five genome associated to five proteins of Rabies are: N, P, M and G. N gene coding for a nucleoprotein is responsible for capsulation of the viral RNA. P gene generates phosphoprotein and serves the main role in transcription and replication of genome RNA. L gene encodes a polymerase for RNA synthesis (the helical RNP core associated with the matrix protein (M) is condensed into a generic bullet-shaped structure, which is a common characteristic of rhabdoviruses). G and M lipid-containing envelope surrounds the RNP core, and the virion-associated RNA polymerase [249-253].

The Rabies virus mainly envenoms the central nervous system. In most cases, the stepwise infection spreads from the entry site to surrounding sites via neuronal pathways, bypasses the Blood-Brain Barrier (BBB), and propagates in the brain and spinal cord. If an individual does not receive a clinical point-of-care and anti-viral treatment immediately after the development of symptoms, it would eventually lead to fatal encephalomyelitis, and the possibility of the death roughly reaches $100 \%$ [252, 254].

In contrast to lethal aspects of many epidemics and epizootics illnesses such as influenza [255, 256], smallpox [257], and rinderpest [258, 259], which decimate the population, Rabies substantially occupies less pales. However, the fatality rate of rubies is approximately 55,000 individuals worldwide each year [246].

Nanostructures and especially NPs have shown great potential for vaccine preparation [260-262], RNA/DNA drug delivery [263-266], and diagnosis [263, 267-269]. About 98\% of entry tiny molecules and colloid-sized particles cannot enter the brain through obstacle BBB [270]. Also, the drug delivery for the treatment of brain diseases such as brain tumors encounters several challenges [271]. One of the most prevalently robust strategies to overcome such problems is using Rabies virus glycoprotein (RVG) ligand of this virus.

\subsection{RABV non-genome sections and immune response}

- SPR

In 2017, Lee et al. [102] have devised a mimetic-virus based on silica gold nanorods (RVGPEGAuNRs@SiO2) as a nanodevice in the content of photothermal therapy. In response to NIR laser (808 nm) irradiation, RVGPEGAuNRs@SiO2 virus-like platform could successfully trigger photothermal effect in the brain and suppress brain tumors and gliomas. Figure 17 represents the overall mechanism for RVG-PEG-AuNRs@SiO2 delivery through neural passways and photothermal therapy as well as the steps for synthesizing RABV-like silica-coated gold nanorods (RVG-PEG-AuNRs@SiO2).

In another work, Jing Xu et al. [103] have fabricated a SPR biosensor chip enabling the recognition of Rabies virus antigens from extracted virus-infected BHK cells. For this purpose, $\mathrm{N}$ protein-specific antibody and the similar antibody synthesized with $\mathrm{G}$ protein were linked on two various flow cells on a CM5 chip. The results have represented the ability of the $\mathrm{mAb}$ mixture ( $\mathrm{N}$ and $\mathrm{G}$ ) for the detection of both NP and GP. The detection rate for $\mathrm{mAb}$ mixture was surpassed that of mAb (N)-linked flow cell. In 2016, Vahid Asgary et al. [104] have assessed the therapeutic effect of green AgNPs on the Rabies vaccine for animals and have compared their results with commercial veterinary conventional methods. The results have shown the increasing impact of AgNPs on the potency of human response to the Rabies vaccine. In 2017, Torchynska et al. [105] investigated the alteration of photoluminescence spectra of $\mathrm{CdSe} / \mathrm{ZnS}$ QDs with various sizes and emissions in non-conjugated and bioconjugated QDs to anti-Interleukin-10 (IL-10) and anti-Pseudo RABV (PRV) antibodies. In this study, 


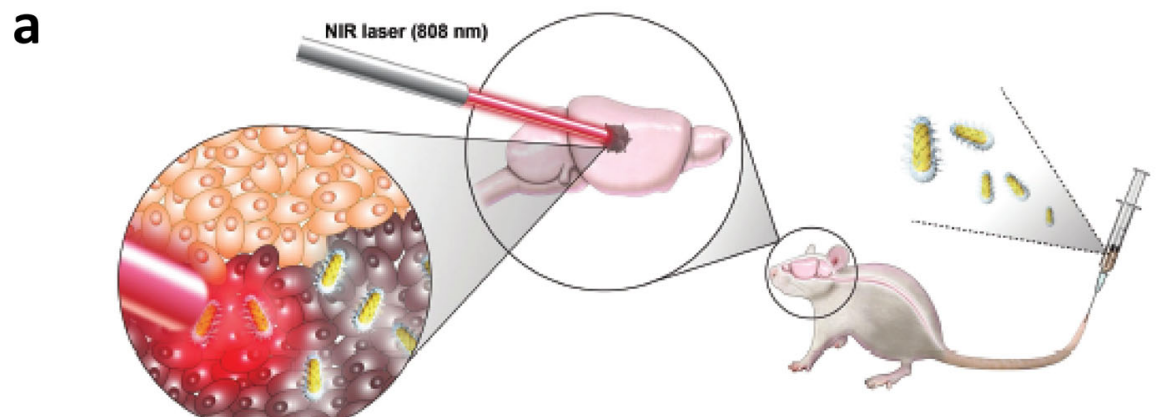

Rabies virus-mimetic silica-coated gold nanorods

b
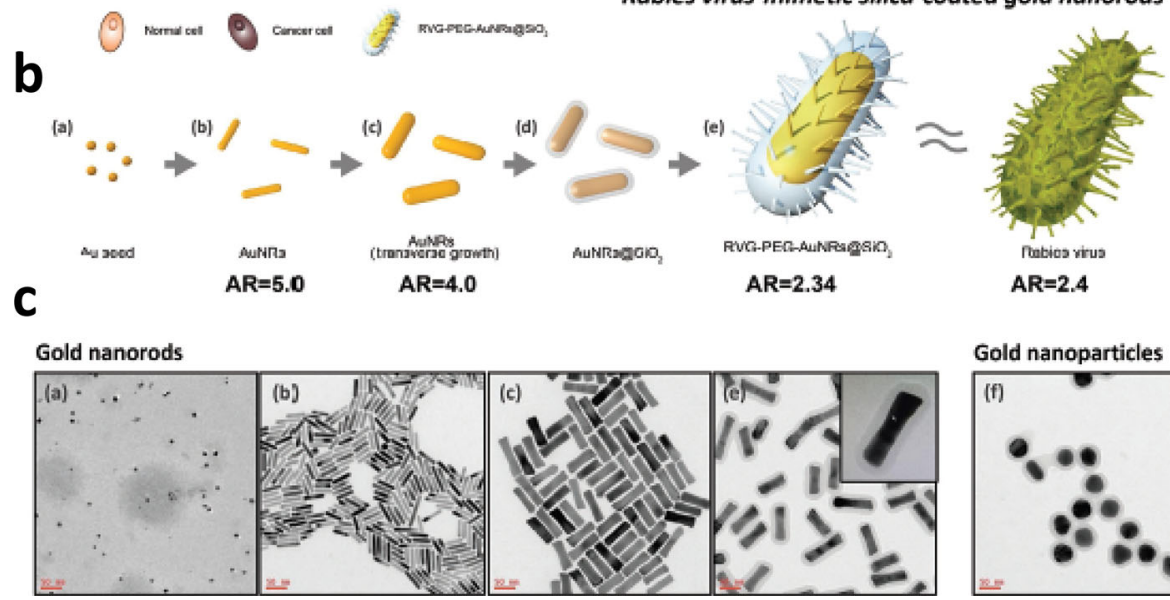

Gold nanoparticles

Fig. 17 A Representation of overall mechanism for RVG-PEG-AuNRs@SiO2 delivery through neural passways and photothermal therapy. B Scheme steps for synthesis of Rabies virus-like silica-coated gold nanorods (RVG-PEG-AuNRs@SiO2): (a) Au seed, (b) longitudinal growth of AuNRs, (c) AuNRs after both of longitudinal and transverse growth, (d) silica-coated AuNRs and (e) RVG29 peptide-PEG5k-conjugated AuNRs@SiO2 (The total dimensions of the structure is identical to the Rabies virus (length/width $\cong 2.4$ )). C Morphological TEM images of steps (a-c and e) and gold NPs (RVG-PEG-AuNPs@SiO2; $\approx 68000 \mathrm{~nm} 3$; f) [102]

they confirmed the presence of the surface enhanced Raman scattering (SERS) effect in bioconjugated QDs. In Table 3, the recent studies of plasmonic detection for RABV can be found.

\section{Norovirus (NOV)}

Human Norovirus (NOV) is a ubiquitous genus of the etiological agent of acute gastroenteritis [272], and it is one of the foremost reasons for diarrheal disease among all ages particularly the elderly, immunocompromised patients, and children and the second reported cause of pediatric gastroenteritis deaths for children under 5 years old [272, 273]. There are approximately 699 million infections and more than 200,000 deaths globally per annum due to this virus [274].

Human NOV inflicts death of all demographics and ages, sometimes leading global epidemics [275]. Because of the ubiquity of this disease and the involvement of a different range of populations, recognition of target groups, as well as the usage of efficient strategies, seems 
challenging. In spite of underlying signs of progress and explorations about infectious diseases, these communicable illnesses own an omnipresent threat to global health [272-274].

Most of the researches have concentrated on the specificity of the initial binding, showing the first step in human virus infections [276, 277]. Histo-blood group antigens that exist on the mucosa of the host gastrointestinal tract are responsible for the binding of NOV capsid proteins to human host glycosylated receptors [278]. Indeed, current efforts are mostly based on developing efficient strategies to interrupt or minimize conjunction between blood group antigen and NOV in order to suppress NOV infection pathogen [279]. One of these strategies is the utilization of fucosylated human milk glycans that are structurally analogous to histoblood group antigen as natural vigorous anti-naNOVirus agents. Glycosylated components available in human milk inhibit the adhesion of NOV capsid to the blood group antigens.

\subsection{NOV non-genome sections and immune response}

\section{- SPR}

Jing Shang et al. [106] have designed a biosensor potent plasmonic-based platform that was able to characterize the binding specificities of viral capsids of two common strains of NOV (VA387 and Norwalk) to a distinct set of human milk carbohydrates. In the end, they have implied that SPRs competitive binding assays had the capability for the prevention of making connection NOV capsids to their host receptor [106, 280]. Aside from interaction between NOV-like particles (NOV VLPs) and human milk glycan, SPR was applied to identify the viruses from impurities contained in a solution [280, 281].

\section{- LSPR}

Takemura et al. [107] have developed a highly sensitive and rapid detection biosensing method in which a LSPR-amplified magnetofluoroimmunoassay (MFIA) was utilized for detection of target NOV in biocombination environment. In their study, they investigated the synthesized hybrid nanocomposites (consisting of gold NPs (AuNPs), magnetic NPs, and CdSeS QDs-anti-NOV Geno group II antibody (Ab). The fabrication procedure for NOV detection via employing hybrid nanocomposites is shown in Fig. 18a. Construction of this plasmonic biosensor made it capable of separating and isolating the target virus from feces in clinical samples by applying the external magnetic field. Furthermore, SPR analysis was utilized to investigate the binding affinity and the associated kinetic of ligands to NOV [282]. In the LSPR-based biosensor reported by Sam Su Heo [108], they detected the noroviral capsid proteins as well as human NOVs. They have immobilized affinity peptides on the LSPR substrate and made it selective for the target substance. Thus, the suggested biosensor had the capability for NOV-related foodborne pathogens.

\section{- SERS}

A novel method of norovirus detector based on graphene mediated surface-enhanced Raman scattering (G-SERS) was proposed via a dual SERS nanotag/substrate platform. The signal amplification of such a SERS-based immunoassay was reported more than $10^{9}$-fold emanating from the combination of chemical and electromagnetic mechanisms of the dual SERS nanotag/substrate system [110].

\subsection{NOV genome}

In another study, Suhee Kim et al. [109] have developed a highly sensitive aptamer-aptamer structure modified with gold nanorods sandwich platform to analyze NOV protein. By applying DNA aptamer sequences (aptamer I-IV) specific for NOV protein conjugated with NRs, 


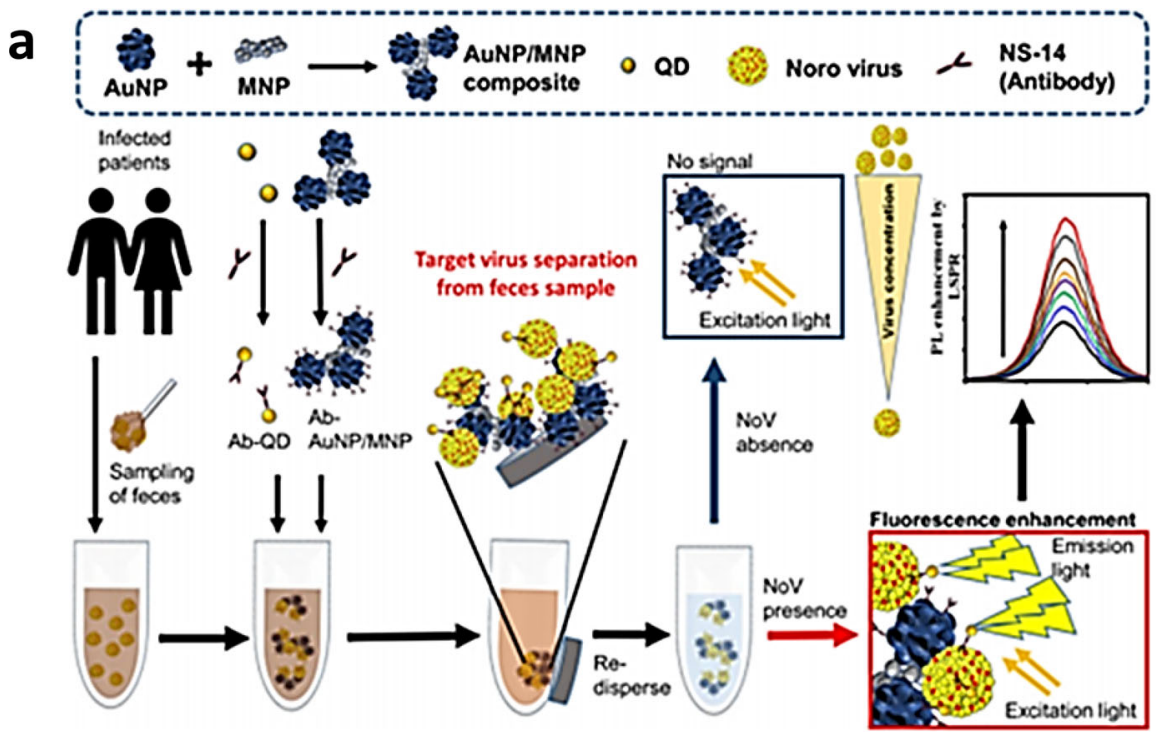

b

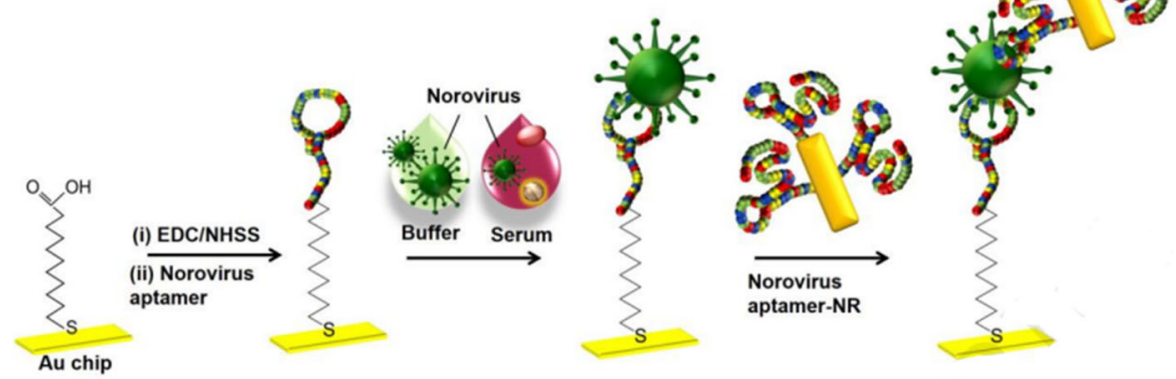

Fig. 18 a Stages for construction of NOV detection biosensor by use of hybrid nanocomposite [107]. b Schematic representing the aptamer-aptamer sandwich assay for trapping NOV capsid protein [109]

they could identify presented NOV capsid protein concentration in human serum solutions and trap them as seen in Fig. 18b. For a chosen aptamer pair, the reported concentration of the NOV protein in buffer solution was approximately $70 \mathrm{Am}$, which was about $10^{5}$ order more than aptamer conjunction without nanorods. In 2019, Shen et al. [111] have devised a DNA-silver nanocluster (DNA-AgNCs) platform as a fluoresce nanoclusters which is able to detect NOV RNA. They have proved that the addition of $\mathrm{Ag}^{+}, \mathrm{NaBH} 4$. B. on the GCC-loop can be utilized to enhance the synthesis of $\mathrm{AgNCs}$, thereby leading to high fluorescence intensity of AgNCs. In Table 3, the recent studies of plasmonic detection for NOV can be found. 


\section{Ebola virus (EBOV)}

The current outbreak of Ebola virus (EBOV; formerly Zaire Ebolavirus) started in March 2014 in which World Health Organization (WHO) declared an epidemic and virulent disease with symptoms of fever, vomiting, hemorrhage, severe diarrhea, a shock-like syndrome after an incubation time (3-21 days) and a high rate of lethality rate [283-285]. The average fatality rate of Ebola virus disease (EVD) varies between 30 and $90 \%$ that depends on the virus species. Until now, four known prototypes of Ebolavirus were reported to cause outbreaks, three of which have led to progressively severe hemorrhagic illnesses in the human being: Zaire virus, Sudan ebolavirus, and Ivory Coast Ebolavirus. The latter, Reston Ebolavirus, was responsible for the development of Ebola in non-human species [286].

EBOV, member of the family Filoviridae in the Order Mononegavirale, was made up by genome containing seven genes: nucleoprotein, P protein (VP35), matrix protein (VP40), glycoprotein (GP), second nucleoprotein (VP30), the protein associated with the envelope (VP24) and RNA-dependent RNA polymerase (L) [287]. Reports have implied that by utilizing virion protein (VP40)-ELISA that selectively could recognize EBOV Zaire species, the detection of all Ebola subtypes is conceived [288]. Another study has shown that nucleoprotein-ELISA is able to detect three of four subtypes [289]. Moreover, plasmonic biosensors as a radical alternative for the detection and diagnosis of viral illnesses have been applied to open a favorable window solving medical-associated problems [289].

\subsection{EBOV non-genome sections and immune response}

\section{- LSPR}

In 2016, Ming-Kiu Tsang et al. [114] have reported the application of lanthanide-doped upconversion nanoprobes to detect EBOV oligonucleotides in two homogeneous and heterogeneous manners. As seen in Fig. 19a, in the innovative heterogeneous approach, upconversion NPs (UCNPs) and AuNPs were immobilized on nanoporous alumina (NAAO) membrane regarding the energy transfer from UCNPs to AuNPs. The implemented tests represented the variation of LoDs from $\mathrm{pM}$ towards Fm, and the significant potential of heterogeneous structure for future clinical detection.

\section{- SERS}

In 2018, Sebba et al. [113] have exploited an immunoassay approach based on the utilization of SERS tags as a powerful tool for the simultaneous detection of antigens from Ebola, Lassa, and Malaria within a single blood sample. In this survey, they could achieve $90 \%$ sensitivity and $97.09 \%$ specificity.

- SEF

Hu et al. [115] devised a technique based on the combination of the lateral flow method and SEF to detect EBOV glycoprotein with multifunctional red fluorescent nanospheres (RNs@Au) containing hundreds of QDs and dozens of AuNPs. RNs@Au were modified by antibody and streptavidin as Ab-RNs@Au-SA to detect virus protein. Further, the signal was intensified by biotin modified RNs@Au.

\subsection{EBOV genome}

In another work, Guohua Li et al. [116] have provided a proof-of- concept biosensing platform in which they used magnetic beads and color-encoded plasmonic nanocrystals (PNCs). They 

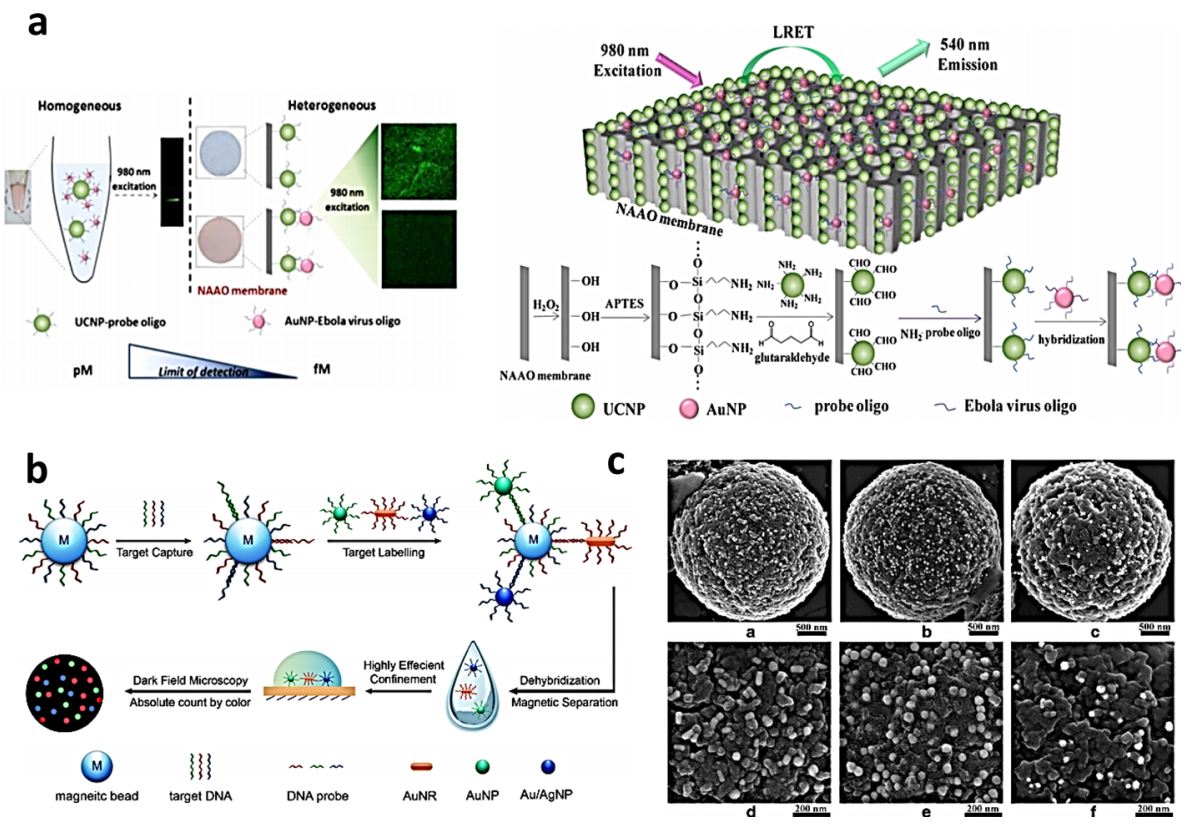

Fig. 19 a (Left) Generally fabricated homogeneous and a heterogeneous assay. (Right) immobilization of AuNPs and UNCPs on the NAAO membrane [114]. b Schematic diagram of the process for multiple DNA detection. $\mathbf{c}$ First row: Represents SEM images of the conjunction of PNCs and magnetic beads in the presence of EBOV, VV, and BA, respectively. Second row: the magnified images of the first row[116]

played a fundamental role in synchronic detection of three types of DNA. By employing astounding optical characteristics of PNCs as well as highly magnetic separating properties of beads, they could distinguish and detect DNA strands of the EBOV, Variola virus (VV), and.

Bacillus anthracis (BA) in defined concentrations. Figure 19b, c states the process of biosensor fabrication for multiple DNA detection and SEM images of hybrid biosensor platform and the SEM images of the structure at the presence of three types of viruses.

Ahmet A. Yanik et al. [112] have designed an optofluidic nanoplasmonic biosensor enabling the assemblage of the whole live viruses from biological samples. They have used group-specific antibodies. Their sensing configuration depended on the transmittance of light from plasmonic nanohole array. They have enveloped the recognition of small RNA virus (vesicular stomatitis virus: VSV and pseudotyped Ebola: PT-Ebola) within a dynamic range spanning three orders of magnitude. For this purpose, they have immobilized antibodies against the Ebola glycoprotein on the sensor surface to capture the intact virion and quantify their concentrations specifically. Figure 20 illustrates their optofluidic biosensor in the presence and absence of target EBOV and transmitted light spectrum diagram for various fluids as well as the repeatability of the sensor. In Table 4, the recent studies of plasmonic detection for NOV can be found.

\section{Dengue virus (DENV)}

Dengue virus (DENV), with a ubiquitous dispensation in tropical and subtropical regions, leads to the most common and rapidly spreading mosquito-borne acute viral disease of 

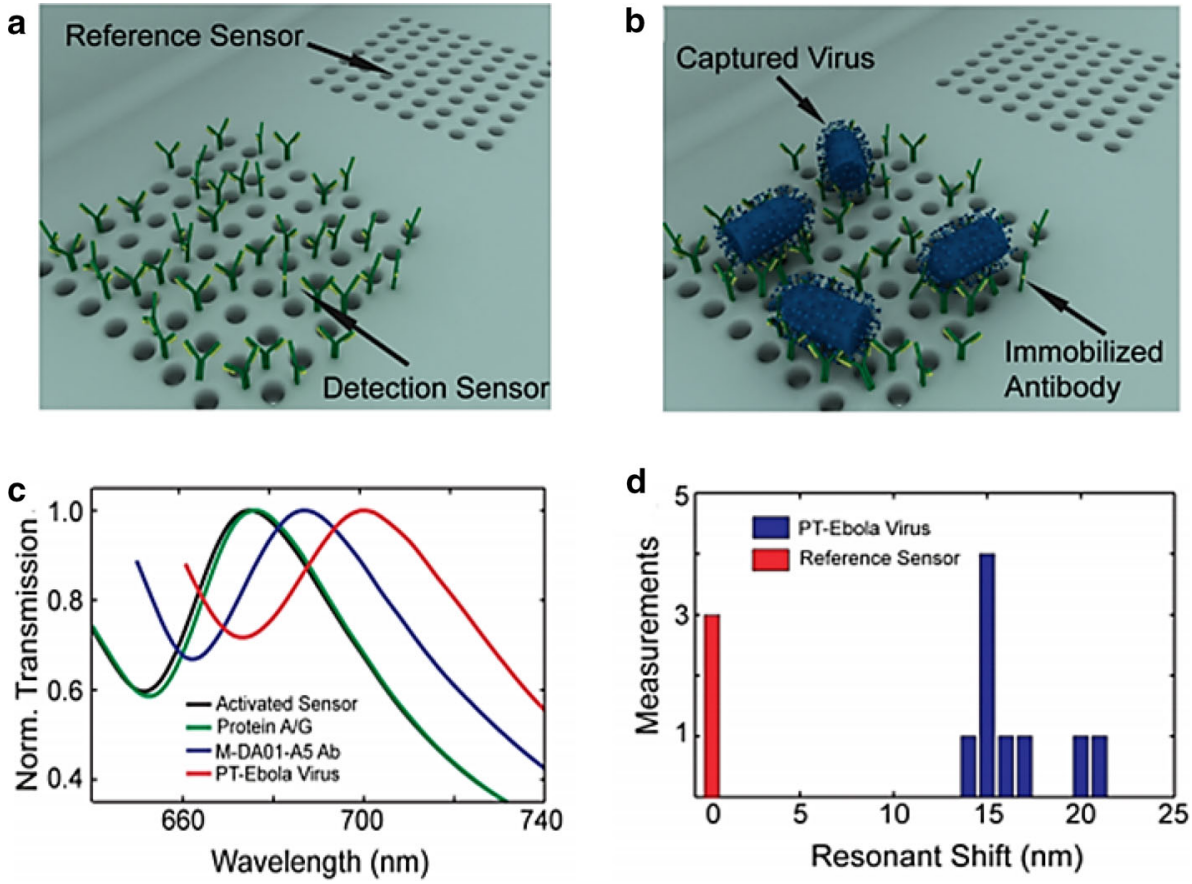

Fig. 20 a, b schematic showing three-dimensional of optofluidic nanoplasmonic biosensors at the absence and presence of captured virus at the surface of biosensor. c Detection of PT- EBOVs according to light transmission at concentration of $108 \mathrm{PFU} / \mathrm{mL}$. d Repeatability of the spectral measurements with various biosensors [112]

humans all over the world [290, 291]. This virus mostly initiates with bite by female Aedes mosquitoes (Aedes aegypti and Aedes albopictus) during their blood meal [291]. Happening in over 130 countries, the burst of this infectious disease has increased 30-fold over the 50 years [290, 292]. Per annum, the estimation of related infections is about 400 million globally, a quarter of which divulges symptoms such as Dengue fever [293]. Dengue-associated manifestations include Dengue hemorrhagic fever (DHF) frequently over $40{ }^{\circ} \mathrm{C}\left(104^{\circ} \mathrm{F}\right)$, headache, encephalitis and meningoencephalitis, aching muscles and joints, devastated vision with a different range from mild to severe blindness, Dengue shock syndrome (DSS) and eventually death [290, 293-296]. Unlike the current efforts and the development of prophylactic vaccines available in only six countries, no antivirals have been reported. As a result, there is an urgent medical need to revise our understanding and knowledge about governing the life cycle of DENV [293]. The causative agent of DENV is enveloped positive-strand RNA, belonging to the Family Flaviviridae, genus Flavivirus. Typically, the genetic material of DENV, comprising 11,000 nucleotide bases, is responsible for coding three different kinds of protein molecules (C, prM and $\mathrm{E}$ ) making virus structure and other seven protein molecules (NS1, NS2a, NS2b, NS3, NS4a, NS4b, NS5) presenting in the host medium for replication [296]. Recognition of protein formative materials for this virus has promised the researchers to delve into plasmonic biosensors as a potential resource for Dengue antibodies and its detection [297]. 
a

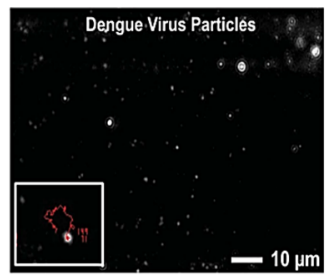

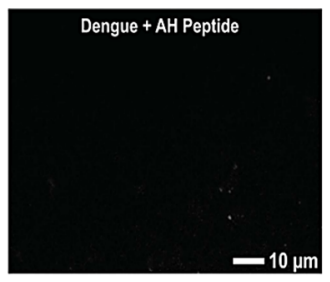

b

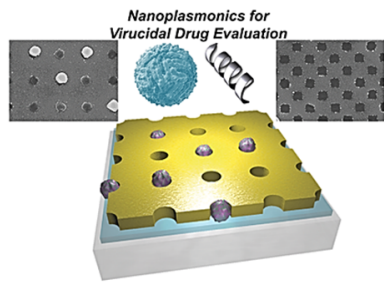

C
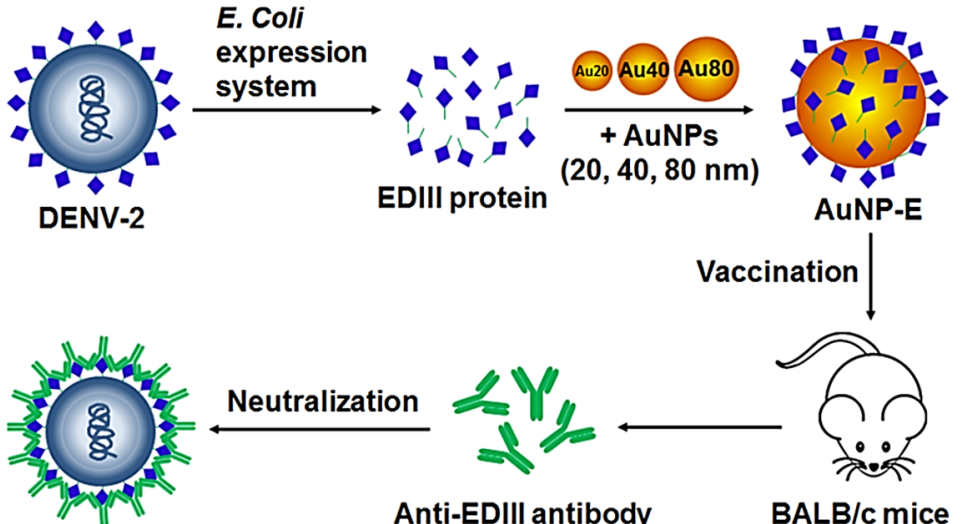

Anti-EDIII antibody

Vaccination

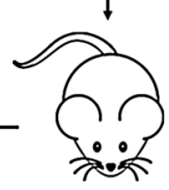

BALB/c mice

Fig. 21 a Optical micrographs (20x) taken from the DENV sample and Dengue particles plus AH peptide. The prior visualize light scattering from each DENV particles in the sample and the latter AH peptide rupture Dengue particles from the specimen. $\mathbf{b}$ The capture of virus particles and lipid vesicles by plasmonic nanohole array [118]. $\mathbf{c}$ The needful steps for the manufacture of the AuNP-E vaccine and its mechanism for serotypespecific neutralization of the DENV [120]

\subsection{DENV non-genome sections and immune response}

- SPR

Jahanshahi et al. [117] have proposed an SPR-based biosensor that enabled the detection of the anti-Dengue in human serum samples. They have immobilized four DENV serotypes as ligands on a biosensor. Regarding the obtained results, they have indicated that minimized serum volume was about $1 \mu \mathrm{l}$ from the patient. SPR angle variation acting as an indicator led to $83-93 \%$ sensitivity and $100 \%$ specificity.

\section{- LSPR}

In another study, Jackman et al. [118] have developed a plasmonic nanohole sensor that enabled capture virus-like particle and analyzed virucidal drug options. They could fabricate a periodic nanohole array configuration in which single particles such as virus particles and lipid vesicles only position within the functionalized nanoholes. Figure 21a illustrates the capturing virus particles by nanohole array in which dimensions of nanoholes are proportional to the sizes of viruses.

This highly sensitive plasmonic biosensor outlined the specific detection of virucidal peptide-induced particle rupture. In addition, Govindarajan et al. [119] have obtained ecofriendly green synthesis of silver NPs (AgNPs) using Anisomeles indica. They have evaluated AgNPs with UV-visible spectrophotometry, Fourier transform infrared spectroscopy (FTIR), scanning electron microscopy (SEM), TEM, energy-dispersive spectroscopy (EDX) 
and X-ray diffraction analysis (XRD). Eventually, they have successfully tested AgNPs potent larvicidal activity against the Dengue vector Aedes albopictus, larvae of the malaria vector Anopheles subpictus, and the Japanese encephalitis vector Culex tritaeniorhynchus. Quach et al. [120] have designed an EDIII-functionalized AuNPs (AuNP-E) vaccine consisting of AuNPs with different range of dimensions and domain III of envelope glycoprotein derived from serotype 2 of the Dengue virus (EDIII). This hybrid vaccine prosperous have studied in mice body and could produce a high level of antibodies. Figure $21 \mathrm{~b}$ indicates the footsteps of fabrication and governed process on the biosensor. Importantly, the amount of induced antibody severely depends on the size of AuNPs and the concentration of the Dengue vaccine as Fig. 21c shows the steps for the manufacture of the AuNP-E vaccine and its mechanism for serotype-specific neutralization of DENV.

\section{- SERS}

Sanchez-Purra et al. [121] have employed SERS by conjugating gold nanostars to specific antibodies for Dengue and Zika capable of differentiating between the nonstructural protein 1 (NS1) biomarkers for both diseases. Their platform not only enhances Zika diagnosis but also could detect both illnesses sooner after infection at the presence of low biomarkers. A flow-cytometry based methodology was proposed which distinguish between the clusters of magnetic fluorescent particles (i.e. analyte) and background signal. The combination of flow cytometry tests of cluster sizes and fluorescence intensity resulted in declining the background signal and the enhancement of sensitivity [122]. In Table 4, the recent studies of plasmonic detection for DENV can be found.

\section{Human papilloma virus (HPV)}

\subsection{HPV and tumorigenesis life cycle}

Human papilloma viruses (HPVs) are recognized as a set of double-stranded DNA (ds DNA) viruses whose target is the creation of infection in epithelial cells of cutaneous (skin) and mucosal surfaces [298].

The initial results of such infection begin with the appearance of genital warts in men and women. Global incidences of around 530,000 cases and approximately death reports about half of the infected people occur every year due to caused cervical cancer in women and oropharyngeal cancer in men [299]. The major number of HPVs are sexually transmitted and becomes a source of a spectrum of severe diseases in the male and female genital tract. These HPVs can be grouped upon to their potential to cause malignancy as low risk, intermediate risk, or high risk. Among known HPVs, types 6 (HPV-6) and 11 (HPV-11), for example, are linked with low-risk diseases, such as genital warts. By contrast, high-risk HPVs, such as HPV-16, HPV-18, HPV-31, HPV-33 and HPV-45, are associated with highlevel intraepithelial lesions, cervical intraepithelial neoplasia 3 (CIN3) and invasive cancer. HPV DNA has been tracked down in more than $94 \%$ of cervical cases investigated, with HPV-16 and HPV-18 being the types most commonly detected [300].

Papillomaviruses with no protective lipid membrane are known as non-enveloped viruses with the approximate length of 55-nm-diameter icosahedral capsids restrained a doublestranded DNA genome of approximately 8000 bp [301]. Dissimilar to enveloped virus family, which makes use of intercellular fusion protein mechanism to invade other cells membrane then get the access to the cytoplasm of the target cell, the non-enveloped ones' invasion tool is still under the discovering and findings indicate that the nuclear envelope establishes a 
channel with the utilization of a specific protein called a nuclear pore. This protein linedchannel organizes the transportation of molecules between the nucleus and the cytoplasm [302].

The genome of all HPV types can be divided into two-stage: (i) the early stage also called $\mathrm{E}$, and at least seven viral proteins have regulatory functions in the infected epithelial cell (E1, E2, E4, E5, E6, E7, E8) encoded during this stage. (ii) The late-stage (L) encodes the two viral structural proteins L1 and L2, that form the viral capsid [303, 304]. The genome is encapsidated in an icosahedral shell that comprises 360 copies of the L1 protein organized into 72 pentameric capsomeres that probably have one copy of L2 at the center [305].

HPV can gain entry into the epithelium through microabrasions [306] or for the high-risk HPVs infecting the cervical epithelium, by allowing cells of the single-layered squamous cellular junction between the endo- and ectocervix, (Fig. 22a) [307]. This is obvious for the high-risk HPVs, effective establishment of infection mainly must be made by viruses on dividing basal (Fig. 22b) and stem, epithelial cells (Fig. 22c) [308, 309]. HPV L1 capsid protein establishes intercellular bond receptors placed on the basement membrane or on the surface of basal layer cells [310]. Heparin sulfate proteoglycans (HSPGs) seem to be the primary receptor for initial interconnection [311]. When HPV binds HSPGs, there is a cyclophilin B-mediated conformational change in the viral capsid such that the $\mathrm{N}$-terminus of the L2 component is exposed on the surface of the virion (Fig. 22d) [312]. The transcription process is initiated upon nuclear entry into the dividing cells of the basal layer or ectocervix viral. Research on HPV31 shown that RNA encoding the viral replication/transcription factors E1 and E2 was the first RNA species to be detected upon nuclear infection [313]. This mechanism must take places first since incoming virus priority task is to carry out initial replication of its genome. Further, following by early expression of the viral transcription factor E2 would give the chance of correct regulation of the early viral promoter to direct expression of the E6 and E7 regulatory proteins that ensure constant survival of HPV-infected cells [314]. E2 retains one DNA-binding and one protein-binding domain linked by a flexible hinge region [315]. E2 initially makes a link with E1, then binds as a dimer of hexamers to the viral origin of replication and utilizes the cellular DNA replication machinery (Fig. 22d) $[316,317]$. The estimated episomal of 50-100 copies per nucleus would generate after the initial replication of an inbound HPV genome [318]. P97 for HPV 16, P53 for all HPVs, and P105 for HPV 18 are early promoters responsible for the expression of proteins at the early stages of the replication cycle [319]. These comprise the E6 and E7 viral oncoproteins [320, 321]. Even with their nomination as oncoproteins, their expression is vital for the normal replicative HPV life cycle. This has been proven in early studies that in situ hybridization, levels of the mRNA encoding increased leading to further changes of these proteins level from the lower to mid-upper in epithelial layers (Fig. 22e) [322-324]. However, the expression of biomarkers that respond to E6 and E7 was found to decrease in the upper epithelial layers [325]. Hence, the biological functionalities of these proteins may be most significant in the early period of viral replication in basal epithelial cells (Fig. 22f). The final stage of the viral life cycle includes growing viral DNA replication, and consequently virion formation. Amplified expression of the viral E1 and E2 proteins is vital to finish this phase. The late phase of the life cycle is denoted by activation (owing to changes in cell signaling) of the viral major late promoter (HPV16: P670; HPV18: P811) that is found in the E7 gene region.

It is noteworthy that the primary reason for progression to cancer seems to be the persistent infection of basal and stem epithelial cells with at least one of the high-risk HPVs over several years [314]. 
a Normal cervix

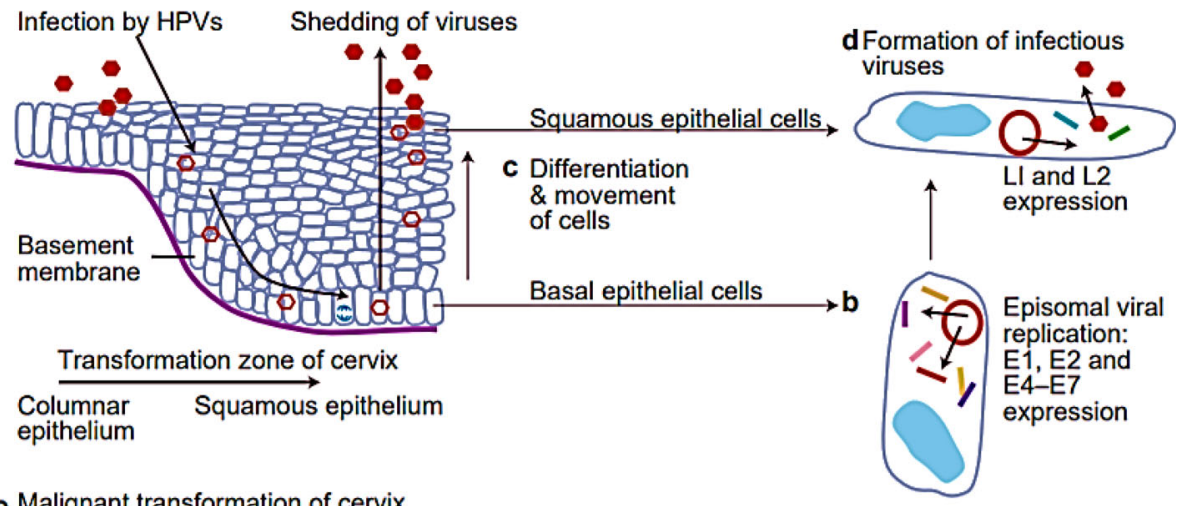

e Malignant transformation of cervix

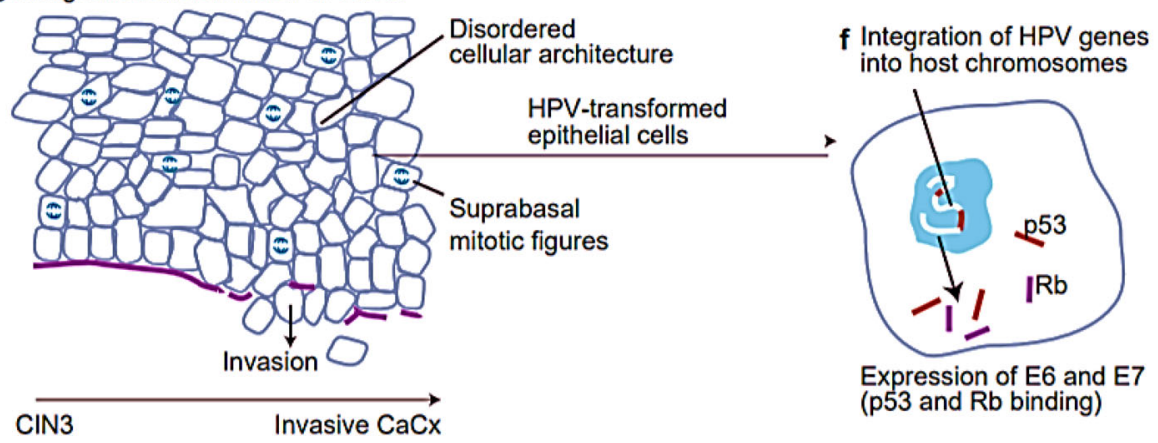

Fig. 22 Human papillomavirus (HPV) infection and replication in cervical epithelial cells. a The normal cervix has a (narrow) transformation zone in which there is an abrupt transition from a columnar epithelium (sometimes via a metaplastic epithelium) to a squamous epithelium; HPVs are probably most infectious to cells that are close to this junction. b HPV viruses gain access to the basal epithelial cells of the cervix via the vagina (for example, during sexual intercourse), where they replicate episomally (outside the host chromosome in the cytoplasm) and express the (early) viral genes E1, E2, E4, E5, E6 and E7. c The infected basal cells, which show signs of cell disruption as a result of the viral infection, continue their differentiation and migration to the epithelial surface, where d the (now) squamous cells start to express the late HPV genes LI and L2. Infectious virus particles are formed and shed into the lumen of the vagina. (e) HPV infection (particularly with the high-risk types) can progress to: (1) HPV-induced mild dysplasia, (2) the final stages of cervical intraepithelial neoplasia (CIN3) and, eventually, (3) invasive cervical cancer (CaCx), when the basement membrane is breached by the cells, allowing local spread and also distant metastasis. (f) In transformed epithelial cells, HPV genes are integrated into the host chromosomes, with an expression of (the oncogenic) E6 and E7 proteins, which bind to the tumor-suppressor proteins p53 and Rb [14]

\section{Plasmonic quantum probes}

The plasmonic-enhanced Raman scattering as a unique signaling from individual mutated metabolites has found many applications in cancer signaling [326-330]. Plasmonic sensing of metabolites can be made with direct [331-333] or indirect RAMAN signals [178, $334,335]$. The sensing limitation of mutated metabolites, including amino acids, proteins, biomarkers, and receptors in the non-cellular environment, caused by the exploitation of RAMAN signals, and substantial grade of cytotoxicity of plasmonic probes during sensing operation motivates the researchers to use the second approach. Thus, plasmonic probes are layered with biocompatible materials (bio-films) such as Polyethylene glycol (PEG), then 


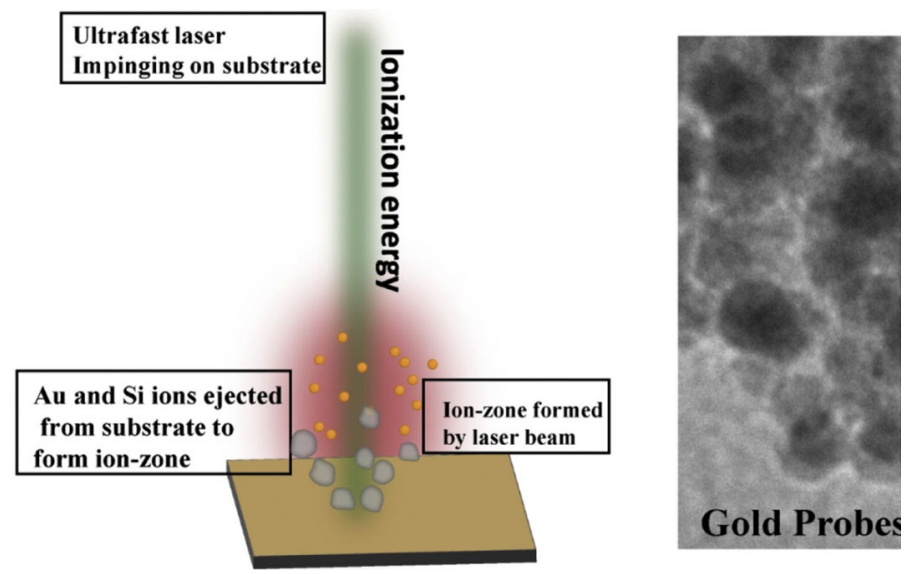

Fig. 23 Schematic representation of Plasmonic quantum probe (PQPs) synthesis by forming an ion zone and HRTEM image of gold probes on silicon carrier [123]

secondary plasmonic material layer coated over the first layer [336]. The size of plasmonic particles has a critical influence on the intra-cellular uptake and dispersion inside the nuclear. Recruiting Gold QDs is a non-invasive way to navigation and dispersion of plasmonic probes inside the cells [337, 338]. The study made by Agarwal et al. [123] introduces gold plasmonic quantum probes (PQP) for monitoring of intracellular biochemistry through plasmonic readout. The experiment initiated by synthesizing non-toxic quantum-size PQP using a femtosecond pulsed laser with a central wavelength of $1030 \mathrm{~nm}$. Upon impinging laser onto the gold coated silicon target, electrons heated up by multiphoton absorption and an ionized plasma form, as shown in Fig. 23.

\subsection{Plasmonic detection of HPV}

Agarwal et al. [123] also described their performed experiment in several steps: (i) The cancerous cell lines of cervical cancer (HeLa) cultured in a T25 tissue culture flask with Modified Eagle's Medium (MEM), 10\% FBS and 1\% antibiotic and antimycotic solution (complete growth medium) and all the cells line were maintained at $37{ }^{\circ} \mathrm{C}$ in $5 \% \mathrm{CO}_{2}$. (ii) The cells were seeded on the top of the synthesized multi-phase plasmonic quantum probes by using a complete growth medium. The cells were seeded for 6 and $18 \mathrm{~h}$. The reaction was stopped by removing the media, followed by washing with Phosphate Saline buffer and fixating the cells by using $4 \%$ paraformaldehyde. Multiple cancer surface biomarkers were sensed by using the PQPs present in the cultured bio-medium at $6 \mathrm{~h}$ and $18 \mathrm{~h}$. (iii) The PQPs then penetrated and distributed in intracellular components (e.g., HPV E6/HPV E7), and nuclear metabolites (DNA, RNA, proteins, and lipids) (Fig. 24a, b) at different uptake rate.

The main reason for this difference is the plasma membrane of different cells has different lipid compositions, which determines the physical property of the cell membrane and makes them react to sensors differently. (iv) A portable Raman spectroscopy with a laser wavelength of $785 \mathrm{~nm}$ suitable for penetration to tissues is used. (v) Monitoring nucleus after 6 and $18 \mathrm{~h}$ of cell seeding, represented in the form of plasmonic Raman signals readout in Fig. $24 \mathrm{c}, \mathrm{d}$ indicated the increase in the intensity of measured signals. The period of which the measurement had been taken is called the progression of cancer, and several phases (G1 phase, S phase G2 phase and M phase as shown in Fig. 24c, d) can be considered for study- 

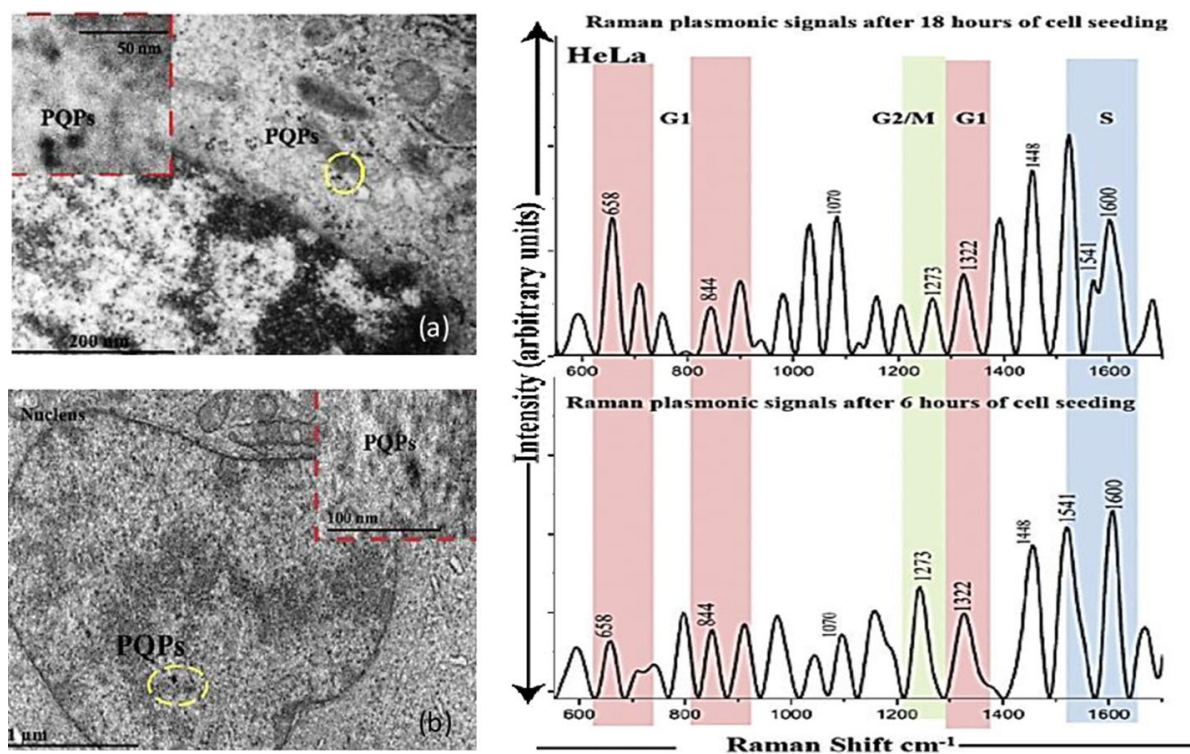

Fig. 24 a The Bio-TEM image showing the presence of PQPs inside the cancerous cells (HeLa), b Bio TEM images show the interaction between plasmonic probes and nucleus components. $\mathbf{c}$ Plasmonic Raman signals response for cervical cancer (HeLa) after 6 and $18 \mathrm{~h}$ of cell seeding to monitor the growth of cells by studying the G0 G1 and G3 phase of the cell cycle [123]

ing the growth of the tumor. During G1 phase cells prepare for cell division, at restriction point, the cell moves to $S$ phase for DNA synthesis and replicates the genetic material. Then after, in the $\mathrm{G} 2$ phase, metabolic changes assemble the cytoplasmic material for mitosis and cytokinesis. In the M phase, a nuclear division takes place, followed by the cell division. The obtained biochemistry information of a cell from the surface to the nucleus is revealed by a PQB detection mechanism, and the applied technique is found useful for rapid and accurate identification of cell types.

SERS in bio-diagnostic applications can be divided into two approaches of extrinsic and intrinsic SERS. The first approach exploiting the highly conserved molecular vibrations of nucleic acids, lipids and other intracellular components to allow contrast agent free differentiation [339], and the second approach exploiting of Raman tagged nano-metal particles as scannable bio component via conjugation of a protein or nucleic acid allowing the direct detection of target analytes [340]. The narrow spectra SERS can be suitably applied for screening six channels of different HPV genotypes with validation HPV GP5 + /GP6 + PCR primer and probe set [124, 341]. The SERS HPV exploited the RenDx assay approach. In short, biotinylated PCR products were denatured and target specific SERS probes then hybridized to target amplicons. The process then fully automated and involves the addition of streptavidin magnetic beads (to capture biotinylated strands with hybridized probes), wash cycles (to remove unbiotinylated template and non-captured probes), elution (removing probes from the magnetically captured amplicons) and addition of eluant to a silver nanoparticle suspension for SERS detection. The assay contained 6 dye-labelled probe channels HPV type specific channels and associated dye spectra known as: HPV16, HPV18, HPV31, HPV45, other HR HPV (including HPV33, 35, 39, 51, 52, 56, 58, 59, 66, 68) and LR HPV (including HPV $6,11,40,42,43,44)$. The validation HPV SERS assay made upon DNA obtained from a 
range of HR HPV and HR HPV16 positive human cell line besides other twenty-five residual liquid-based cytology sample were screened through the GP5 + /GP6 + PCR-ELISA for detection the presence or absence of HPV [125]. The evaluation of the performance the assay has confirmed that HPV16, HPV18 and HPV45 were detectable significantly at $1 \times 102$ and $1 \times 104$ copies, respectively, by both SERS and PCR-EIA [4].

\section{Herpes simplex virus (HSV)}

One of the main reasons for herpes appearing throughout the body, especially on the genitals or mouth, is herpes simplex virus, known as HSV. To categorize HSV primarily based on the emerged regions, there are two species of herpes; HSV1: mostly generates oral herpes as a highly contagious infection providing cold sores and painful blisters or ulcers environs the mouth and face. HSV2: Generally responsible for genital herpes and genital herpes prevalence as a lifelong, incurable, and sexually transmitted disease; however, HSV1 could cause genital herpes [342, 343]. For the accomplishment of the fusion process between the viral envelope and host membrane, four glycoproteins, $\mathrm{gD}, \mathrm{gH} / \mathrm{gL}$, and $\mathrm{gB}$, are crucial [126]. The gD protein regarded as an easily accessible aim for biological participations by attachment to specific co-receptors and intermediacy of viral entry to host medium, making gD a suitable target in therapeutic interventions [344].

\subsection{HSV non-genome sections and immune response}

\section{- SPR}

Cairns et al. [126] developed a model based on the SPR, suggesting a direct binding between the ectodomain of $\mathrm{gD}$ and the ectodomain of $\mathrm{gH} / \mathrm{gL}$ under defined conditions. To localize such interaction, they utilized several spectacular anti-gD monoclonal antibodies from six antigenic communities to characterize the interfered interactions. The results implicate the interaction $\mathrm{gD}$ and $\mathrm{gH} / \mathrm{gL}$ that supports a significant role for HSV entry [126].

\section{- LSPR}

Recently, Rodriguez-Izquierdo et al. [129] surveyed the effect of AuNPs (NPAuG1-S2, NPAuG2-S4, and NPAuG3-S8) in treatment of HSV-1 infection in a neural-derived SK-NMC cell line model, reduction of HSV-1-induced $\beta$-secretase activity, as well as amyloid- $\beta$ accumulation in SK-APP-D1 modifies cell line. Furthermore, they demonstrated the ability of such AuNPs in the crossing of the blood-brain barrier (BBB) without any reported damage to in the vivo mice model. HSV can cause an eye disease called conjunctivitis, and its correct diagnosis is important at the earliest possible stage [345]. Corneal scrapings is required during clinical findings and the alternative way to eliminate patient discomfort is collecting tear film sample [346-348]. Synthetic tear can reference the molarities of proteins, immunoglobulin, carbohydrates, acids and ions exist in real tear [349-352].

\section{- SERS}

The SERS effect for accurate monitoring of HSV needs metal particle (Ag or $\mathrm{Au}$ ) in the order of $10-100 \mathrm{~nm}$ in dimeter. The silver substrate of tear film took the advantage of Tollens' reaction, which is a glass based substrate coated with silver nitrate that is reduced by an aldehyde and D-glucose [353]. After preparation of metal thin film the synthetic analyte of tears dried onto the substrate and went under the laser power of $6.7 \mathrm{~mW}$ centered at $830 \mathrm{~nm}$ and 


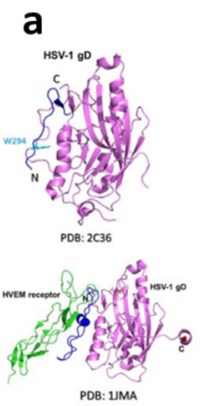

C

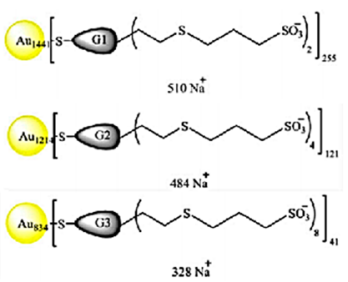

b

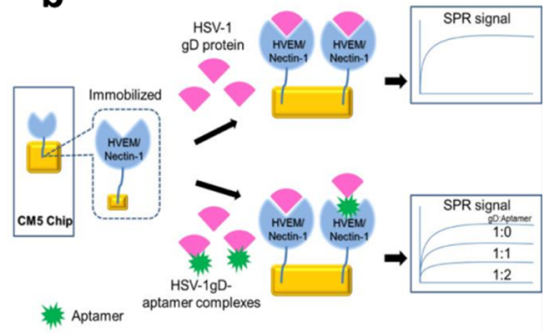

$10 \mathrm{~h}$

$24 \mathrm{~h}$

$48 \mathrm{~h}$

d
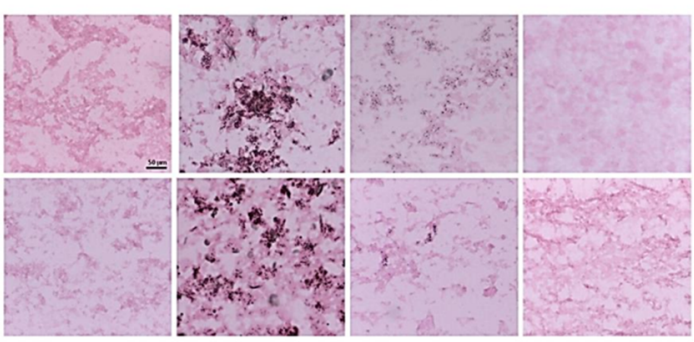

Fig. 25 a Crystal structure of the HSV-1 gD protein in a free and synthetic body. (b) Overall monitoring of inhibitors that interfere with interactions between HSV-1 gD and human receptors (HVEM or Nectin1) by SPR analysis [127]. c Schematic representation of selected NPAuG1-S2, NPAuG2-S4, and NPAuG3-S8 with various structures. d NPAuG3-S8 accumulation in cerebral tissue and time-dependence of crossing NPAuG3S8 from BBB [129]

periodic capturing of $60 \mathrm{~s}$. The average sensitivity and specificity for silver mirror reaction glass were $77.3 \pm 8.3 \%$ compared with $78.3 \pm 6.2 \%$ for $\mathrm{g}$, old thin film. Therefore it can be decided that the application of SERS with metallic synthetic substrates is sensitive and specific to the presence of HSV [128].

\subsection{HSV genome}

- SPR

Subash C. B. Gopinath et al. [127] proposed a molecular assay SPR-based approach in which they could separate RNA aptamers (aptamer-1 and aptamer-5) binding to the gD protein of HSV-1 with high affinity and having the ability to characterize the gD protein of a various virus, HSV-2 (Fig. 25a, b). Their study allows the continuous monitoring of the interactions between the $\mathrm{gD}$ protein and the host receptors (HSV-1 target cell receptor (HVEM) and nectin-1). The reported assay utilized for investigation of sulfated polysaccharides impact, including heparan sulfate, on interference with gD-HVEM interactions. Infectious HSV-1 overrunning nervous system are associated with neurodegenerative diseases. Under such conditions, the balance between the amyloidogenic and non-amyloidogenic pathways gets unbalanced, promoting the accumulation of amyloid- $\beta$ peptides, the risk of the neurodegenerative diseases [129]. In Fig. 25c, d, the schematic representation of selected NPAuG1-S2, NPAuG2-S4, and NPAuG3-S8 with various structures are shown besides shown NPAuG3-S8 accumulation in cerebral tissue and time-dependence of crossing NPAuG3-S8 from BBB. 


\section{Conclusion}

In this review, we have highlighted the role of plasmonics in the detection of viral diseases. Plasmonics, as a non-invasive, real-time, and highly resolved technique provides a proper platform for cost-effective and rapid detection. Undoubtedly, the progress in early-stage detection plays a critical role to monitor the transmission of the virus in preventing pandemic disasters. The focus of our study was on 11 deadliest viruses for human beings, including SARS, MERS, COVID-19, HIV, Influenza, Hepatitis B, Zika, Rabies, Ebola, Norovirus, Dengue, HPV and HSV. We have investigated the integration of plasmonics with the genome/nongenome sections of the virus and immune response of human to the related viral infections.

Specifically, the plasmonic detection of viruses could be summarized as follows:

- For SARS-CoV, its proteins (N, S and ME), related antibodies (IgG) and RNA genome could be the target of plasmonic detection while the immobilization of proteins $(\mathrm{N}, \mathrm{S}$, ACE2), peptides, RNA and hCypA on the chip surface could provide proper interaction of these target elements on the chip.

- For MERS-CoV, detection targets could be hDPP4, hD26, RBD viral protein while immobilized agents on the plasmonic chip could be MERS antibodies (4c2, 2E6, hMS-1) and RBDs in order to provide a proper interaction.

- For COVID-19, detection targets could be Mpro proteinase and heparin while immobilized agents on the plasmonic chip could be ligands and S1 protein RBD.

- For influenza virus, detection targets could be HA/NA genes, DNA, aptamers of J3APT and JH4APT, ssDNA, dsDNA while immobilized agents on the plasmonic chip could be EB2-B3 antibodies, GBP-fusion protein, HA protein and sialic-acid terminated glycerol dendron.

- For Hepatitis B virus, detection targets could be both antigens and antibodies as well as DNAs. Immobilized agents on the plasmonic chip could be Thionine-AuNPs, DNAs, antibodies, antigens and protein ligands.

- For HIV, p24 antigen was detected using immobilized antibodies on the chip surface.

- For Zika virus, detection targets could be NS1 protein, neonatal Fc receptor and RNA. Immobilized agents on the plasmonic chip could be antibodies (i.e. IgG and $\operatorname{IgM}$ ), ssDNA and FC-Ivermectin-NPs.

- For Rabies virus, detection targets could be glycoprotein ligand, N and G proteins. Immobilized agents on the plasmonic chip could be $\mathrm{N}$ and $\mathrm{G}$ antibodies.

- For Norovirus virus, detection targets could be its capsids, pathogens and strains (i.e. VA387 and Norwalk). Immobilized agents on the plasmonic chip could be milk glycan, antibodies, peptides and DNA aptamers.

- For Ebola virus, virus detection targets could be its RNA, glycoprotein, oligonucleotide and DNA. Immobilized agents on the plasmonic chip could be its antibodies, UCNPs and PNCs.

- For Dengue virus, detection targets could be its antigens, peptides and glycoprotein. Immobilized agents on the plasmonic chip could be its antibodies and serotypes as ligands.

- For HPV, detection targets could be its P53 and Rb. Immobilized agent on the plasmonic chip could be its paraformaldehyde.

- For Herpes simplex virus, detection targets could be its RNA and glycoprotein. Immobilized agents on the plasmonic chip could be gD proteins.

We hope that this review could open novel approach for the designation of efficient and highly resolved detection techniques as well as practical and rapid approach for vaccine study. 


\section{References}

1. Organization, W.H.; Available from: https://www.who.int/emergencies/diseases/novel-coronavirus-201 9

2. Worldometer. Available from: https://www.worldometers.info/coronavirus/

3. M. Rusnati et al., Bridging the past and the future of virology: surface plasmon resonance as a powerful tool to investigate virus/host interactions. Crit. Rev. Microbiol. 41(2), 238-260 (2015)

4. B. Marintcheva, Chapter 1 - Introduction to Viral Structure, Diversity and Biology**Parts of this chapter were originally published in Marintcheva B. A box of paradoxes: the fascinating world of viruses. Bridgew Rev 2013;32(2):25-8. http://vc.bridgew.edu/br_rev/vol32/iss2/8 and are reproduced here with the permission of the editor, in Harnessing the Power of Viruses, B. Marintcheva, Editor. 2018, Academic Press. p. $1-26$

5. J.C. Huang et al., Detection of severe acute respiratory syndrome (SARS) coronavirus nucleocapsid protein in human serum using a localized surface plasmon coupled fluorescence fiber-optic biosensor. Biosens. Bioelectron. 25(2), 320-325 (2009)

6. T.J. Park et al., A self-assembled fusion protein-based surface plasmon resonance biosensor for rapid diagnosis of severe acute respiratory syndrome. Talanta 79(2), 295-301 (2009)

7. L.A. Layqah, S. Eissa, An electrochemical immunosensor for the corona virus associated with the Middle East respiratory syndrome using an array of gold nanoparticle-modified carbon electrodes. Microchim. Acta 186(4), 224 (2019)

8. B. Udugama, et al. Diagnosing COVID-19: The Disease and Tools for Detection. ACS Nano (2020)

9. Radiologyinfo. Available from: https://www.radiologyinfo.org/

10. D. Cui, X. Chen, Y. Wang, Detection of SARS-CoV Antigen via SPR analytical systems with reference. Pier Andrea Serra, p. 169 (2010)

11. S. Souf, Recent advances in diagnostic testing for viral infections. Biosci Horizons Int. J. Stud. Res. 9 (2016)

12. S. Chen et al., Techniques used for the discovery of therapeutic compounds: the case of SARS. Drug Discov. Today Technol. 3(3), 277-283 (2006)

13. P. Prabakaran et al., Structure of severe acute respiratory syndrome coronavirus receptor-binding domain complexed with neutralizing antibody. J. Biol. Chem. 281(23), 15829-15836 (2006)

14. Y. Yang, Q. Wang, D. Guo, A novel strategy for analyzing RNA-protein interactions by surface plasmon resonance biosensor. Mol. Biotechnol. 40(1), 87-93 (2008)

15. A.-W. Struck et al., A hexapeptide of the receptor-binding domain of SARS corona virus spike protein blocks viral entry into host cells via the human receptor ACE2. Antiviral Res. 94(3), 288-296 (2012)

16. F. Sohrabi, S.M. Hamidi, Fabrication methods of plasmonic and magnetoplasmonic crystals: a review. Eur. Phys. J. Plus 132(1), 15 (2017)

17. Z. Zalevsky, I. Abdulhalim, Chapter 6 - Plasmonics, in Integrated nanophotonic devices (Second Edition). ed. by Z. Zalevsky, I. Abdulhalim (William Andrew Publishing, Oxford, 2014), pp. 179-245

18. F. Sohrabi, M.S. Hamidi, Neuroplasmonics: From Kretschmann configuration to plasmonic crystals. Eur. Phys. J. Plus 131(7), 1-15 (2016)

19. J. Homola, Surface plasmon resonance sensors for detection of chemical and biological species. Chem Rev 108(2), 462-493 (2008)

20. K. Matsubara, S. Kawata, S. Minami, A compact surface plasmon resonance sensor for measurement of water in process. Appl. Spectros 42(8), 1375-1379 (1988)

21. L.-M. Zhang, D. Uttamchandani, Optical chemical sensing employing surface plasmon resonance. Electr. Lett. 24, 1469-1470 (1988)

22. C. Nylander, B. Liedberg, T. Lind, Gas detection by means of surface plasmon resonance. Sens. Actuators 3, 79-88 (1982)

23. J.M. Brockman, B.P. Nelson, R.M. Corn, Surface plasmon resonance imaging measurements of ultrathin organic films. Ann. Rev. Phys. Chem. 51, 41-63 (2000)

24. H. Raether, Surface Plasmons on Smooth and Rough Surfaces and on Gratings (Springer-Verlag, Berlin, 1986)

25. I. Prigogine, S.A. Rice, Advances in chemical physics, ed. I. Prigogine and S.A. Rice. (Wiley, New York, 1983)

26. W. Knoll, Interfaces and thin films as seen by bound electromagnetic waves. Ann. Rev. Phys. Chem. 49, 569-638 (1998)

27. H. Raether, Surface plasmons on smooth and rough surfaces and on gratings, ed. H. Raether, (SpringerVerlag, Berlin, 1988)

28. Y. Huang et al., Theoretical analysis of voltage-dependent fiber optic surface plasmon resonance sensor. Opt. Commun. 308, 109-114 (2013) 
29. S. Saeidifard et al., Two-dimensional plasmonic biosensing platform: Cellular activity detection under laser stimulation. J. Appl. Phys. 126(10), 104701 (2019)

30. T. Asadishad et al., Detection of nicotine effect on colon cells in a plasmonic platform. J. Lasers Med. Sci. 11(1), 8-13 (2020)

31. T. Asadishad et al., Flexible neuro-plasmonic sensor based on patterned two dimensional structure to detect methadone. in Saratov fall meeting 2019: optical and nano-technologies for biology and medicine. International Society for Optics and Photonics (2020)

32. F. Sohrabi et al., Phase-sensitive optical neural recording of cerebellum tissue on a flexible interface. J Appl Phys 127(11), 113101 (2020)

33. F. Sohrabi, S.M. Hamidi, Optical detection of brain activity using plasmonic ellipsometry technique. Sens. Actuators B Chem. 251, 153-163 (2017)

34. F. Sohrabi et al., One dimensional photonic crystal as an efficient tool for in-vivo optical sensing of neural activity. Opt. Mater. 96, 109275 (2019)

35. I. Banga et al., Biosensors and Their Application for the Detection of Avian Influenza Virus, in Nanotechnology in Modern Animal Biotechnology. (Elsevier, Amsterdam, 2019), pp. 1-16

36. A.M. Shrivastav, U. Cvelbar, I. Abdulhalim, A comprehensive review on plasmonic-based biosensors used in viral diagnostics. Commun. Biol. 4(1), 1-12 (2021)

37. K.M. Mayer, J.H. Hafner, Localized surface plasmon resonance sensors. Chem. Rev. 111(6), 3828-3857 (2011)

38. S.V. Gaponenko, D.V. Guzatov, Colloidal plasmonics for active nanophotonics. Proc. IEEE 108(5), 704-720 (2020)

39. H. Lee et al., Inhibitor recognition specificity of MERS-CoV papain-like protease may differ from that of SARS-CoV. ACS Chem. Biol. 10(6), 1456-1465 (2015)

40. N. Zhu et al. A novel coronavirus from patients with pneumonia in China, 2019. N. Engl. J. Med. (2020)

41. S. Hatakeyama et al., Dissection and identification of regions required to form pseudoparticles by the interaction between the nucleocapsid $(\mathrm{N})$ and membrane $(\mathrm{M})$ proteins of SARS coronavirus. Virology 380(1), 99-108 (2008)

42. Swiss Institute of Bioinformatics. Available from: https://viralzone.expasy.org/

43. H. Luo et al., Severe acute respiratory syndrome coronavirus membrane protein interacts with nucleocapsid protein mostly through their carboxyl termini by electrostatic attraction. Int. J. Biochem. Cell Biol.. 38(4), 589-599 (2006)

44. H. Luo et al., In vitro biochemical and thermodynamic characterization of nucleocapsid protein of SARS. Biophys. Chem. 112(1), 15-25 (2004)

45. C. Luo et al., Nucleocapsid protein of SARS coronavirus tightly binds to human cyclophilin A. Biochem. Biophys. Res. Commun. 321(3), 557-565 (2004)

46. H. Chen et al., Mass spectroscopic characterization of the coronavirus infectious bronchitis virus nucleoprotein and elucidation of the role of phosphorylation in RNA binding by using surface plasmon resonance. J. Virol. 79(2), 1164-1179 (2005)

47. Q. Wang et al., Interactions of SARS coronavirus nucleocapsid protein with the host cell proteasome subunit p42. Virol. J. 7(1), 99 (2010)

48. B. Zhou et al., The nucleocapsid protein of severe acute respiratory syndrome coronavirus inhibits

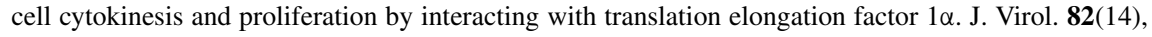
6962-6971 (2008)

49. S. Liu et al., Interaction between heptad repeat 1 and 2 regions in spike protein of SARS-associated coronavirus: implications for virus fusogenic mechanism and identification of fusion inhibitors. The Lancet 363(9413), 938-947 (2004)

50. D.-G. Ahn et al., RNA aptamer-based sensitive detection of SARS coronavirus nucleocapsid protein. Analyst 134(9), 1896-1901 (2009)

51. B. Tripet et al., Template-based coiled-coil antigens elicit neutralizing antibodies to the SARScoronavirus. J. Struct. Biol. 155(2), 176-194 (2006)

52. J. Sui et al., Potent neutralization of severe acute respiratory syndrome (SARS) coronavirus by a human $\mathrm{mAb}$ to S1 protein that blocks receptor association. Proc. Natl. Acad. Sci. 101(8), 2536-2541 (2004)

53. J. Sui et al., Broadening of neutralization activity to directly block a dominant antibody-driven SARScoronavirus evolution pathway. PLoS Pathog. 4(11), e1000197 (2008)

54. T.J. Park et al., Protein nanopatterns and biosensors using gold binding polypeptide as a fusion partner. Anal. Chem. 78(20), 7197-7205 (2006)

55. S. Chen et al. SARS coronavirus 3CLpro N-terminus is indispensable for proteolytic activity but not for enzyme dimerization: biochemical and thermodynamic investigation in conjunction with molecular dynamics simulations. J. Biol. Chem. (2004) 
56. J. Liu et al., Production of an anti-severe acute respiratory syndrome (SARS) coronavirus human monoclonal antibody Fab fragment by using a combinatorial immunoglobulin gene library derived from patients who recovered from SARS. Clin. Vaccine Immunol. 13(5), 594-597 (2006)

57. W. Song et al., Identification of residues on human receptor DPP4 critical for MERS-CoV binding and entry. Virology 471, 49-53 (2014)

58. Y. Li et al., A humanized neutralizing antibody against MERS-CoV targeting the receptor-binding domain of the spike protein. Cell Res. 25(11), 1237-1249 (2015)

59. Q. Wang et al., Bat origins of MERS-CoV supported by bat coronavirus HKU4 usage of human receptor CD26. Cell Host Microbe 16(3), 328-337 (2014)

60. G. Lu et al., Molecular basis of binding between novel human coronavirus MERS-CoV and its receptor CD26. Nature 500(7461), 227-231 (2013)

61. G. Zhao et al., A novel nanobody targeting Middle East respiratory syndrome coronavirus (MERS-CoV) receptor-binding domain has potent cross-neutralizing activity and protective efficacy against MERSCoV. J. Virol. 92(18), e00837-e918 (2018)

62. H. Qiu et al., Single-dose treatment with a humanized neutralizing antibody affords full protection of a human transgenic mouse model from lethal Middle East respiratory syndrome (MERS)-coronavirus infection. Antiviral Res. 132, 141-148 (2016)

63. X. Yu et al., Structural basis for the neutralization of MERS-CoV by a human monoclonal antibody MERS-27. Sci. Rep. 5, 13133 (2015)

64. Z. Li et al., FEP-based screening prompts drug repositioning against COVID-19. bioRxiv (2020)

65. C. Mycroft-West et al. The 2019 coronavirus (SARS-CoV-2) surface protein (Spike) S1 Receptor Binding Domain undergoes conformational change upon heparin binding. bioRxiv, (2020)

66. X. Liu et al., Therapeutic effects of dipyridamole on COVID-19 patients with coagulation dysfunction. medRxiv, (2020)

67. H.I. Labouta, et al., Localized plasmonic photothermal therapy as a life-saving treatment paradigm for hospitalized COVID-19 patients. Plasmonics, p. 1-5 (2021)

68. A. Pramanik et al., The rapid diagnosis and effective inhibition of coronavirus using spike antibody attached gold nanoparticles. Nanoscale Advances 3(6), 1588-1596 (2021)

69. N.C. Cady et al., Multiplexed detection and quantification of human antibody response to COVID-19 infection using a plasmon enhanced biosensor platform. Biosens. Bioelectr. 171, 112679 (2021)

70. G. Qiu et al., Thermoplasmonic-assisted cyclic cleavage amplification for self-validating plasmonic detection of SARS-CoV-2. ACS Nano 15(4), 7536-7546 (2021)

71. H. Liu et al., Development of a SERS-based lateral flow immunoassay for rapid and ultra-sensitive detection of anti-SARS-CoV-2 IgM/IgG in clinical samples. Sens. Actuators B Chem. 329, 129196 (2021)

72. C. Wang et al., Development of spike protein-based fluorescence lateral flow assay for the simultaneous detection of SARS-CoV-2 specific IgM and IgG. Analyst, (2021)

73. Y. Peng et al., Charge-transfer resonance and electromagnetic enhancement synergistically enabling MXenes with excellent SERS sensitivity for SARS-CoV-2 S protein detection. Nano-micro Lett. 13(1), $1-17(2021)$

74. X. Peng et al., Promising near-infrared plasmonic biosensor employed for specific detection of SARSCoV-2 and its spike glycoprotein. J. Phys. 22(10), 103046 (2020)

75. H. Bai et al., A SPR aptasensor for detection of avian influenza virus H5N1. Sensors 12(9), 12506-12518 (2012)

76. C. Estmer Nilsson et al., A novel assay for influenza virus quantification using surface plasmon resonance. Vaccine 28(3), 759-766 (2010)

77. Y.-F. Chang et al., Simple strategy for rapid and sensitive detection of avian influenza A H7N9 virus based on intensity-modulated SPR biosensor and new generated antibody. Anal. Chem. 90(3), 1861-1869 (2018)

78. S.H. Kim et al., Specific detection of avian influenza $\mathrm{H} 5 \mathrm{~N} 2$ whole virus particles on lateral flow strips using a pair of sandwich-type aptamers. Biosens. Bioelectron. 134, 123-129 (2019)

79. C.L. Wong et al., Plasmonic contrast imaging biosensor for the detection of H3N2 influenza proteinantibody and DNA-DNA molecular binding. IEEE Sens. J. 19(24), 11828-11833 (2019)

80. X. Zhao et al., Optical fiber sensor based on surface plasmon resonance for rapid detection of avian influenza virus subtype H6: Initial studies. J. Virol. Methods 233, 15-22 (2016)

81. I. Papp et al., Inhibition of influenza virus infection by multivalent sialic-acid-functionalized gold nanoparticles. Small 6(24), 2900-2906 (2010)

82. M.J. Marín et al., Glyconanoparticles for the plasmonic detection and discrimination between human and avian influenza virus. Org. Biomol. Chem. 11(41), 7101-7107 (2013) 
83. T.J. Park et al., Development of label-free optical diagnosis for sensitive detection of influenza virus with genetically engineered fusion protein. Talanta 89, 246-252 (2012)

84. W. Maneeprakorn et al., Surface-enhanced Raman scattering based lateral flow immunochromatographic assay for sensitive influenza detection. RSC Adv. 6(113), 112079-112085 (2016)

85. Y. Pang et al., A fluorescent aptasensor for H5N1 influenza virus detection based-on the core-shell nanoparticles metal-enhanced fluorescence (MEF). Biosens. Bioelectron. 66, 527-532 (2015)

86. J. Lee et al., A plasmon-assisted fluoro-immunoassay using gold nanoparticle-decorated carbon nanotubes for monitoring the influenza virus. Biosens. Bioelectron. 64, 311-317 (2015)

87. Z. Ghafary et al., A novel immunosensing method based on the capture and enzymatic release of sandwich-type covalently conjugated thionine-gold nanoparticles as a new fluorescence label used for ultrasensitive detection of hepatitis B virus surface antigen. ACS Omega 4(13), 15323-15336 (2019)

88. J. Liu et al., A novel immunochromatographic assay using ultramarine blue particles as visible label for quantitative detection of hepatitis B virus surface antigen. Anal. Chim. Acta 1098, 140-147 (2020)

89. Y.-H. Choi et al., Development of SPR biosensor for the detection of human hepatitis B virus using plasma-treated parylene-N film. Biosens. Bioelectron. 56, 286-294 (2014)

90. M. Li et al., Plasmonic nanorice antenna on triangle nanoarray for surface-enhanced Raman scattering detection of hepatitis B virus DNA. Anal. Chem. 85(4), 2072-2078 (2013)

91. S. Zheng et al., Label-free optical diagnosis of hepatitis B virus with genetically engineered fusion proteins. Talanta 82(2), 803-809 (2010)

92. T. Riedel et al., Hepatitis B plasmonic biosensor for the analysis of clinical serum samples. Biosens. Bioelectron. 85, 272-279 (2016)

93. T.S. Riedel et al., Plasmonic hepatitis B biosensor for the analysis of clinical saliva. Anal. Chem. 89(5), 2972-2977 (2017)

94. P.M. Kosaka et al., Ultrasensitive detection of HIV-1 p24 antigen by a hybrid nanomechanicaloptoplasmonic platform with potential for detecting HIV-1 at first week after infection. PLoS ONE 12(2), e0171899 (2017)

95. J. Hu et al., Sub-attomolar HIV-1 DNA detection using surface-enhanced Raman spectroscopy. Analyst 135(5), 1084-1089 (2010)

96. A. Kurdekar et al., Sub-picogram level sensitivity in HIV diagnostics achieved with the europium nanoparticle immunoassay through metal enhanced fluorescence. Nanoscale Advances 1(1), 273-280 (2019)

97. Q. Jiang et al., Rapid, point-of-care, paper-based plasmonic biosensor for zika virus diagnosis. Adv. Biosyst. 1(9), 1700096 (2017)

98. S.A. Camacho et al., Zika immunoassay based on surface-enhanced raman scattering nanoprobes. ACS Sens. 3(3), 587-594 (2018)

99. M. Steinmetz et al., A sensitive label-free impedimetric DNA biosensor based on silsesquioxanefunctionalized gold nanoparticles for Zika Virus detection. Biosens. Bioelectr. 141, 111351 (2019)

100. O. Adegoke et al., Localized surface plasmon resonance-mediated fluorescence signals in plasmonic nanoparticle-quantum dot hybrids for ultrasensitive Zika virus RNA detection via hairpin hybridization assays. Biosens. Bioelectron. 94, 513-522 (2017)

101. R.K. Singh et al., Zika virus-emergence, evolution, pathology, diagnosis, and control: current global scenario and future perspectives-a comprehensive review. Veterinary Quart. 36(3), 150-175 (2016)

102. C. Lee et al., Rabies virus-inspired silica-coated gold nanorods as a photothermal therapeutic platform for treating brain tumors. Adv. Mater. 29(13), 1605563 (2017)

103. J. Xu et al., A surface plasmon resonance biosensor for direct detection of the rabies virus. Acta Vet. Brno 81(2), 107-111 (2012)

104. V. Asgary et al., Green synthesis and evaluation of silver nanoparticles as adjuvant in rabies veterinary vaccine. Int. J. Nanomed. 11, 3597 (2016)

105. T. Torchynska, G. Polupan, L.V. Macotela, Emission transformation in CdSe/ZnS quantum dots conjugated to biomolecules. J. Photochem. Photobiol., B 170, 309-313 (2017)

106. J. Shang et al., Identifying human milk glycans that inhibit norovirus binding using surface plasmon resonance. Glycobiology 23(12), 1491-1498 (2013)

107. K. Takemura et al., Ultrasensitive detection of norovirus using a magnetofluoroimmunoassay based on synergic properties of gold/magnetic nanoparticle hybrid nanocomposites and quantum dots. Sens. Actuators B Chem. 296, 126672 (2019)

108. N.S. Heo et al., Affinity peptide-guided plasmonic biosensor for detection of noroviral protein and human norovirus. Biotechnol. Bioprocess Eng. 24(2), 318-325 (2019)

109. S. Kim, S. Lee, H.J. Lee, An aptamer-aptamer sandwich assay with nanorod-enhanced surface plasmon resonance for attomolar concentration of norovirus capsid protein. Sens. Actuators B Chem. 273, 1029-1036 (2018) 
110. O.J. Achadu et al., Molybdenum trioxide nanocubes aligned on a graphene oxide substrate for the detection of norovirus by surface-enhanced raman scattering. ACS Appl. Mater. Interfaces. 12(39), 43522-43534 (2020)

111. F. Shen et al., DNA-silver nanocluster probe for norovirus RNA detection based on changes in secondary structure of nucleic acids. Anal. Biochem. 583, 113365 (2019)

112. A.A. Yanik et al., An optofluidic nanoplasmonic biosensor for direct detection of live viruses from biological media. Nano Lett. 10(12), 4962-4969 (2010)

113. D. Sebba et al. A point-of-care diagnostic for differentiating Ebola from endemic febrile diseases. Sci. Trans. Med. 10(471) (2018)

114. M.-K. Tsang et al., Ultrasensitive detection of Ebola virus oligonucleotide based on upconversion nanoprobe/nanoporous membrane system. ACS Nano 10(1), 598-605 (2016)

115. J. Hu et al., Dual-signal readout nanospheres for rapid point-of-care detection of ebola virus glycoprotein. Anal. Chem. 89(24), 13105-13111 (2017)

116. G. Li et al., Digital triplex DNA assay based on plasmonic nanocrystals. Anal. Bioanal. Chem. 409(14), 3657-3666 (2017)

117. P. Jahanshahi et al., Rapid immunoglobulin M-based dengue diagnostic test using surface plasmon resonance biosensor. Sci. Rep. 4, 3851 (2014)

118. J.A. Jackman et al., Plasmonic nanohole sensor for capturing single virus-like particles toward virucidal drug evaluation. Small 12(9), 1159-1166 (2016)

119. M. Govindarajan et al., Green synthesis and characterization of silver nanoparticles fabricated using Anisomeles indica: mosquitocidal potential against malaria, dengue and Japanese encephalitis vectors. Exp. Parasitol. 161, 40-47 (2016)

120. Q.H. Quach et al., Size-dependent neutralizing activity of gold nanoparticle-based subunit vaccine against dengue virus. Acta Biomater. 78, 224-235 (2018)

121. M. Sánchez-Purrà et al., Surface-enhanced Raman spectroscopy-based sandwich immunoassays for multiplexed detection of Zika and Dengue viral biomarkers. ACS Infect. Dis. 3(10), 767-776 (2017)

122. K. Sanjaya et al., Flow-cytometry detection of fluorescent magnetic nanoparticle clusters increases sensitivity of dengue immunoassay. Anal. Chim. Acta 1107, 85-91 (2020)

123. A. Agarwal, K. Venkatakrishnan, B. Tan, Cancer signaling by plasmonic quantum probes. Appl. Mater. Today 18, 100465 (2020)

124. S. Hibbitts et al., Human papilloma virus genotyping by surface-enhanced Raman scattering. Anal. Methods 6(5), 1288-1290 (2014)

125. S. Hibbitts et al., Human papillomavirus prevalence in women attending routine cervical screening in South Wales, UK: a cross-sectional study. Br. J. Cancer 99(11), 1929-1933 (2008)

126. T.M. Cairns et al., Surface plasmon resonance reveals direct binding of herpes simplex virus glycoproteins $\mathrm{gH} / \mathrm{gL}$ to $\mathrm{gD}$ and locates a gH/gL binding site on gD. J. Virol. 93(15), e00289-e319 (2019)

127. S.C. Gopinath, K. Hayashi, P.K. Kumar, Aptamer that binds to the gD protein of herpes simplex virus 1 and efficiently inhibits viral entry. J. Virol. 86(12), 6732-6744 (2012)

128. J.M. Reyes-Goddard, H. Barr, N. Stone, Surface enhanced Raman scattering of herpes simplex virus in tear film. Photodiagn. Photodyn. Ther. 5(1), 42-49 (2008)

129. M.J. Serramia et al., Gold nanoparticles crossing blood-brain barrier prevent HSV-1 infection and reduce herpes associated amyloid- $\beta$ secretion. J. Clin. Med. 9(1), 155 (2020)

130. Available from: https://www.who.int/csr/sar

131. Z. Zhu et al., Potent cross-reactive neutralization of SARS coronavirus isolates by human monoclonal antibodies. Proc. Natl. Acad. Sci. 104(29), 12123-12128 (2007)

132. S. Wu, Invasion, in Molecular Medical Microbiology. (Elsevier, Amsterdam, 2015), pp. 423-448

133. H. Luo et al., The nucleocapsid protein of SARS coronavirus has a high binding affinity to the human cellular heterogeneous nuclear ribonucleoprotein A1. FEBS Lett. 579(12), 2623-2628 (2005)

134. S. Hearty et al., Surface plasmon resonance for vaccine design and efficacy studies: recent applications and future trends. Exp. Rev. Vaccines 9(6), 645-664 (2010)

135. L. Chen et al., Discovering severe acute respiratory syndrome coronavirus 3CL protease inhibitors: virtual screening, surface plasmon resonance, and fluorescence resonance energy transfer assays. J. Biomol. Screen. 11(8), 915-921 (2006)

136. T.N. Cheema et al., Intelligent computing with Levenberg-Marquardt artificial neural networks for nonlinear system of COVID-19 epidemic model for future generation disease control. Eur. Phys. J. Plus 135(11), 932 (2020)

137. I. Ciufolini, A. Paolozzi, Mathematical prediction of the time evolution of the COVID-19 pandemic in Italy by a Gauss error function and Monte Carlo simulations. Eur. Phys. J. Plus 135(4), 355 (2020) 
138. I. Ciufolini, A. Paolozzi, An improved mathematical prediction of the time evolution of the Covid-19 pandemic in Italy, with a Monte Carlo simulation and error analyses. Eur. Phys. J. Plus 135(6), 495 (2020)

139. A. Ianni, N. Rossi, Describing the COVID-19 outbreak during the lockdown: fitting modified SIR models to data. Eur. Phys. J. Plus 135(11), 885 (2020)

140. F. Köhler-Rieper, C.H.F. Röhl, E. De. Micheli, A novel deterministic forecast model for the Covid-19 epidemic based on a single ordinary integro-differential equation. Eur. Phys. J. Plus 135(7), 599 (2020)

141. S. Olaniyi et al., Mathematical modelling and optimal cost-effective control of COVID-19 transmission dynamics. Eur. Phys. J. Plus 135(11), 938 (2020)

142. M. Radiom, J.-F. Berret, Common trends in the epidemic of Covid-19 disease. Eur. Phys. J. Plus 135(6), 517 (2020)

143. A. Gowrisankar, L. Rondoni, S. Banerjee, Can India develop herd immunity against COVID-19? Eur. Phys. J. Plus 135(6), 526 (2020)

144. S. Hassanpour, A. Saadati, M. Hasanzadeh, pDNA conjugated with citrate capped silver nanoparticles towards ultrasensitive bio-assay of haemophilus influenza in human biofluids: A novel optical biosensor. J. Pharm. Biomed. Anal. 180, 113050 (2020)

145. World Health Organization, WHO manual on animal influenza diagnosis and surveillance. World Health Organization (2002)

146. cdc. Available from: https://www.cdc.gov/flu/about/viruses/types.html

147. M. Saeed, A. Wu, Biosensors for swine influenza viruses. Nanobiosensors, p. 311-327 (2020)

148. Z. Wu et al., Digital single virus immunoassay for ultrasensitive multiplex avian influenza virus detection based on fluorescent magnetic multifunctional nanospheres. ACS Appl. Mater. Interfaces. 11(6), 5762-5770 (2019)

149. N.-S. Zhong et al., Chinese guidelines for diagnosis and treatment of influenza (2011). J. Thorac. Dis. 3(4), 274 (2011)

150. L. Van Elden et al., Simultaneous detection of influenza viruses A and B using real-time quantitative PCR. J. Clin. Microbiol. 39(1), 196-200 (2001)

151. F.G. Hayden et al., Efficacy and safety of the neuraminidase inhibitor zanamivir in the treatment of influenzavirus infections. N. Engl. J. Med. 337(13), 874-880 (1997)

152. H. Sakamoto et al., A novel optical biosensing system using Mach-Zehnder-type optical waveguide for influenza virus detection. Appl. Biochem. Biotechnol. 178(4), 687-694 (2016)

153. V.-T. Nguyen et al., Recent advances in high-sensitivity detection methods for paper-based lateral-flow assay. Biosens. Bioelectr. p. 112015 (2020)

154. S.C. Gopinath, K. Awazu, M. Fujimaki, Detection of influenza viruses by a waveguide-mode sensor. Anal. Methods 2(12), 1880-1884 (2010)

155. R. Randriantsilefisoa et al., Double trouble for viruses: a hydrogel nanocomposite catches the influenza virus while shrinking and changing color. Chem. Commun. (2020)

156. S. Hassanpour et al., Recent trends in rapid detection of influenza infections by bio and nanobiosensor. TrAC Trends Anal. Chem. 98, 201-215 (2018)

157. Y. Saylan, A. Denizli, Virus detection using nanosensors, in Nanosensors for Smart Cities. (Elsevier, Amsterdam, 2020), pp. 501-511

158. J.-Y. Lim et al., Identification of newly emerging influenza viruses by surface-enhanced Raman spectroscopy. Anal. Chem. 87(23), 11652-11659 (2015)

159. S. Jeong et al., Fluorometric detection of influenza viral RNA using graphene oxide. Anal. Biochem. 561, 66-69 (2018)

160. Healthline. Available from: https://www.healthline.com/health/hepatitis

161. A. Bosch et al., Waterborne viruses associated with hepatitis outbreak. J. Am. Water Works Ass. 83(3), 80-83 (1991)

162. S. Hassanpour et al., Diagnosis of hepatitis via nanomaterial-based electrochemical, optical or piezoelectrical biosensors: a review on recent advancements. Microchim. Acta 185(12), 568 (2018)

163. J. Zhou et al., Plasma microRNA panel to diagnose hepatitis B virus-related hepatocellular carcinoma. J. Clin. Oncol. 29(36), 4781-4788 (2011)

164. G. Sebastiani et al., Stepwise combination algorithms of non-invasive markers to diagnose significant fibrosis in chronic hepatitis C. J. Hepatol. 44(4), 686-693 (2006)

165. R. Chou, N. Wasson, Blood tests to diagnose fibrosis or cirrhosis in patients with chronic hepatitis $\mathrm{C}$ virus infection: a systematic review. Ann. Intern. Med. 158(11), 807-820 (2013)

166. S. Chevaliez, Virological tools to diagnose and monitor hepatitis C virus infection. Clin. Microbiol. Infect. 17(2), 116-121 (2011)

167. K.J. Stibbe et al., Comparison of non-invasive assessment to diagnose liver fibrosis in chronic hepatitis B and C patients. Scand. J. Gastroenterol. 46(7-8), 962-972 (2011) 
168. J. Bissonnette et al., A prospective study of the utility of plasma biomarkers to diagnose alcoholic hepatitis. Hepatology 66(2), 555-563 (2017)

169. H. Lu et al., Diagnosis of hepatitis B based on Raman spectroscopy combined with a multiscale convolutional neural network. Vib. Spectrosc. 107, 103038 (2020)

170. S. Khan et al., Optical screening of hepatitis-B infected blood sera using optical technique and neural network classifier. Photodiagn. Photodyn. Ther. 27, 375-379 (2019)

171. Q. Wang, Y. Shi, Photoacoustic viscoelasticity imaging for the detection of acute hepatitis: a feasibility study. Biophys. Rep. p. 1-8 (2020)

172. B.H. Cha et al., Detection of Hepatitis B Virus (HBV) DNA at femtomolar concentrations using a silica nanoparticle-enhanced microcantilever sensor. Biosens. Bioelectron. 25(1), 130-135 (2009)

173. M. Shevtsov et al., Applicability of metal nanoparticles in the detection and monitoring of hepatitis B virus infection. Viruses 9(7), 193 (2017)

174. X. Yin et al., Demonstration of real-time and accelerated stability of hepatitis E vaccine with a combination of different physicochemical and immunochemical methods. J. Pharm. Biomed. Anal. 177, 112880 (2020)

175. F. Sohrabi et al., Plasmophore enhancement in fibroblast green fluorescent protein-positive cells excited by smoke. ACS Omega, (2020)

176. J. Homola et al., Spectral surface plasmon resonance biosensor for detection of staphylococcal enterotoxin B in milk. Int. J. Food Microbiol. 75(1-2), 61-69 (2002)

177. F. Barré-Sinoussi et al., Isolation of a T-lymphotropic retrovirus from a patient at risk for acquired immune deficiency syndrome (AIDS). Science 220(4599), 868-871 (1983)

178. M. Steinmetz et al., A sensitive label-free impedimetric DNA biosensor based on silsesquioxanefunctionalized gold nanoparticles for Zika Virus detection. Biosens. Bioelectron. 141, 111351 (2019)

179. P.M. Sharp, B.H. Hahn, Origins of HIV and the AIDS pandemic. Cold Spring Harbor Perspect. Med. 1(1), a006841 (2011)

180. N.R. Faria et al., The early spread and epidemic ignition of HIV-1 in human populations. Science 346(6205), 56-61 (2014)

181. F. Clavel et al., Isolation of a new human retrovirus from West African patients with AIDS. Science 233(4761), 343-346 (1986)

182. HIV/AIDS, J.U.N.P.O. and D. UNAIDS, Geneva, Switzerland; 2018. North American, Western and Central Europe: AIDS epidemic update regional summary, p. 1-16 (2019)

183. W.-S. Ryu, Molecular Virology of Human Pathogenic Viruses (Academic Press, Cambridge, 2016)

184. E.A. Emini, The Human Immunodeficiency Virus: Biology, Immunology, and Therapy (Princeton University Press, New Jersey, 2002)

185. B.N. Fields, D.M. Knipe, Fundamental Virology (Lippincott Williams and Wilkins, Philadelphia, 1991)

186. G.A.C. Blood, Human immunodeficiency virus (HIV). Trans. Med. Hemotherapy 43(3), 203 (2016)

187. D.J. Felmlee et al., Hepatitis C virus, cholesterol and lipoproteins-impact for the viral life cycle and pathogenesis of liver disease. Viruses 5(5), 1292-1324 (2013)

188. J.J. Skehel, G. Schild, The polypeptide composition of influenza A viruses. Virology 44(2), 396-408 (1971)

189. P.-J. Enzmann, F. Weiland, Structural similarities of hog cholera virus with togaviruses. Adv. Virol. 57(4), 339-348 (1978)

190. A. Joss et al., Ribonucleic acid and protein synthesis in chick embryo cells infected with fowl plague virus. J. Virol. 4(6), 816-822 (1969)

191. H.R. Gelderblom, Assembly and morphology of HIV: potential effect of structure on viral function. AIDS 5(6), 617-638 (1991)

192. P.I. Parren et al., The neutralizing antibody response to HIV-1: viral evasion and escape from humoral immunity. AIDS (Supplement) 13(A), S137-S162 (1999)

193. J. Rychert et al., Detection of HIV gp120 in plasma during early HIV infection is associated with increased proinflammatory and immunoregulatory cytokines. AIDS Res. Hum. Retrovir. 26(10), 1139-1145 (2010)

194. C. Mariani et al., Role of Gag and lipids during HIV-1 assembly in CD4+ T cells and macrophages. Front. Microbiol. 5, 312 (2014)

195. M. Niedrig et al., Inhibition of infectious human immunodeficiency virus type 1 particle formation by Gag protein-derived peptides. J. Gen. Virol. 75(6), 1469-1474 (1994)

196. E.W. Fiebig et al., Dynamics of HIV viremia and antibody seroconversion in plasma donors: implications for diagnosis and staging of primary HIV infection. AIDS 17(13), 1871-1879 (2003)

197. H. Gelderblom et al., Zur Struktur und Funktion bei HIV: Gesichertes, neue Felder und offene Fragen. AIDS-Forschung 8(5), 231-242 (1993)

198. M.L. Nolan, A.E. Greenberg, M.G. Fowler, A review of clinical trials to prevent mother-to-child HIV-1 transmission in Africa and inform rational intervention strategies. AIDS 16(15), 1991-1999 (2002) 
199. K.L. Collins et al., HIV-1 Nef protein protects infected primary cells against killing by cytotoxic T lymphocytes. Nature 391(6665), 397-401 (1998)

200. F. Peter, HIV nef: the mother of all evil? Immunity 9(4), 433-437 (1998)

201. A.M. Joseph, M. Kumar, D. Mitra, Nef:"necessary and enforcing factor" in HIV infection. Curr. HIV Res. 3(1), 87-94 (2005)

202. W.I. Sundquist, H.-G. Kräusslich, HIV-1 assembly, budding, and maturation. Cold Spring Harbor Perspect. Med. 2(7), a006924 (2012)

203. M.S. Cohen et al., Acute HIV-1 infection. N. Engl. J. Med. 364(20), 1943-1954 (2011)

204. T.D. Ly et al., The variable sensitivity of HIV Ag/Ab combination assays in the detection of $\mathrm{p} 24 \mathrm{Ag}$ according to genotype could compromise the diagnosis of early HIV infection. J. Clin. Virol. 55(2), $121-127$ (2012)

205. K.E. Shafer-Peltier et al., Toward a glucose biosensor based on surface-enhanced Raman scattering. J. Am. Chem. Soc. 125(2), 588-593 (2003)

206. N.R. Isola, D.L. Stokes, T. Vo-Dinh, Surface-enhanced Raman gene probe for HIV detection. Anal. Chem. 70(7), 1352-1356 (1998)

207. Y.C. Cao, R. Jin, C.A. Mirkin, Nanoparticles with Raman spectroscopic fingerprints for DNA and RNA detection. Science 297(5586), 1536-1540 (2002)

208. T. Vo-Dinh, L.R. Allain, D.L. Stokes, Cancer gene detection using surface-enhanced Raman scattering (SERS). J. Raman Spectrosc. 33(7), 511-516 (2002)

209. M. Culha et al., Surface-enhanced Raman scattering substrate based on a self-assembled monolayer for use in gene diagnostics. Anal. Chem. 75(22), 6196-6201 (2003)

210. M. Moskovits, Surface-enhanced spectroscopy. Rev. Modern Phys. 57(3), 783 (1985)

211. A. Otto et al., Surface-enhanced Raman scattering. J. Phys.: Condens. Matter 4(5), 1143 (1992)

212. S. Nie, S.R. Emory, Probing single molecules and single nanoparticles by surface-enhanced Raman scattering. Science 275(5303), 1102-1106 (1997)

213. H. Xu et al., Spectroscopy of single hemoglobin molecules by surface enhanced Raman scattering. Phys. Rev. Lett. 83(21), 4357 (1999)

214. M. Hamatake et al., A simple competitive RT-PCR assay for quantitation of HIV-1 subtype B and non-B RNA in plasma. J. Virol. Methods 142(1-2), 113-117 (2007)

215. G. Presnova et al., Streptavidin conjugates with gold nanoparticles for visualization of single DNA interactions on the silicon surface. Biochem. Moscow Suppl. Ser. B Biomed. Chem. 8(2), 164-167 (2014)

216. P.M. Kosaka et al., Tackling reproducibility in microcantilever biosensors: a statistical approach for sensitive and specific end-point detection of immunoreactions. Analyst 138(3), 863-872 (2013)

217. J. Tamayo et al., Imaging the surface stress and vibration modes of a microcantilever by laser beam deflection microscopy. Nanotechnology 23(31), 315501 (2012)

218. N. Martínez et al., High throughput optical readout of dense arrays of nanomechanical systems for sensing applications. Rev. Sci. Instrum. 81(12), 125109 (2010)

219. P.M. Kosaka et al., Detection of cancer biomarkers in serum using a hybrid mechanical and optoplasmonic nanosensor. Nat. Nanotechnol. 9(12), 1047 (2014)

220. F. Macnamara, Zika virus: a report on three cases of human infection during an epidemic of jaundice in Nigeria. Trans. R. Soc. Trop. Med. Hyg. 48(2), 139-145 (1954)

221. E. Monlun et al., ARBOVIRUS AFFECTING HUMANS IN SOUTHEASTERN SENEGALSURVEILLANCE IN HUMANS AND MOSQUITOS (1988-1991). Bull. Soc. Pathol. Exot. 86(1), 21-28 (1993)

222. M. Weinbren, M. Williams, Zika virus: further isolations in the Zika area, and some studies on the strains isolated. Trans. R. Soc. Trop. Med. Hyg. 52(3), 263-268 (1958)

223. D. Musso, D.J. Gubler, Zika virus. Clin. Microbiol. Rev. 29(3), 487-524 (2016)

224. L.R. Petersen et al., Zika virus. N. Engl. J. Med. 374(16), 1552-1563 (2016)

225. D. Baud et al., An update on Zika virus infection. The Lancet 390(10107), 2099-2109 (2017)

226. F.M. Szaba et al., Zika virus infection in immunocompetent pregnant mice causes fetal damage and placental pathology in the absence of fetal infection. PLoS Pathog. 14(4), e1006994 (2018)

227. S.R. da Silva, S.J. Gao, Zika virus: an update on epidemiology, pathology, molecular biology, and animal model. J. Med. Virol. 88(8), 1291-1296 (2016)

228. J.T. Beaver et al., Evolution of two major Zika virus lineages: implications for pathology, immune response, and vaccine development. Front. Immunol. 9, 1640 (2018)

229. J.M. Ritter, R.B. Martines, S.R. Zaki, Zika virus: pathology from the pandemic. Arch. Pathol. Lab. Med. 141(1), 49-59 (2017)

230. M. Atif et al., Zika virus disease: a current review of the literature. Infection 44(6), 695-705 (2016) 
231. O. Faye et al., Molecular evolution of Zika virus during its emergence in the 20th century. PLoS Negl. Trop. Dis. 8(1) (2014)

232. T.R. Kreil et al., West Nile virus and the safety of plasma derivatives: verification of high safety margins, and the validity of predictions based on model virus data. Transfusion 43(8), 1023-1028 (2003)

233. M.N. Balm et al., A diagnostic polymerase chain reaction assay for Zika virus. J. Med. Virol. 84(9), $1501-1505$ (2012)

234. C. Shan et al., Zika virus: diagnosis, therapeutics, and vaccine. ACS Infect. Dis. 2(3), 170-172 (2016)

235. M. Pérez-Olmeda et al., Evaluation of the LIAISON XL Zika Capture IgM II for the Diagnosis of Zika Virus Infections. Viruses 12(1), 69 (2020)

236. S.J.R.D. Silva, K. Pardee, L. Pena, Loop-mediated isothermal amplification (LAMP) for the diagnosis of Zika virus: a review. Viruses 12(1), 19 (2020)

237. R. Hamel et al., Biology of Zika virus infection in human skin cells. J. Virol. 89(17), 8880-8896 (2015)

238. A. Buckley, E. Gould, Detection of virus-specific antigen in the nuclei or nucleoli of cells infected with Zika or Langat virus. J. Gen. Virol. 69(8), 1913-1920 (1988)

239. H. Song et al., Zika virus NS1 structure reveals diversity of electrostatic surfaces among flaviviruses. Nat. Struct. Mol. Biol. 23(5), 456 (2016)

240. R.K. Singh et al., Advances in diagnosis, surveillance, and monitoring of Zika virus: an update. Front. Microbiol. 8, 2677 (2018)

241. A.R. Plourde, E.M. Bloch, A literature review of Zika virus. Emerg. Infect. Dis. 22(7), 1185 (2016)

242. R. Peters, M. Stevenson, Zika virus diagnosis: challenges and solutions. Clin. Microbiol. Infect. 25(2), 142-146 (2019)

243. G. Benelli, Green synthesized nanoparticles in the fight against mosquito-borne diseases and cancer-a brief review. Enzyme Microb. Technol. 95, 58-68 (2016)

244. J. Lee, K. Takemura, E.Y. Park, Plasmonic nanomaterial-based optical biosensing platforms for virus detection. Sensors 17(10), 2332 (2017)

245. C. Consales, V. Bolzan, Rabies review: immunopathology, clinical aspects and treatment. J. Venom. Anim. Toxins Incl. Trop. Dis. 13(1), 5-38 (2007)

246. A.J. Nigg, P.L. Walker, Overview prevention and treatment of rabies. Pharm. J. Hum. Pharm. Drug Therapy 29(10), 1182-1195 (2009)

247. C.E. Rupprecht, R.V. Gibbons, Prophylaxis against rabies. N. Engl. J. Med. 351(25), 2626-2635 (2004)

248. G. Schumock, G. Brundage, M. Chapman, Pharmacotherapy self-assessment program. (American College of Clinical Pharmacy, Kansas City, 2005)

249. C.E. Rupprecht, C.A. Hanlon, T. Hemachudha, Rabies re-examined. Lancet. Infect. Dis 2(6), 327-343 (2002)

250. J.H. Cox, The structural proteins of rabies virus. Comp. Immunol. Microbiol. Infect. Dis. 5(1-3), 21-25 (1982)

251. A.K. Gupta et al., The phosphoprotein of rabies virus is phosphorylated by a unique cellular protein kinase and specific isomers of protein kinase C. J. Virol. 74(1), 91-98 (2000)

252. A. King, G. Turner, Rabies: a review. J. Comp. Pathol. 108(1), 1-39 (1993)

253. W.H. Wunner, Rabies virus, in Rabies. (Elsevier, Amsterdam, 2003), pp. 23-77

254. Rabies. 2008; Available from: http://www.cdc.gov/Rabies/

255. D. Kobasa et al., Aberrant innate immune response in lethal infection of macaques with the 1918 influenza virus. Nature 445(7125), 319-323 (2007)

256. S.H. Seo, E. Hoffmann, R.G. Webster, Lethal H5N1 influenza viruses escape host anti-viral cytokine responses. Nat. Med. 8(9), 950-954 (2002)

257. D.S. Chertow, J. Kindrachuk, Influenza, Measles, SARS, MERS, and Smallpox, in Highly Infectious Diseases in Critical Care. (Springer, Berlin, 2020), pp. 69-96

258. T. Sunseri, The rinderpest campaigns: a virus, its vaccines, and global development in the twentieth century by Amanda Kay McVety. Bull. Hist. Med. 93(2), 285-286 (2019)

259. D. Butler, Sequence and destroy: the quest to eliminate the last stocks of deadly rinderpest virus. Nature 572(7767), 18 (2019)

260. L. Fries et al., A randomized, blinded, dose-ranging trial of an ebola virus glycoprotein (EBOV GP) nanoparticle vaccine with matrix-M $\mathrm{M}^{\mathrm{TM}}$ adjuvant in healthy adults. J. Infect. Dis. (2019)

261. L. Niu et al., Intradermal delivery of vaccine nanoparticles using hollow microneedle array generates enhanced and balanced immune response. J. Control. Release 294, 268-278 (2019)

262. A.F. El-Sissi et al., Chitosan and chitosan nanoparticles as adjuvant in local Rift Valley Fever inactivated vaccine. 3 Biotech 10(3), 88 (2020)

263. M. Sharifi et a., Plasmonic gold nanoparticles: Optical manipulation, imaging, drug delivery and therapy. J. Controll. Release (2019) 
264. S.R.S. Veloso et al. Magnetogels based on magnetic/plasmonic nanoparticles and self-assembled peptide hydrogels as drug nanocarriers. in I Jornadas da Ciência-Concentra o Conhecimento. 2019. Universidade do Minho. Escola de Ciências (EC)

265. C. Qian et al., Identification of Nanoparticles via Plasmonic Scattering Interferometry. Angew. Chem. Int. Ed. 58(13), 4217-4220 (2019)

266. J.G. Croissant, T.M. Guardado-Alvarez, Photocracking silica: tuning the plasmonic photothermal degradation of mesoporous silica encapsulating gold nanoparticles for cargo release. Inorganics 7(6), 72 (2019)

267. M.R. Ali, Y. Wu, M.A. El-Sayed, Gold-nanoparticle-assisted plasmonic photothermal therapy advances toward clinical application. J. Phys. Chem. C 123(25), 15375-15393 (2019)

268. Y. Hernández, B.C. Galarreta, Noble metal-based plasmonic nanoparticles for SERS imaging and photothermal therapy, in Nanomaterials for Magnetic and Optical Hyperthermia Applications. (Elsevier, Amsterdam, 2019), pp. 83-109

269. A. Popov, et al. Fabrication of plasmonic titanium nitride nanoparticles by femtosecond laser ablation in water and organic solvents. in Сборник трудов конференции «International Conference on Advanced Laser Technologies (ALT)». 2019. Федеральное государственное бюджетное учреждение науки Институт общей физики ....

270. H.J. Byeon et al., Doxorubicin-loaded nanoparticles consisted of cationic-and mannose-modifiedalbumins for dual-targeting in brain tumors. J. Control. Release 225, 301-313 (2016)

271. H. Yang, Nanoparticle-mediated brain-specific drug delivery, imaging, and diagnosis. Pharm. Res. 27(9), 1759-1771 (2010)

272. B.A. Lopman et al., The vast and varied global burden of norovirus: prospects for prevention and control. PLoS Med. 13(4) (2016)

273. J.L. Cannon et al., Birth cohort studies assessing norovirus infection and immunity in young children: a review. Clin. Infect. Dis. 69(2), 357-365 (2019)

274. N.E. Netzler, D.E. Tuipulotu, P.A. White, Norovirus antivirals: Where are we now? Med. Res. Rev. 39(3), 860-886 (2019)

275. K. Green, Caliciviridae: the noroviruses, in Fields virology, 6th edn., ed. by D.M. Knipe, P.M. Howley, J.I. Cohen, D.E. Griffin, R.A. Lamb, M.A. Martin et al. (Lippincott Williams and Wilkins, Philadelphia, PA, 2013), pp. 508-609

276. G.E. Rydell et al., QCM-D studies of human norovirus VLPs binding to glycosphingolipids in supported lipid bilayers reveal strain-specific characteristics. Glycobiology 19(11), 1176-1184 (2009)

277. M. Tan, X. Jiang, Association of histo-blood group antigens with susceptibility to norovirus infection may be strain-specific rather than genogroup dependent. J. Infect. Dis. 198(6), 940-1-942-3 (2008)

278. M. Tan, X. Jiang, Norovirus-host interaction: implications for disease control and prevention. Expert Rev. Mol. Med. 9(19), 1-22 (2007)

279. M. Tan et al., Noroviral P particle: structure, function and applications in virus-host interaction. Virology 382(1), 115-123 (2008)

280. A. de Rougemont et al., Qualitative and quantitative analysis of the binding of GII. 4 norovirus variants onto human blood group antigens. J. Virol. 85(9), 4057-4070 (2011)

281. I.S. Lee et al., Ni/NiO core/shell nanoparticles for selective binding and magnetic separation of histidinetagged proteins. J. Am. Chem. Soc. 128(33), 10658-10659 (2006)

282. L. Liu, M.D. Moore, A survey of analytical techniques for noroviruses. Foods 9(3), 318 (2020)

283. S. Baize et al., Emergence of zaire ebola virus disease in Guinea. N. Engl. J. Med. 371(15), 1418-1425 (2014)

284. L. Xu et al., Immunization for Ebola virus infection. Nat. Med. 4(1), 37-42 (1998)

285. X. Qiu et al., Reversion of advanced Ebola virus disease in nonhuman primates with ZMapp. Nature 514(7520), 47-53 (2014)

286. J.-S. Yu et al., Detection of Ebola virus envelope using monoclonal and polyclonal antibodies in ELISA, surface plasmon resonance and a quartz crystal microbalance immunosensor. J. Virol. Methods 137(2), 219-228 (2006)

287. T. Ikegami et al., Genome structure of Ebola virus subtype Reston: differences among Ebola subtypes. Adv. Virol. 146(10), 2021-2027 (2001)

288. A. Lucht et al., Production of monoclonal antibodies and development of an antigen capture ELISA directed against the envelope glycoprotein GP of Ebola virus. Med. Microbiol. Immunol. 193(4), 181-187 (2004)

289. M. Niikura et al., Detection of Ebola viral antigen by enzyme-linked immunosorbent assay using a novel monoclonal antibody to nucleoprotein. J. Clin. Microbiol. 39(9), 3267-3271 (2001)

290. P. Prashar et al. Knowledge, attitude and practices of univer-sity students towards prevention of dengue in Northern India: a questionnaire-based study. Emerg. Infect. Dis. Diag. J. EIDDJ-100002, 1 (2019) 
291. R. Castro-Orozco, N. Alvis-Guzman, Role of oxidative and nitrosative stress in dengue pathogenesis: a mini-review. J. Mol. Genetic Med. 10(229), 1747-862 (2016)

292. World Health Organization et al., Dengue: guidelines for diagnosis, treatment, prevention and control. World Health Organization (2009)

293. L. Chatel-Chaix, The remodeling of the cytoplasm by dengue virus. J. Bacteriol. Mycol. 3(4: 1039), 1-6 (2016)

294. R. Domingues, G. Kuster, Diagnosis and management neurologic manifestations associated with acute dengue virus infection. J Neuroinfect Dis 5(138), 2 (2014)

295. S. Behera, P. Nanda, S.K. Behera, Possible ocular associations of Dengu. (2011)

296. S. Tanweer, t al., A brief review on dengu. Asian J. Pharm. Res. Dev. pp. 1-6 (2017)

297. O. Parkash, R.H. Shueb, Diagnosis of dengue infection using conventional and biosensor based techniques. Viruses 7(10), 5410-5427 (2015)

298. H. Pfister, J. Ter Schegget, Role of HPV in cutaneous premalignant and malignant tumors. Clin. Dermatol. 15(3), 335-347 (1997)

299. S. de Sanjosé et al., Burden of human papillomavirus (HPV)-related cancers attributable to HPVs 6/11/16/18/31/33/45/52 and 58. JNCI Cancer Spect 2(4), pky045 (2018)

300. N. Guimerà et al., Human papillomavirus 16 is an aetiological factor of scrotal cancer. Br. J. Cancer 116(9), 1218-1222 (2017)

301. S. Firquet et al., Survival of enveloped and non-enveloped viruses on inanimate surfaces. Microbes Environ, p. ME14145 (2015)

302. A.E. Smith, A. Helenius, How viruses enter animal cells. Science 304(5668), 237-242 (2004)

303. K. Van Doorslaer et al., The Papillomavirus Episteme: a central resource for papillomavirus sequence data and analysis. Nucleic Acids Res. 41(D1), D571-D578 (2012)

304. K. Van Doorslaer et al., The Papillomavirus Episteme: a major update to the papillomavirus sequence database. Nucleic Acids Res. 45(D1), D499-D506 (2017)

305. C.B. Buck, B.L. Trus, The papillomavirus virion: a machine built to hide molecular Achilles' heels, in Viral Molecular Machines. (Springer, Berlin, 2012), pp. 403-422

306. J. Doorbar, The papillomavirus life cycle. J. Clin. Virol. 32, 7-15 (2005)

307. M. Herfs et al., A discrete population of squamocolumnar junction cells implicated in the pathogenesis of cervical cancer. Proc. Natl. Acad. Sci. 109(26), 10516-10521 (2012)

308. D. Pyeon et al., Establishment of human papillomavirus infection requires cell cycle progression. PLoS Pathogens, 5(2) (2009)

309. K. Egawa, Do human papillomaviruses target epidermal stem cells? Dermatology 207(3), 251-254 (2003)

310. A.B. Raff et al., The evolving field of human papillomavirus receptor research: a review of binding and entry. J. Virol. 87(11), 6062-6072 (2013)

311. J.T. Schiller, P.M. Day, R.C. Kines, Current understanding of the mechanism of HPV infection. Gynecol. Oncol. 118(1), S12-S17 (2010)

312. M. Bienkowska-Haba, H.D. Patel, M. Sapp, Target cell cyclophilins facilitate human papillomavirus type 16 infection. PLoS Pathogens, 5(7) (2009)

313. M.A. Ozbun, Human papillomavirus type $31 \mathrm{~b}$ infection of human keratinocytes and the onset of early transcription. J. Virol. 76(22), 11291-11300 (2002)

314. C.A. Moody, L.A. Laimins, Human papillomavirus oncoproteins: pathways to transformation. Nat. Rev. Cancer 10(8), 550-560 (2010)

315. R.S. Hegde, The papillomavirus E2 proteins: structure, function, and biology. Annu. Rev. Biophys. Biomol. Struct. 31(1), 343-360 (2002)

316. C.M. Sanders, A. Stenlund, Recruitment and loading of the E1 initiator protein: an ATP-dependent process catalysed by a transcription factor. EMBO J. 17(23), 7044-7055 (1998)

317. C.M. Sanders, A. Stenlund, Transcription factor-dependent loading of the E1 initiator reveals modular assembly of the papillomavirus origin melting complex. J. Biol. Chem. 275(5), 3522-3534 (2000)

318. G.A. Maglennon, P. McIntosh, J. Doorbar, Persistence of viral DNA in the epithelial basal layer suggests a model for papillomavirus latency following immune regression. Virology 414(2), 153-163 (2011)

319. S.V. Graham, Human papillomavirus: gene expression, regulation and prospects for novel diagnostic methods and antiviral therapies. Future Microbiol. 5(10), 1493-1506 (2010)

320. S.B.V. Pol, A.J. Klingelhutz, Papillomavirus E6 oncoproteins. Virology 445(1-2), 115-137 (2013)

321. A. Roman, K. Munger, The papillomavirus E7 proteins. Virology 445(1-2), 138-168 (2013)

322. E. Beyer-Finkler et al., Cell differentiation-related gene expression of human papillomavirus 33. Med. Microbiol. Immunol. 179(4), 185-192 (1990)

323. M.H. Stoler et al., Human papillomavirus type 16 and 18 gene expression in cervical neoplasias. Hum. Pathol. 23(2), 117-128 (1992) 
324. M.H. Stoler et al., Differentiation-linked human papillomavirus types 6 and 11 transcription in genital condylomata revealed by in situ hybridization with message-specific RNA probes. Virology 172(1), 331-340 (1989)

325. K. Middleton et al., Organization of human papillomavirus productive cycle during neoplastic progression provides a basis for selection of diagnostic markers. J. Virol. 77(19), 10186-10201 (2003)

326. H.-N. Wang, T. Vo-Dinh, Multiplex detection of breast cancer biomarkers using plasmonic molecular sentinel nanoprobes. Nanotechnology 20(6), 065101 (2009)

327. S. Sloan-Dennison, Z.D. Schultz, Label-free plasmonic nanostar probes to illuminate in vitro membrane receptor recognition. Chem. Sci. 10(6), 1807-1815 (2019)

328. J. Su et al., Multicolor gold-silver nano-mushrooms as ready-to-use SERS probes for ultrasensitive and multiplex DNA/miRNA detection. Anal. Chem. 89(4), 2531-2538 (2017)

329. A. Pallaoro et al., Rapid identification by surface-enhanced Raman spectroscopy of cancer cells at low concentrations flowing in a microfluidic channel. ACS Nano 9(4), 4328-4336 (2015)

330. P. Owens et al., Sensing of p53 and EGFR biomarkers using high efficiency SERS substrates. Biosensors 5(4), 664-677 (2015)

331. S. Dick et al., SERS and SERRS detection of the DNA Lesion 8-nitroguanine a self-labeling modification. Chem. A Eur. J. 23(44), 10663-10669 (2017)

332. E. Papadopoulou, S.E. Bell, Label-free detection of single-base mismatches in DNA by surface-enhanced Raman spectroscopy. Angew. Chem. Int. Ed. 50(39), 9058-9061 (2011)

333. L.-J. Xu et al., Label-free surface-enhanced Raman spectroscopy detection of DNA with single-base sensitivity. J. Am. Chem. Soc. 137(15), 5149-5154 (2015)

334. S.R. Panikkanvalappil et al., Surface-enhanced Raman spectroscopy for real-time monitoring of reactive oxygen species-induced DNA damage and its prevention by platinum nanoparticles. ACS Nano 7(9), 7524-7533 (2013)

335. B. Kang, L.A. Austin, M.A. El-Sayed, Observing real-time molecular event dynamics of apoptosis in living cancer cells using nuclear-targeted plasmonically enhanced Raman nanoprobes. ACS Nano 8(5), 4883-4892 (2014)

336. X. Qian et al., In vivo tumor targeting and spectroscopic detection with surface-enhanced Raman nanoparticle tags. Nat. Biotechnol. 26(1), 83-90 (2008)

337. G. Sonavane, K. Tomoda, K. Makino, Biodistribution of colloidal gold nanoparticles after intravenous administration: effect of particle size. Colloids Surf., B 66(2), 274-280 (2008)

338. A.M. Alkilany et al., Cellular uptake and cytotoxicity of gold nanorods: molecular origin of cytotoxicity and surface effects. Small 5(6), 701-708 (2009)

339. A.F. Palonpon et al., Raman and SERS microscopy for molecular imaging of live cells. Nat. Protoc. 8(4), 677-692 (2013)

340. C.L. Zavaleta et al., A Raman-based endoscopic strategy for multiplexed molecular imaging. Proc. Natl. Acad. Sci. 110(25), E2288-E2297 (2013)

341. M.V. Jacobs et al., A general primer GP5+/GP6 (+)-mediated PCR-enzyme immunoassay method for rapid detection of 14 high-risk and 6 low-risk human papillomavirus genotypes in cervical scrapings. J. Clin. Microbiol. 35(3), 791-795 (1997)

342. Healthline. Herpes. cited 2020; Available from: https://www.healthline.com/health/herpes-simplex

343. WHO. Herpes. [cited 2020; Available from: https://www.who.int/news-room/fact-sheets/detail/herpessimplex-virus

344. P.K. Kumar, Systematic screening of viral entry inhibitors using surface plasmon resonance. Rev. Med. Virol. 27(6), e1952 (2017)

345. D. Pavan-Langstone, Viral disease of the cornea external eye. Princ. Pract. Ophthalmol. Clin. Pract. (1993)

346. P.Y. Robert et al., Multiplex detection of herpesviruses in tear fluid using the "stair primers" PCR method: prospective study of 93 patients. J. Med. Virol. 66(4), 506-511 (2002)

347. F. Hidalgo et al., Diagnosis of herpetic keratoconjunctivitis by nested polymerase chain reaction in human tear film. Eur. J. Clin. Microbiol. Infect. Dis. 17(2), 120-123 (1998)

348. H.E. Kaufman et al., HSV-1 DNA in tears and saliva of normal adults. Invest. Ophthalmol. Vis. Sci. 46(1), 241-247 (2005)

349. I. Mackie, D. Seal, Diagnostic implications of tear protein profiles. Br. J. Ophthalmol. 68(5), 321-324 (1984)

350. R.J. Fullard, D.L. Tucker, Changes in human tear protein levels with progressively increasing stimulus. Invest. Ophthalmol. Vis. Sci. 32(8), 2290-2301 (1991)

351. V. Ng, P. Cho, The relationship between total tear protein concentrations determined by different methods and standards. Graefes Arch. Clin. Exp. Ophthalmol. 238(7), 571-576 (2000) 
352. J. Suh, M. Moskovits, Surface-enhanced Raman spectroscopy of amino acids and nucleotide bases adsorbed on silver. J. Am. Chem. Soc. 108(16), 4711-4718 (1986)

353. F. Ni, T.M. Cotton, Chemical procedure for preparing surface-enhanced Raman scattering active silver films. Anal. Chem. 58(14), 3159-3163 (1986) 